\title{
ALEATORIZAÇÃO e ÉTICA MÉDICA
}

\author{
Dália Ballas Wajsbrot
}

Dissertação apresentada ao Instituto de Matemática e Estatística da Universidade de São Paulo para a obtenção do grau de mestre em Estatística

Área de Concentração: Estatística

Orientador: Sergio Wechsler

São Paulo, Julho de 1997 


\section{ALEATORIZAÇÃO e ÉTICA MÉDICA}

Este exemplar corresponde à redação final da dissertação devidamente corrigida e apresentada por Dália Ballas Wajsbrot e aprovada pela Comissão Julgadora.

São Paulo, 23 de julho de 1997.

\section{Banca Examinadora}

Prof. Dr. Sergio Wechsler - IME-USP

Prof. Dr. Carlos Alberto Bragança Pereira - IME-USP

Prof. Dr. Maximiano Tadeu Vila Albers - HC FMUSP 


\section{Resumo}

Experimentos clínicos aleatorizados são estudos onde se avalia comparativamente a eficácia de dois ou mais tratamentos. A aleatorização enquanto método de seleção dos tratamentos é um aspecto que gera várias críticas de cunho estatístico, bem como questionamentos relacionados à ética médica. A expressão equiparação individual foi introduzida por Freedman (1987) para descrever um estado de genuína incerteza de um pesquisador com relação aos méritos relativos de dois ou mais tratamentos. Em havendo equiparação, seria ético conduzir um experimento clínico aleatorizado. O dilema ético surge ao considerarmos os interesses individuais do paciente. A aleatorização quando utilizada na análise dos dados é o maior alvo das críticas, principalmente sob inferência bayesiana. Quando utilizada no planejamento apenas, a aleatorização é aceita e até mesmo recomendada por Kadane e Seidenfeld (1990). Kadane, Sedransk e Seidenfeld (Kadane, 1996), fazem uma proposta de um planejamento bayesiano (KSS), aleatorizando apenas tratamentos admissíveis para um paciente, de modo que seus interesses sejam considerados. Em conjunto com um grupo de anestesistas do Hospital Johns Hopkins, o Prof. Kadane conduziu um experimento clínico utilizando o planejamento bayesiano KSS.

\section{Abstract}

Evaluating the efficacy of two treatments is the aim of randomized clinical trials. Randomization while a method for selecting treatments is very criticized by bayesian statisticians and also raises many ethical questions. The term individual equipoise was introduced by Freedman (1987) to describe a state of genuine uncertainty of the investigator regarding the relative merits of the treatments under study. In having equipoise, it may be ethical to conduct any randomized clinical trial. The ethical dilemma arises when considering the patient's best interest. Randomizing to analyze data is not accepted in bayesian inference. When applied to the design only, randomization is accepted and even recommended by Kadane and Seidenfeld (1990). Kadane, Sedransk e Seidenfeld (Kadane, 1996) have proposed a bayesian design (KSS), which randomizes a treatment only if it is considered admissible to a patient. A clinical trial using the KSS design was conducted by Prof. Kadane, together with a group of anesthesiologists of Johns Hopkins Medical Institution. 


\section{AGRADECIMENTOS}

Este trabalho é fruto de uma dedicação "roubada" de outras atividades da vida profissional e pessoal. Talvez o longo tempo cronológico que levou este trabalho para ser amadurecido e concluído tenha feito com que o meu interesse pelo assunto fosse cada vez maior. Várias pessoas contribuíram para que este trabalho se concretizasse. Tento expressar aqui os meus sinceros agradecimentos:

Ao meu orientador Sérgio Wechsler, pela sua brilhante orientação, e pela escolha do tema.

Aos professores Carlos Alberto Bragança Pereira e Júlio da Mota Singer, por terem sido meus educadores.

Ao meu marido Charles Wajsbrot, pelo apoio incondicional e sacrificados finsde-semana.

À Paula Goldenstein Strassmann, pela amizade e iniciação à minha vida profissional.

À Rita Helena Antonelli Cardoso, pelo constante incentivo e crédito a mim concedido.

Ao Instituto do Coração, pela contribuição à minha formação enquanto Bioestatística.

À toda equipe do estudo MASS, pela oportunidade de questionamento e intermináveis discussões a respeito de aleatorização e ética médica, aplicados à uma pesquisa prática.

À minha querida mãe e irmãos, Carmen, Harry e Márcio Ballas, pela incansável torcida. 
Dedico este trabalho à memória de meu pai, que me ensinou o valor do aprender.

Dedico este trabalho a um ser que aguarda dentro de mim, sua hora de vir ao mundo. 


\section{ÍNDICE}

CAPITULO 1 - EXPERIMENTOS CLÍNICOS...............................................................

1.1. Experimentos Clinicos Aleatorizados.......................................................................... 3

1.2. A Importância dos Experimentos Clínicos Aleatorizados..................................................... 5

1.3. As Quatro Fases da Pesquisa Clínica......................................................................... 7

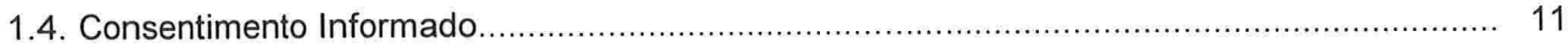

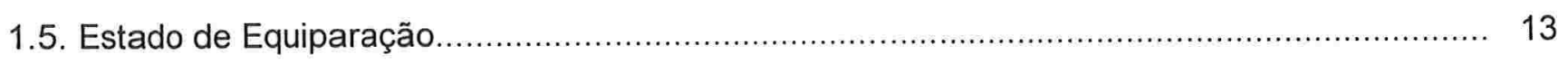

CAPÍTULO 2 - ALEATORIZAÇÃO........................................................................ 15

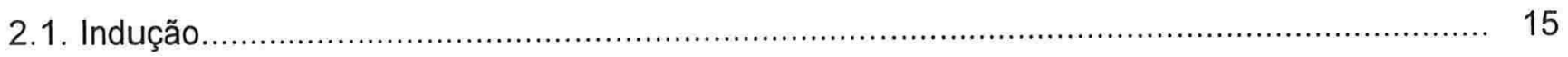

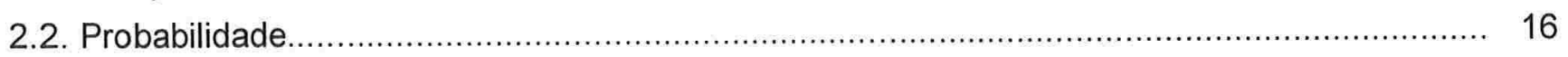

2.3. Aleatoriedade

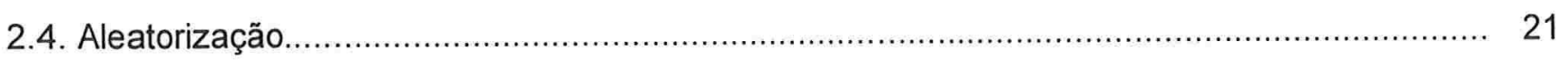

2.5. Justificativas para Aleatorização em Experimentos Clínicos ................................................ 22

2.5.1. Distribuição de Referência............................................................................. 23

2.5.2. Vícios de Seleção (Vícios do Observador)....................................................... 29

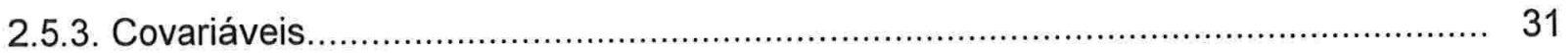

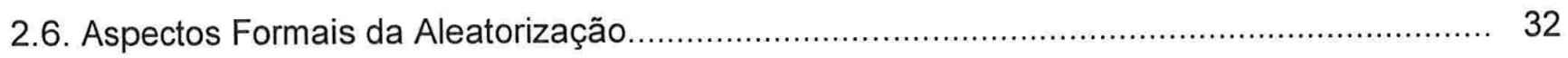

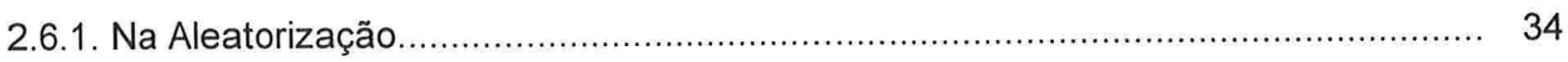

2.6.2. Na Modificação ou Redução dos Dados.......................................................... 38

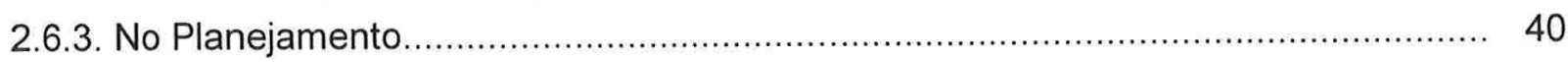

2.7. O Que Pensam os Bayesianos a Respeito da Aleatorização.............................................. 44

2.7.1. Aleatorizar Não é Racional....................................................................... 44

2.7.2. Aleatorizar Viola o Princípio da Verossimilhança................................................... 45

2.7.3. Defendendo a Aleatorização........................................................................... 47

CAPÍTULO 3 - O DILEMA ÉTICO .......................................................................... 51

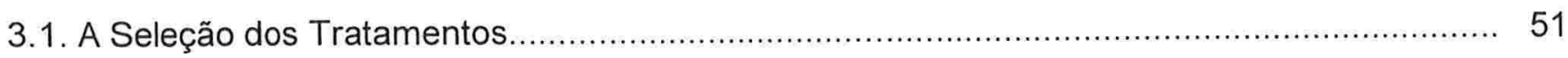

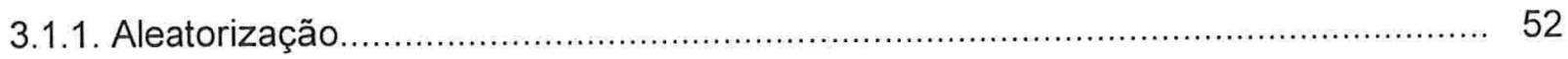

3.1.2. Seleção do Tratamento Segundo o Paciente....................................................... 53

3.1.3. Controles concorrentes (a proposta de Royall) ……......................................... 53

3.1.4. Experimentos-para-aprender e Experimentos-para-provar.................................. 56

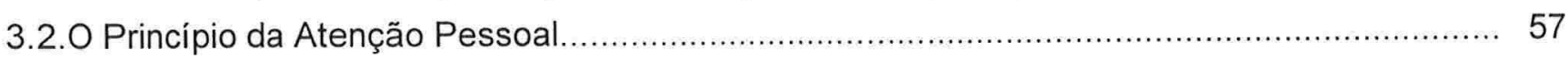

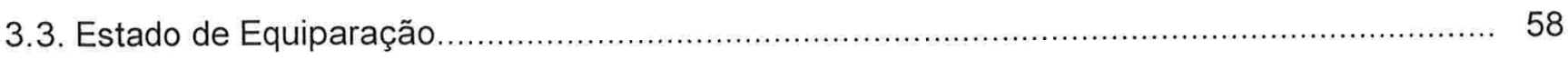

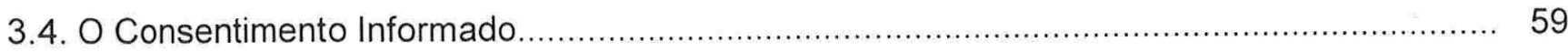

3.5. Os Momentos de um Experimento Clínico onde Pode Surgir o Dilema Ético.......................... 62 


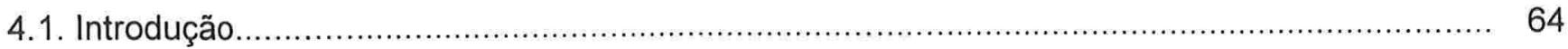

4.2. Métodos de Atribuição de Tratamentos................................................................... 65

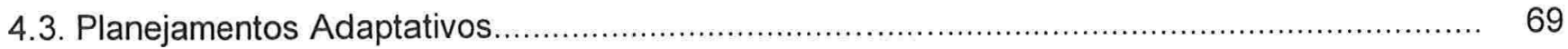

4.4. O Planejamento Play-the-Winner Aleatorizado (PWA)_............................................... 70

4.5. O Primeiro Experimento ECMO (Bartlett et al. 1985) ……............................................ 72

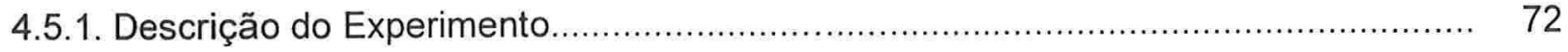

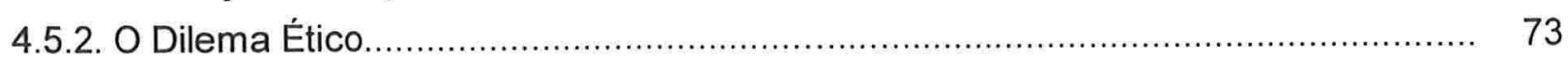

4.5.3. O Método de Seleção dos Tratamentos............................................................. 74

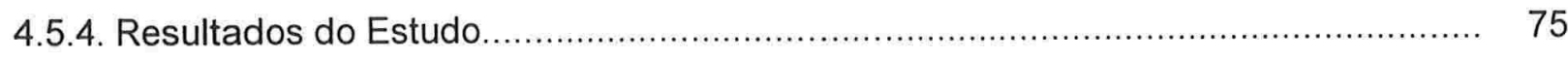

4.5.5. O Consentimento Informado .................................................................... 76

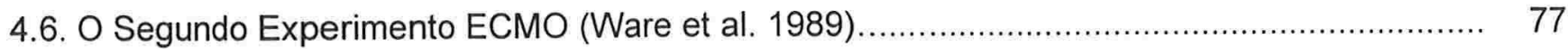

4.6.1. O Dilema Ético........................................................................................ 77

4.6.2. O Método de Seleção dos Tratamentos............................................................. 80

4.6.3. Resultados do Estudo............................................................................... 81

CAPÍTULO 5 - UM PLANEJAMENTO BAYESIANO _.................................................. 82

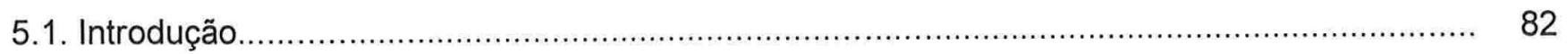

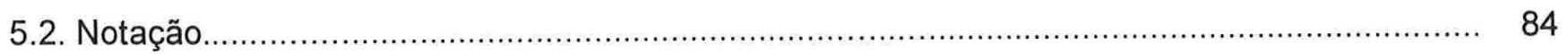

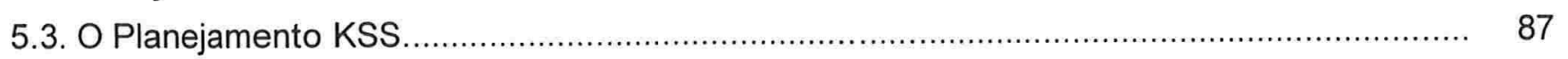

5.4. Uma Variação do Planejamento KSS......................................................................... 91

CAPÍTULO 6 - UMA APLICAÇÃO 95

PRÁTICA.

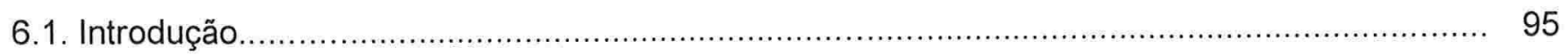

6.2. Objetivo do Estudo Verapamil versus Nitropussiato (VENI) ............................................ 96

6.3. A Aprovação do Protocolo pela Comissão de Ética........................................................... 97

6.4. Aspectos Computacionais do Estudo...................................................................... 100

6.5. A Experiência dos Especialistas - A Identificação de Prioris.................................................... 103

6.6. O Método de Seleção de Tratamentos Utilizado no VENI.................................................... 106

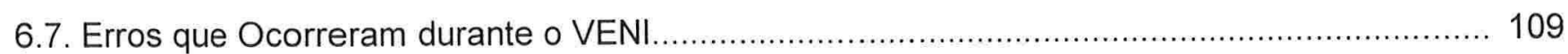

6.8. Resultados do Estudo - Análise Bayesiana....................................................................... 113

$\begin{array}{lc}\text { CONSIDERAÇÕES } & 123\end{array}$

FINAIS

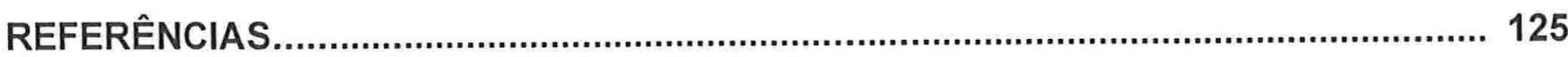




\section{INTRODUÇÃO}

Experimentos clínicos aleatorizados são amplamente utilizados na pesquisa cientifica na área médica. Alguns autores consideram que este é "o método mais confiável", "o único método", "o método mais seguro", o "melhor método" para se estudar a eficácia relativa de dois ou mais tratamentos em seres humanos. Estes estudos comparativos cuja principal característica é o fato do método de atribuição de tratamentos aos pacientes ser a aleatorização o, são assunto do capítulo 1.

As várias justificativas da aleatorização nestes estudos são discutidas no capítulo2. A introdução de vícios de seleção e a influência de covariáveis na resposta do paciente ao tratamento são justificativas relacionadas ao modo de conduzir o experimento, ou seja, ao planejamento. Bastante criticada pela inferência bayesiana, a inferência frequentista necessita deste artifício para gerar distribuições de referência. Quando aplicada à análise dos dados, a aleatorização é condenada pelo Princípio da Verossimilhança e, se vista sob o enfoque de teoria da decisão, a aleatorização não é adequada, por não maximizar a utilidade esperada.

O questionamento ético destes estudos é tema do capítulo 3. Freedman (1987) utiliza o conceito de equiparação individual (equipoise) para descrever um estado de genuína incerteza a respeito dos méritos relativos de um ou mais tratamentos. Em havendo esta incerteza genuína, seria ético conduzir um experimento clínico aleatorizado, conforme determinado pelo planejamento experimental "ideal". Apesar disto, quando enfocado o interesse do paciente, o médico é responsável por determinar o que ele pensa ser o melhor tratamento para este caso em particular. Em algumas situações da pesquisa clínica, o melhor para paciente não é o mais recomendável para a pesquisa. Aleatorizar é a conduta indicada pela pesquisa, ao passo que o desejo do paciente é que o seu médico escolha o tratamento. A aleatorização é o aspecto mais delicado deste contexto. Outro aspecto a ser discutido é o consentimento informado, 
documento que o paciente assina ao consentir a sua participação do estudo, após ter sido informado sobre seus aspectos relevantes.

A busca por um tipo de experimento clínico mais ético não é uma novidade. Esta procura parece ter sido motivada e motivadora do desenvolvimento dos experimentos sequenciais na década de 50 e também pelos planejamentos adaptativos nos anos de 1960 e 1970 (Schaffner, 1996). Os planejamentos adaptativos são aqueles cujo método de seleção de tratamentos incorpora a informação que surge no desenrolar do experimento às probabilidades de atribuição dos tratamentos aos pacientes. Com este tipo de planejamento, procura-se atribuir a mais pacientes o tratamento que está se saindo melhor até aquele ponto do experimento. No capitulo 4 apresentaremos dois experimentos clínicos onde foram aplicados os planejamentos adaptativos. Estas foram duas situações onde o dilema ético esteve claramente presente (Bartlett et al., 1985 e Ware et al., 1989), ambas referentes a um tratamento alternativo de hipertensão pulmonar persistente severa em recém-nascidos, o ECMO (extra-corporeal membrane oxigenation).

Em 1980, Kadane e Sedransk propõem uma solução que incorpora a nova informação à medida que esta é gerada pelo experimento, numa tentativa de proteger pacientes de tratamentos que possam ser desaconselháveis. $O$ conceito de tratamentos admissíveis é introduzido por estes autores para restringir a aleatorização apenas a estes tratamentos. Esta representa uma melhora em direção à solução do dilema ético. Apresentaremos no capítulo 5, a solução bayesiana proposta por Kadane, Sedransk e Seidenfeld (Kadane, 1996): o planejamento KSS.

Seis anos após, Kadane (1986) mostra o andamento de um experimento em que esta proposta é aplicada. Em 1996, o livro "Bayesian Methods and Ethics in a Clinical Trial Design", reúne vários enfoques práticos e teóricos deste assunto, inclusive os resultados deste experimento. O capítulo 6 é uma coletânea de alguns aspectos interessantes deste experimento. 


\section{CAPÍTULO 1 - EXPERIMENTOS CLÍNICOS}

\subsection{Experimentos Clínicos Aleatorizados}

1.2. A Importância de Experimentos Clínicos Aleatorizados

1.3. As Quatro Fases da Pesquisa Clínica

1.4. Consentimento Informado

1.5. Estado de Equiparação

\subsection{Experimentos Clínicos Aleatorizados}

O conceito de experimentos introduzido por Fisher (1935) refere-se a estudos onde o pesquisador exerce algum controle sobre as unidades amostrais, principalmente em relação ao tratamento a ser aplicado a cada uma delas. Neste tipo de estudo, é mais razoável a realização de inferências a respeito das causas de um determinado efeito, uma vez que elas são propositadamente controladas pelo investigador. Segundo Berry (1996), um experimento consiste em fazer algo e observar seu resultado. Por fazer algo, entendemos que o autor refere-se ao controle da alocação de tratamentos, visando determinar as causas de determinado resultado.

Alguns autores utilizam a expressão estudos controlados para estes experimentos. Quando não há interferência alguma do investigador no método de atribuição dos tratamentos às unidades amostrais, dizemos que o estudo é observacional.

Quando há interesse em avaliar a eficácia de um tratamento em seres humanos, o método de pesquisa mais tradicional consiste em comparar um grupo de pessoas 
submetidas a este tratamento (grupo experimental) com um grupo submetido a um tratamento considerado convencional ou com um grupo não submetido a tratamento. Este último grupo é chamado grupo controle e, idealmente, deve ser idêntico ao grupo experimental em todos os aspectos, com exceção do tratamento em questão. Alguns autores referem-se a experimentos que têm um ou mais grupos controle como experimentos controlados. Esta expressão também é utilizada para designar experimentos, que são estudos controlados pelo investigador (Berry, 1996). No presente trabalho, utilizaremos este último sentido da expressão.

Em um experimento, o processo de atribuição de tratamentos às unidades amostrais é um dos aspectos mais importantes do controle exercido pelo investigador. A aleatorização é um processo de seleção de tratamento para cada unidade amostral realizado por meio de um "sorteio": lançamento de uma moeda, de um dado, extração de bolas de uma urna, uso de uma tabela de números aleatórios, etc...

Os experimentos que possuem como unidade amostral seres humanos são denominados experimentos clínicos. Pesquisadores na área da saúde dão muita importância à metodologia de pesquisa conhecida como experimentos clínicos aleatorizados, que são estudos controlados, em seres humanos, objetivando avaliar o efeito comparativo de um tratamento, e cujo processo de atribuição de tratamentos é a aleatorização.

Bailar III, na introdução do livro Clinical Trial - Issues and Approaches (1983), comenta que não há uma definição precisa de experimento clínico. Este termo, 
segundo o autor, refere-se a um grupo de abordagens para avaliação dos méritos relativos de duas ou mais intervenções médicas ${ }^{1}$.

Pocock (1983), em seu livro Clinical Trials - A Practical Approach, utiliza a seguinte definição de experimentos clínicos: "um experimento clínico é qualquer forma de experimento controlado que envolva pacientes e que seja planejado para identificar o tratamento mais adequado para futuros pacientes com determinada condição médica". Royall (1991) fornece uma definição mais geral: "experimentos clínicos são estudos médicos com seres humanos, onde há incerteza a respeito de qual dentre duas ou mais terapias é preferivel".

\subsection{A Importância de Experimentos Clínicos Aleatorizados}

Se por um lado, o experimento clínico aleatorizado é considerado o melhor, único, mais definitivo e mais confiável método de se avaliar o efeito de um tratamento em seres humanos, por outro lado, existem várias críticas em relação ao valor da aleatorização (ver capítulo 2) e suas implicações éticas quanto ao dever do médico para com o paciente (ver capítulo 3).

Alguns autores (Cowan, 1981) consideram que o experimento clínico aleatorizado é uma necessidade científica, alegando não ser possível realizar inferências estatísticas válidas a partir de estudos não aleatorizados: "Com algumas exceções, a participação de qualquer grupo de pacientes em um experimento não aleatorizado é totalmente injustificada e anti-ética, uma vez que nada pode ser

\footnotetext{
${ }^{1}$ Neste trabalho, o termo tratamento será utilizada para referir-se a qualquer tipo de intervenção médica.
} 
aprendido com ele" ${ }^{2}$. Esta idéia provavelmente está ligada a uma semente plantada por Fisher (1935), que diz respeito a experimentos aleatorizados (Royall, 1991).

Como uma forma de salientar sua importância, Friedman et al. (1985) usam a expressão "mais definitivo" para caracterizar o experimento clínico aleatorizado enquanto método de estudo do efeito de um tratamento, sem no entanto menosprezar outras formas de investigação científica. Da mesma forma, Byar et al. (1976) consideram o experimento clínico aleatorizado o método "mais confiável para se atingir este objetivo (de estudar a eficácia de um tratamento)".

Alguns autores admitem que o experimento clínico aleatorizado é o melhor método, dentre os disponíveis, insinuando simplesmente que não conhecem outro método para avaliar a efetividade relativa de diferentes tratamentos. Mosteller, Gilbert e McPeek (1983) consideram que, quando bem executado, este tipo de experimento fornece a evidência mais forte. Bailar III (1983) considera que "nenhum outro método para estudar os méritos relativos de tratamentos pode aproximar-se da precisão na estimação dos efeitos e da força de inferência permitidas pelos experimentos clínicos aleatorizados" 3

Um pouco mais forte é a frase de Zelen (1979) dizendo que o experimento clínico aleatorizado é a "base científica para a medicina terapêutica". Pocock (1983) e Tukey (1977) são mais radicais, referindo-se ao experimento clínico aleatorizado como sendo a "única fonte confiável"4.

\footnotetext{
${ }^{2}$ grifos da autora

${ }^{3}$ grifos da autora

${ }^{4}$ grifos da autora
} 
Royall (1991) e Hill (1963) questionam a validade ética do experimento clínico aleatorizado (ver capítulo 3). Segundo estes autores, a supervalorização deste método de investigação científica tem impedido o desenvolvimento de métodos estatistica e eticamente mais satisfatórios que, idealmente, poderiam expressar um meio-termo entre um experimento bem planejado e o dever do médico com os interesses do paciente. São palavras de Royall (1991): “... quanto mais o estatístico entender e conhecer a relação médico-paciente e o verdadeiro problema ético, melhor ele poderá ajudar a delinear um experimento que poderá ser menos que ideal sob o ponto de vista experimental, porém de algum valor para a Medicina."

\subsection{As Quatro Fases da Pesquisa Clínica}

A pesquisa clínica envolvendo tratamentos com drogas em seres humanos decompõe-se em quatro tipos: os estudos chamados fase I, II, III e IV. Apesar de cada fase ter uma característica mais marcante, é tênue a linha que as divide.

Experimentos onde se deseja investigar a toxicidade de uma droga são denominados estudos fase $I$. Nos estudos fase I, um tratamento (uma droga ou combinação de drogas) ainda não aplicado em seres humanos será utilizado pela primeira vez. Estes são estudos-piloto, geralmente pequenos em termos de tamanho amostral, tendo por objetivo avaliar os efeitos farmacológicos da droga e determinar posologias com toxicidade aceitável. Algumas vezes, são aplicados a uma amostra de voluntários sadios. Estudos Fase I geralmente não são aleatorizados.

Em uma revisão feita por Smith et al. (1996) dos estudos fase I publicados de 1991 a 1993 pelo M.D. Anderson Cancer Center, observou-se que 100\% dos estudos 
utilizaram o método de planejamento convencional, onde coortes sucessivas de 3 pacientes, recebendo doses escaladas gradualmente, são avaliadas quanto à toxicidade do tratamento.

O número total de pacientes estudados dependerá da toxicidade observada em cada coorte. Assim sendo, se na primeira coorte de 3 pacientes forem observados 2 ou 3 pacientes com níveis de toxicidade inaceitáveis, o estudo será interrompido. Opostamente, se nenhum dos 3 pacientes apresentar toxicidade, a próxima coorte de 3 pacientes receberá a segunda dose. Se toxicidade for observada em apenas 1 paciente da primeira coorte, serão selecionados 3 pacientes adicionais para receber a primeira dose. Neste caso, o estudo será interrompido se, além do paciente que já apresentou toxicidade, mais 2 ou 3 apresentarem, somando 3 ou 4 pacientes em uma coorte de 6 . Em caso contrário (um total de 1 ou 2, dentre 6 pacientes), o estudo passará para a próxima coorte. A figura 1.1 ilustra este esquema.

Uma vez estabelecidas a toxicidade da droga e sua dose recomendada através de um estudo fase I, o próximo passo é um estudo fase II. Estes estudos são planejados para decidir se um certo tratamento tem eficácia suficiente para que mais estudos sejam realizados. Espera-se que tratamentos ineficazes sejam impedidos de prosseguir neste ponto, de modo que os futuros pacientes não os recebam em estudos mais avançados (Herson, 1979). Os estudos Fase II visam descobrir se um tratamento tem alguma atividade benéfica e avaliar seu efeito terapêutico. A maioria destes estudos não é aleatorizada, têm tamanho de amostra reduzido e a unidade amostral é o paciente. 
O principal objetivo de um estudo fase III é avaliar de forma mais precisa a eficácia de um tratamento e seus efeitos adversos. Estes estudos têm como principal característica o fato de serem comparativos. Na maior parte das vezes, são estudos aleatorizados e consideram um número maior de pacientes. Estes estudos são classificados como experimentos clínicos aleatorizados, de acordo com as definições da seção 1.1. Nem todos os experimentos clínicos aleatorizados podem ser classificados como fase III, pois esta classificação aplica-se somente a estudos com drogas.

Finalmente, os estudos fase IV (quase sempre aleatorizados) contam com um grande número de tratamentos e pacientes e visam a comprovação clínica de indicação já com doses da droga bem definidas, após aprovação da droga por órgão regulatório competente. Outros propósitos deste tipo de estudo são: avaliar a incidência de efeitos colaterais raros, determinar efeitos da droga sobre morbidade e mortalidade. Estes são estudos que tentam provar ou demonstrar à comunidade científica a validade de um novo tratamento proposto. Algumas vezes, o termo fase $I V$ é utilizado para descrever propagandas de marketing que visam chamar a atenção de uma nova droga para um grande número de médicos. Segundo Pocock (1983), estes estudos têm valor científico limitado por terem um caráter mais de divulgação a nivel de venda do produto associado ao tratamento do que uma divulgação científica. 


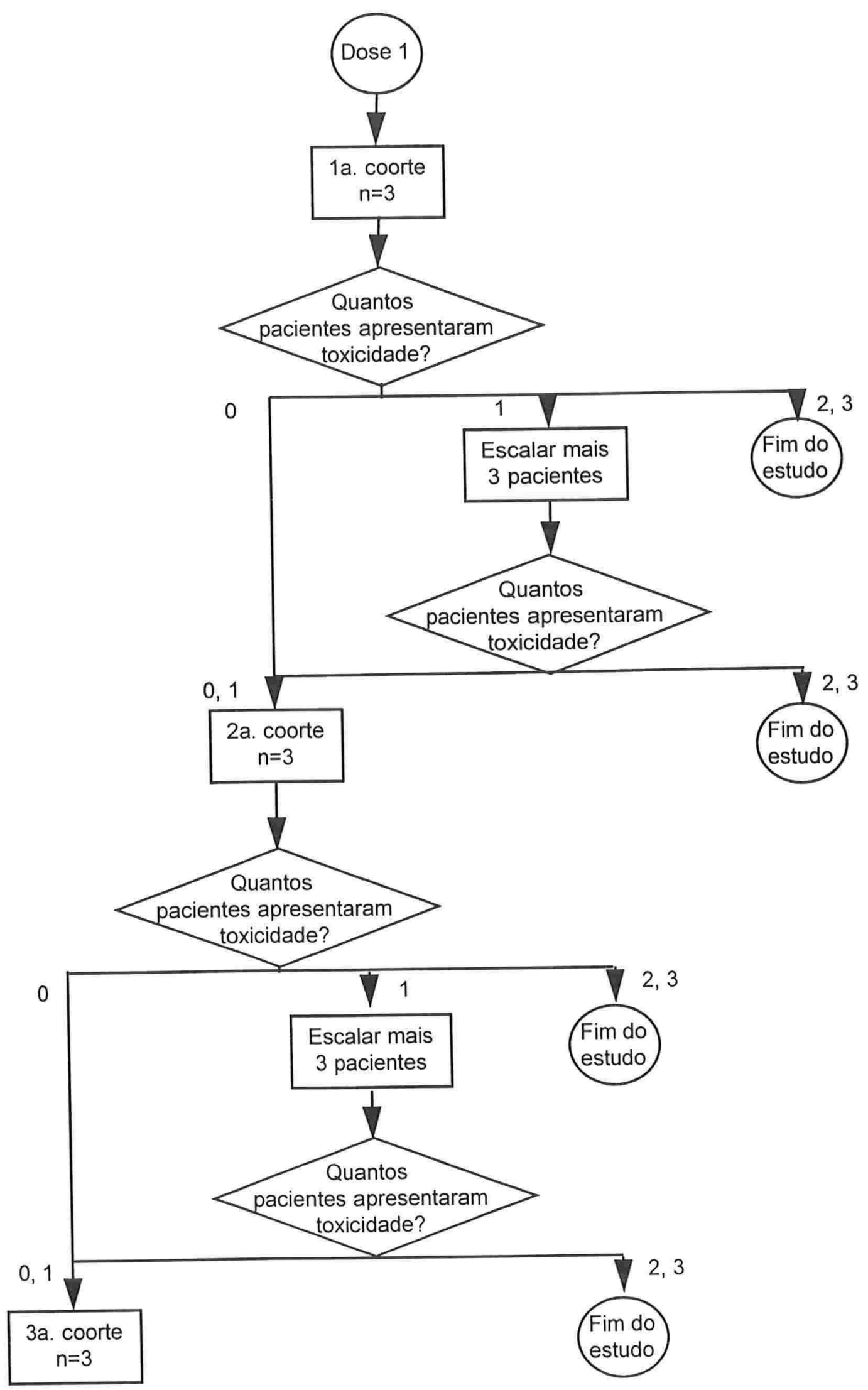

Figura 1.1. Esquema típico de um estudo fase I 
Friedman et al. (1985) consideram a questão do "timing" de um experimento clínico. Se, por um lado, o experimento clínico (estudo fase III) deve ser feito o mais cedo possível - antes que o tratamento passe a fazer parte da prática médica geral, por outro lado, antes de conduzir um experimento clínico, o pesquisador deve ter o conhecimento e as ferramentas necessárias para tal, saber sobre a segurança (estudos fases I), bem como os possiveis resultados da intervenção (estudos fase II).

Outro aspecto colocado por Friedman et al. (1985) é a estabilidade relativa do tratamento. Por exemplo, experimentos a longo prazo que envolvem intervenções cirúrgicas podem não representar a realidade destas ao final do estudo, pois em geral os métodos cirúrgicos melhoram constantemente. Uma solução para isto seria adiar o início de um experimento clínico até que um procedimento atingisse um nível a partir do qual poucas mudanças devessem ocorrer. Entretanto, este adiamento poderia significar um tempo de espera tão grande que o procedimento passaria a ser aceito como eficaz e então seria impossível conduzir um experimento clínico.

Apesar de todas as dificuldade, geralmente é possivel se conduzir um experimento clínico que leve em conta estes aperfeiçoamentos nas técnicas operatórias e, como em todos os aspectos deste tipo de estudo, o bom senso deverá ser usado para se determinar o momento correto de realizá-lo.

\subsection{Consentimento Informado}

Em estudos que envolvem seres humanos, o consentimento informado é um documento que é oferecido ao paciente para que este, após informado sobre o estudo, dê o seu consentimento em participar do mesmo. Entende-se que uma vez que o 
paciente tenha assinado este documento, ele tenha consentido participar de um estudo a respeito do qual tenha sido bem informado. A necessidade deste documento baseiase em conceitos da ética médica envolvendo os direitos do paciente. Vários problemas éticos podem surgir em torno do consentimento informado. Estes serão discutidos com detalhe na seção 3.4 .

Em experimentos clínicos aleatorizados, muitas vezes o grupo controle recebe o tratamento convencional idêntico ao tratamento de qualquer paciente que não participe do estudo. Zelen (1979) criou o consentimento informado aleatorizado, onde o paciente somente assinará este documento se ele for aleatorizado para receber o tratamento experimental. Os pacientes que forem selecionados para o tratamento controle seriam submetidos ao mesmo tratamento se não estivessem participando do estudo. Assim sendo, evita-se o trabalho desnecessário de explicar ao paciente todo o experimento e de solicitar seu consentimento para dele participar com um novo tratamento, sem efetivamente recebê-lo. Em algumas ocasiões, a abordagem do consentimento informado é extremamente estressante para o paciente e sua família, pois ele é exposto a uma situação de tomar uma decisão delicada. Um experimento clínico onde foi aplicado o consentimento informado aleatorizado está descrito no capítulo 4 , seção 4.3 .

Uma crítica muito severa a este tipo de procedimento para obter o consentimento do paciente é o fato deste não estar sendo informado da possibilidade de um tratamento alternativo (ainda que em fase experimental). Poupá-lo através da omissão de informação pode não ser honesto. A Medicina moderna tem cada vez menos espaço para condutas paternalistas como no passado, onde a responsabilidade 
e autoridade de uma decisão sobre determinado tratamento ou conduta cabia somente ao médico. Hoje em dia, médico, colegas, paciente e família tendem a decidir em conjunto o que fazer sob determinadas situações delicadas - o que divide o peso da responsabilidade entre as partes interessadas.

\subsection{Estado de Equiparação}

Freedman (1987) utilizou o termo "equipoise" para descrever o que seria o estado de um pesquisador com genuina e simétrica incerteza a respeito dos méritos comparados dos tratamentos de interesse. Este estado de equiparação (ou indistinção) individual é uma condição necessária para se conduzir um experimento clínico ético.

Podemos dizer que parte dos problemas éticos concentra-se em torno da verdadeira presença do estado de equiparação do pesquisador com relação aos tratamentos que serão estudados. O estado de equiparação pode estar presente no início do experimento, quando o pesquisador pouco conhece a respeito principalmente do tratamento experimental. Por força do próprio andamento do experimento, a experiência do pesquisador cresce e, consequentemente, a existência de estado de equiparação neste estágio do experimento torna-se bastante discutivel. Vários autores questionam a ética dos experimentos clínicos utilizando este argumento: o estado de equiparação geralmente existe no início do experimento, mas, à medida que dados vão se acumulando, o pesquisador necessariamente sai deste estado de equiparação (antes do término do experimento). Na seção 3.4 serão discutidos vários aspectos dos 
dilemas éticos em experimentos clínicos, com particular enfoque nos vários momentos onde estes podem surgir.

Por equiparação clínica (clinical equipoise), Freedman (1987) descreve o estado de incerteza de um grupo de investigadores com relação aos méritos relativos de um tratamento. Esta é uma condição mais fraca que a equiparação individual, uma vez que cada investigador individualmente pode ter a sua preferência com relação a um determinado tratamento, bastando haver discordância entre eles para que seja caracterizado o estado de equiparação clínica. Alguns autores consideram suficiente a presença do estado de equiparação clínica, ao passo que outros requerem que haja equiparação individual de todos os pesquisadores envolvidos para que o experimento clínico aleatorizado seja considerado ético. 


\section{CAPÍTULO 2 - ALEATORIZAÇÃO}

2.1. Indução

2.2. Probabilidade

2.3. Aleatoriedade

2.4. Aleatorização

2.5. Justificativas para Aleatorização em Experimentos Clínicos

2.5.1. Distribuição de Referência

2.5.2. Vícios de Seleção (Vícios do Observador)

2.5.3. Covariáveis

2.6. Aspectos Formais da Aleatorização

2.6.1. Na Inferência

2.6.2. Na Modificação ou Redução os Dados

2.6.3. No Planejamento

2.7. O Que Pensam os Bayesianos a Respeito da Aleatorização

2.7.1. Aleatorizar Não é Racional

2.7.2. Aleatorizar Viola o Princípio da Verossimilhança

2.7.3. Defendendo a Aleatorização

\subsection{Indução}

Extrapolação, generalização podem ser entendidos como sinônimos de indução. Ou seja, fazer indução é generalizar para um todo, conclusões obtidas a partir de uma parte. Por exemplo, podemos inferir a respeito do número de pessoas com AIDS 
(Síndrome da Imuno-deficiência Adquirida) no estado de São Paulo, a partir de dados obtidos de uma amostra. Este é um processo de indução, distinto ao da dedução, que é utilizado em demonstrações matemáticas, onde estabelece-se que certo resultado aplica-se ao todo.

Fisher escreveu, em Design of Experiments (1935, 1a. edição, seção 4, pg. 7) que "a inferência indutiva é o único processo que nós conhecemos através do qual essencialmente novos conhecimentos vêm ao mundo", e na página 3 da seção 2: "A pesquisa científica baseia-se na suposição de que é válido fazer inferências válidas a partir de resultados de experimentação, ou, que é possível argumentar das consequências para as causas, das observações para as hipóteses, de uma amostra para uma população da qual a amostra foi extraída".

Qualquer inferência do particular para o geral é acompanhada de incerteza. Podemos entender que inferência estatística é todo processo de diminuição de incerteza que se utiliza de informação.

\subsection{Probabilidade}

Probabilidade é um conceito muito conhecido por todos, sejam pessoas ligadas ao ambiente de pesquisa, matemáticos, estatísticos, médicos, economistas, ou pessoas nem mesmo alfabetizadas. Saber o que é probabilidade não é um privilégio de nenhuma classe social, cultural ou intelectual. Probabilidade está presente em todos os momentos da nossa vida: ao nascimento, na vida quotidiana, nas relações humanas, na saúde, na doença, nas finanças,... sempre podemos aplicar o conceito de probabilidade. Qual é a probabilidade de uma mulher grávida dar luz a uma menina? 
Qual é a probabilidade do arroz queimar, se o fogo estiver baixo? Qual é a probabilidade de um amigo ficar chateado com determinada atitude nossa? Qual é a probabilidade de um paciente com hipertensão ter um infarto? Qual é a probabilidade da poupança ter um certo rendimento? Qual é a probabilidade...? Todos têm um palpite a respeito de qual é cada uma destas probabilidades.

Além de sabermos intuitivamente o que é probabilidade, há uma descrição matemática clara e precisa deste conceito, conhecida como os axiomas de Kolmogorov:

Definição: Probabilidade é uma função cujo domínio é uma classe adequada $Y$ de subconjuntos de $\Omega$ e que satisfaz os seguintes axiomas:

1. $P(A) \geq 0, \forall A \in \mathcal{J}$

2. $P(\Omega)=1$

3. $\mathrm{P}\left(\bigcup_{\infty} \mathrm{A}_{\mathrm{i}}\right)=\sum_{\infty} \mathrm{P}\left(\mathrm{A}_{\mathrm{i}}\right)$, sempre que $A_{1}, A_{2}, \ldots$ forem dois a dois disjuntos em $\mathcal{Y}$

Poucos ousam questionar ou divergir sobre o cálculo de probabilidades gerado pelos axiomas de Kolmogorov. Esta ferramenta matemática é fundamental para a inferência estatística, seja ela bayesiana, frequentista, ou qualquer outra. Apesar desta definição ser universal, os estatísticos divergem com relação à interpretação deste conceito tão conhecido.

\section{Probabilidade Frequentista ou Física}

A interpretação frequentista entende que, em um experimento, a probabilidade do evento A é o limite da frequência relativa de ocorrências do evento em uma 
sequência de repetições independentes do experimento. Discutiremos a seguir mais detalhadamente os conceitos sublinhados na interpretação frequentista.

A primeira dificuldade que surge nesta interpretação é o conceito de limite: Qual é o limite em uma sequência de repetições independentes de um experimento? Todos entendem que o limite é o número em torno do qual a frequência relativa se estabiliza, quando o número de repetições aumenta muito, ou é "grande". Que número de repetições é grande o suficiente para ser considerado um grande número de repetições? Quem garante que esta sequência se estabilizará? Nem sempre é possivel realizar o experimento muitas vezes.

Para que as repetições sejam independentes, a probabilidade de ocorrência do evento em uma repetição do experimento não deve afetar a ocorrência do evento em outra repetição. Esta definição de repetições independentes envolve probabilidade e, neste caso, esta interpretação seria recursiva. Esta expressão pode ser substituída por "repetições do experimento realizadas sempre sob as mesmas condições", mas o problema continua: é impossível realizar dois experimentos exatamente sob as mesmas condições, pois, no mínimo, o tempo mudou do primeiro para o segundo experimento. Uma leitura mais flexível diria que as mudanças que ocorrem do primeiro para o segundo experimento são imperceptiveis e irrelevantes, de modo que é possivel que as mesmas condições sejam julgadas reproduzidas ou mantidas para as duas situações. Sejam estas mudanças perceptíveis ou imperceptiveis, o julgamento da importância destas mudanças é subjetivo, o que destrói a interpretação frequentista como sendo uma interpretação objetiva. 
Na seção 3, página 6, Fisher (1935) aponta que um dos motivos pelos quais ele rejeita os axiomas de Bayes (referindo-se à probabilidade subjetivista) é: "O axioma (de Bayes) leva à aparentes contradições matemáticas. Ao explicar estas contradições, os adeptos da probabilidade inversa ${ }^{1}$ parecem ser forçados a considerar a probabilidade matemática, não como uma quantidade objetiva medida através de frequências observáveis, mas meramente como uma medida de tendências psicológicas, respeitando teoremas que são inúteis para propósitos científicos”. Para Fisher, o fato do processo de inferência envolver incerteza "não quer dizer que esta inferência não possa ser absolutamente rigorosa, pois a natureza e o grau de incerteza podem ser expressos rigorosamente. A teoria da probabilidade, desenvolvida em sua aplicação em jogos de azar ${ }^{2}$, é um clássico exemplo de que incerteza pode ser expressa rigorosamente $^{3}$. Se o aparato do jogador for honesto ${ }^{4}$, as probabilidades dos possiveis diferentes eventos podem ser inferidas através de um argumento dedutivo rigoroso" (Fisher, 1935, 1a. edição, seção 2, pg. 4). Esta interpretação "lógica" ou "dedutiva" de probabilidade não se sustenta, pois as simetrias necessárias (honestidade dos aparatos, etc.) são adotados pela pessoa, consistindo, portanto novamente um caso particular de subjetividade.

\footnotetext{
1 interpretação subjetivista de probabilidade

2 roletas, apostas, dados, etc.

${ }^{3}$ grifos da autora

${ }^{4}$ dado não viciado, por exemplo
} 


\section{Probabilidade Subjetivista}

Os bayesianos, adeptos da interpretação subjetivista de probabilidade, entendem que probabilidade é uma medida pessoal e subjetiva, de modo que cada pessoa possui a sua probabilidade a respeito de qualquer quantidade desconhecida. Estes estatísticos acham que probabilidade deve ser utilizada para quantificar o desconhecimento (ou conhecimento) e atualizada com os dados (através da fórmula de Bayes). Esta é uma abordagem que pretende ser normativa e não descritiva. Ou seja, a inferência bayesiana ensina como deve agir uma pessoa para evitar certos tipos de inconsistências comportamentais indesejáveis: as incoerências (Bernardo e Smith, 1994 e Loschi, 1992). A postura subjetivista remove ainda todas as dificuldades da interpretação frequentista.

Lindley diz que probabilidade é uma relação entre você e o mundo. A interpretação bayesiana entende que probabilidade é uma medida pessoal de incerteza, ou ainda, probabilidade é uma expressão numérica que revela o quanto você acredita ou apostaria na ocorrência de um evento. A famosa expressão de Bruno De Finetti diz que "probabilidade não existe", no sentido de ser um conceito totalmente pessoal e subjetivo, que só existe na mente das pessoas, sem uma existência física.

\subsection{Aleatoriedade}

As duas principais escolas de inferência estatística, a frequentista e a bayesiana, utilizam a palavra aleatório para designar qualquer entidade a que seja atribuída uma probabilidade. Apesar disto, há profunda divergência no que diz respeito à atribuição de probabilidade a determinadas entidades. Segundo os bayesianos, qualquer pessoa 
possui incerteza a respeito de qualquer coisa que lhe seja desconhecida (ou "aleatória"). Contrariamente, para os estatísticos frequentistas, desconhecido não é o mesmo que aleatório. Segundo eles, os parâmetros, por exemplo são considerados fixos e desconhecidos, sendo proibida a atribuição de probabilidade a eles. A noção frequentista demanda repetibilidade para eventos "aleatórios", sendo portanto restrita e mal-definida (ver seção 2.2).

\subsection{Aleatorização}

A discussão apresentada anteriormente refere-se a probabilidade e aleatoriedade. A expressão aleatorização, apesar de estar ligada a estes dois conceitos, necessita por si só de uma definição. No contexto de experimentos de um modo geral, a aleatorização é entendida como um método de seleção de tratamentos que envolve mecanismos artificiais para a produção de resultados, ou "Ioterias". As probabilidades envolvidas são tipicamente "lotéricas" e quase sempre reduzidas à distribuição uniforme discreta, a exemplo de uma urna, um dado, uma roleta, tabela de números aleatórios, etc.

Para Kempthorne (1977), "um estudo é um experimento somente se determinadas forças são variadas de acordo com a vontade, capricho ou escolha do pesquisador". Conforme descrito na seção 1.1, a aleatorização é típica dos experimentos e Kempthorne (1977) enfatiza que causalidade somente pode ser inferida através destes estudos. Quando seres humanos são as unidades amostrais, ou seja, em experimentos clínicos, a aleatorização é fundamental, pois há uma variabilidade intrínseca das unidades amostrais. Se fosse possível "fabricar" unidades amostrais 
idênticas, não haveria necessidade de aleatorização. Neste caso, a combinação do tratamento A com a primeira unidade amostral comparativamente ao tratamento B aplicado à segunda unidade amostra reduzir-se-ia meramente à comparação entre os tratamentos $A$ e $B$ e, obviamente, não haveria vantagem nenhuma na atribuição do tratamento $\mathrm{A}$ à uma das unidades e o tratamento B à outra.

Na visão de Fisher (1935, 1a. edição, seção 21, pg. 45): “... o ato físico de aleatorizar ... é necessário para a validade de qualquer teste de significância”, e Royall (1991) aponta que Fisher plantou "uma semente da doutrina que vive hoje como o Princípio da Aleatorização, segundo o qual, a aleatorização deliberada cria a única distribuição de probabilidade na qual podem basear-se inferências estatísticas válidas".

Em experimentos clínicos aleatorizados, a aleatoriedade é introduzida através do processo de alocação dos tratamentos aos pacientes, ou seja, através da aleatorização (lembrando que, para os estatísticos frequentistas, não é permitido atribuir probabilidades a um parâmetro, por exemplo). Este argumento favorece a aleatorização quando nos submetemos a uma interpretação frequentista de probabilidade, uma vez que na inferência bayesiana aleatoriedade é introduzida no contexto somente na medida em que há algo desconhecido. Por este motivo, a impressão mais superficial é que aleatorização esteja mais ligada à visão frequentista do que à bayesiana.

\subsection{Justificativas para Aleatorização em Experimentos Clínicos}

São três as justificativas técnicas mais frequentes para que haja aleatorização em experimentos clínicos: a introdução de uma distribuição de referência (seção 2.5.1), 
a minimização dos vícios de seleção (seção 2.5.2) e a eliminação da influência de covariáveis que podem estar associadas à resposta (seção 2.5.3).

\subsubsection{Distribuição de Referência}

Até a elaboração dos testes de permutação de Fisher, testes estatísticos como o t-Student eram construídos com base na suposição de que os dados possuem distribuição normal (ou Gaussiana). Em 1935, Fisher deu sentido aos experimentos e à aleatorização, demonstrando ser possível a análise estatística dos dados com base na aleatorização somente, sem a necessidade de nenhuma suposição probabilística a respeito de uma população subjacente imaginária. O termo teste de uma hipótese mais ampla foi atribuído à situação de se testar a hipótese de igualdade de duas médias, sem a suposição de distribuição normal. A aleatorização é responsável por criar "concretamente" uma distribuição de referência, a partir da qual possa ser calculado o nível descritivo de probabilidade (p). Nas palavras do autor (Fisher, 1935, 1a. edição, seção 21, pg. 45): “... o ato físico de aleatorizar, ... necessário para a validade de qualquer teste de significância, fornece meios de ... examinar a hipótese mais ampla na qual não é implicada normalidade. O procedimento aritmético deste exame é tedioso, e nós devemos fornecer os resultados de modo a mostrar a possibilidade de uma verificação independente dos métodos mais práticos segundo o bom senso."

A presença de aleatoriedade é bem fundamentada através da aleatorização. Os testes de permutação baseiam-se exclusivamente na alocação aleatória das unidades amostrais, o que implica que probabilidade (frequentista) é introduzida na análise estatística exclusivamente a partir desta alocação aleatória. 
Na primeira edição do livro 'Design of Experiments', em 1935, Sir R.A. Fisher aparenta pensar que os testes de permutação são mais "válidos" do que os testes baseados em suposições de distribuições para os dados. Assim sendo, quando possivel a realização de aleatorização, o tipo teste mais recomendado seria de permutação: autor (Fisher, 1935, 1a. edição, seção 17, pg. 34): "Por acidente histórico, a teoria dos erros ${ }^{5}$, através da qual dados quantitativos podem ser interpretados, foi desenvolvida sem referência a métodos experimentais. ... a realização física de um experimento deve governar o procedimento estatístico de sua interpretação. Ao utilizarmos a teoria dos erros, nossas conclusões baseiam-se em uma ou mais estimativas do erro derivadas dos dados e adequadas para o conjunto de comparações que desejamos realizar. Estas estimativas podem ou não ser válidas para o propósito que intencionamos, dependendo do que realmente tenha sido realizado. É bem possivel que um experimento tenha sido conduzido de tal forma que não haja nenhuma estimativa de erro válida. Neste caso, rigorosamente não se pode dizer que o experimento seja capaz de provar nada. Talvez este estudo não deva ser chamado de experimento, mas de experiência, na qual nós teremos que basear nossas opiniões , por falta de algo melhor."

"Se um experimento nos permite calcular uma estimativa válida do erro, sua estrutura deve determinar completamente o procedimento estatístico através do qual esta estimativa deve ser calculada. Caso contrário, não existe uma interpretação dos

\footnotetext{
${ }^{5}$ teoria baseada na distribuição normal
} 
dados que seja inambigua, pois não podemos ter certeza de que algum outro método igualmente válido de interpretação não levaria a um resultado diferente."

Apesar desta primeira impressão, na sétima edição do mesmo livro (1960) a noção de que testes de permutação seriam mais apropriados foi para outra direção: quando Fisher adicionou uma nova seção ao capítulo que menciona os testes de permutação (Fisher, 1960, 7a. edição, seção 21.1, pg. 48)

"Recentemente, testes que usam o ato físico de aleatorizar para gerar uma distribuição de frequências (sob a hipótese nula) têm sido designados pelo nome de testes 'não-paramétricos'. Algumas afirmações extravagantes têm sido realizadas a respeito destes testes. O exemplo deste capítulo ${ }^{6}$, publicado em 1935 não foi de forma alguma colocado para substituir os testes práticos baseados na teoria Gaussiana dos erros. A utilidade destes testes não-paramétricos consiste na habilidade de gerar uma confirmação quando suspeita-se correta ou, mais frequentemente, incorretamente, que os testes mais simples ${ }^{7}$ tenham sido prejudicados por desvios da normalidade.

Eles ${ }^{8}$ supõem menor conhecimento (ou maior ignorância) a respeito do material experimental que os testes convencionais, e esta tem sido a atração para alguns matemáticos, que geralmente discutem experimentação sem conhecimento pessoal do material. Entretanto, em lógica indutiva, uma suposição errada de ignorância não é inócua; ela pode levar a alguns absurdos. Pesquisadores devem lembrar que eles e seus colegas geralmente conhecem mais a respeito do tipo de material que estão lidando do que os autores de livros escritos sem esta experiência pessoal e que um

\footnotetext{
${ }^{6}$ o exemplo do chá-com-leite (ver seção 2.6.3)

${ }^{7}$ os baseados em teoria normal

${ }^{8}$ os testes não-paramétricos
} 
teste mais complexo, ou mais inteligivel, não deve servir aos seus propósitos melhor, em qualquer sentido, que os de valor comprovado em sua própria área."

Basu (1980) entende que a adição desta seção ao capítulo, aliada ao misterioso silêncio de Fisher com relação a testes de permutação durante 25 anos após a primeira edição do livro Design of Experiments, são indícios de que Fisher tenha mudado de idéia ao longo destes anos, desconsiderando a importância destes testes. "Durante os últimos 27 anos de sua extraordinária carreira, encontramos Sir Ronald cogitando idéias tão revolucionárias quanto o Princípio da Condicionalidade e o Princípio da Verossimilhança e brincando com a idéia recém-elaborada de distribuição de probabilidade fiducial... Em vista da reconsideração pós-fiducial de Fisher a respeito de inferência estatistica, a inserção daquela seção ${ }^{9}$ extraordinariamente curta na sétima edição do livro Design of Experiments foi praticamente inevitável" (Basu, 1980, pg.382).

No entanto, Hinkley (1980, pg.583) interpreta o misterioso silêncio de Fisher com relação a este assunto de uma outra maneira: "Talvez, a visão de Fisher após 25 anos fosse tão conhecida e aceita que não tenha sido necessário repeti-la em um livro de inferência estatística para modelos paramétricos de probabilidade... Fisher afirmava que a aleatorização poderia garantir a relevância dos modelos paramétricos, mas ele se deu conta de que a aleatorização era suficiente, mais do que necessária, pois a Natureza geralmente já deve ter feito a aleatorização por nós". Para este autor, a mensagem de Fisher é que "a distribuição aleatória literalmente introduzida pela aleatorização experimental tem seu valor em verificar a validade da análise convencional".

\footnotetext{
${ }^{9}$ a seção 21.1
} 
Kempthorne (1980) compartilha da mesma interpretação de Hinkley a respeito da visão de Fisher com relação aos testes de permutação: "... é nítido que Fisher concebeu várias formas de inferência que vão desde os testes de significância até distribuições de parâmetros desconhecidos. Ele não rejeitou os testes de significância em 1956 (Fisher, 1956). Além disso não há evidências de que ele tenha rejeitado o exemplo da Dama provando chá com leite". Ao mencionar este exemplo, Kempthorne refere-se aos testes de significância de um modo geral, uma vez que a forma de Fisher introduzi-los foi através deste exemplo, conforme será abordado na seção 2.6.3.

\section{Testes de Permutação}

A seguir, descreveremos um exemplo de teste de permutação. Sejam $m_{1}$ e $m_{2}$ as médias de observações realizadas em pacientes submetidos respectivamente aos tratamentos $T_{1}$ e $T_{2}$. Há interesse em se testar a hipótese $H_{0}$ de que não há efeito de tratamento. Há $\left(\begin{array}{l}2 r \\ r\end{array}\right)$ possiveis formas de distribuir $2 r$ pacientes em dois conjuntos de tamanho r. A distribuição sob a hipótese nula dos possíveis valores de $\left|m_{1}-m_{2}\right|$ pode ser construída, e o valor amostral desta diferença pode ser localizado na distribuição. Assim sendo, o nível descritivo de significância é dado por: $p=P_{\mathrm{Ho}_{0}}\left(\left|M_{1}-M_{2}\right| \geq\left|m_{1}-m_{2}\right|\right)$. Suponha por exemplo que $r=3$, os dados observados são: $(13,12,10,9,11,14)$ e os tratamentos recebidos por cada paciente são $\left(T_{1}, T_{1}, T_{2}, T_{1}, T_{2}, T_{2}\right)$. A tabela 2.1 mostra as 20 possíveis combinações de 6 pacientes dispostos em dois grupos de 3 e os respectivos valores das médias $m_{1}$ e $m_{2}$, além da diferença em módulo $\left|m_{1}-m_{2}\right|$. A segunda configuração, em negrito, corresponde ao valor observado na amostra. A 
tabela 2.2 mostra as distribuições de probabilidade e de probabilidade acumulada de $\left|M_{1}-M_{2}\right|$. O nível descritivo de significância (ou p-value) deste teste é

$$
p=P_{H_{0}}\left(\left|M_{1}-M_{2}\right| \geq|-0,33|\right)=1,00
$$

Com outras disposições das duas amostras, os níveis descritivos poderiam ser:

$$
\begin{aligned}
& p_{1}=P_{H_{0}}\left(\left|M_{1}-M_{2}\right| \geq 0,67\right)=0,75 ; p_{2}=P_{H_{0}}\left(\left|M_{1}-M_{2}\right| \geq 1,00\right)=0,70 ; p_{3}=P_{H_{0}}\left(\left|M_{1}-M_{2}\right| \geq 1,67\right)=0,40 \\
& ; p_{4}=P_{H_{0}}\left(\left|M_{1}-M_{2}\right| \geq 2,33\right)=0,25 \text { e } p_{5}=P_{H_{0}}\left(\left|M_{1}-M_{2}\right| \geq 3,00\right)=0,15
\end{aligned}
$$

\begin{tabular}{|c|c|c|c|c|c|c|c|c|c|}
\hline & \multicolumn{6}{|c|}{ Valores Observados } & \multicolumn{3}{|c|}{ Estatísticas } \\
\hline & 13 & 12 & 10 & 9 & 11 & 14 & $m_{1}$ & $m_{2}$ & $\left|m_{1}-m_{2}\right|$ \\
\hline 1 & $T_{1}$ & $\mathrm{~T}_{1}$ & $\mathrm{~T}_{1}$ & $\mathrm{~T}_{2}$ & $\mathrm{~T}_{2}$ & $\overline{T_{2}}$ & 11,67 & 11,33 & 0,33 \\
\hline 2 & $T_{1}$ & $T_{1}$ & $T_{2}$ & $T_{1}$ & $T_{2}$ & $T_{2}$ & 11,33 & 11,67 & $-0,33$ \\
\hline 3 & $T_{1}$ & $\mathrm{~T}_{1}$ & $\mathrm{~T}_{2}$ & $\mathrm{~T}_{2}$ & $T_{1}$ & $\mathrm{~T}_{2}$ & 12,00 & 11,00 & 1,00 \\
\hline 4 & $T_{1}$ & $T_{1}$ & $\mathrm{~T}_{2}$ & $\mathrm{~T}_{2}$ & $T_{2}$ & $\mathrm{~T}_{1}$ & 13,00 & 10,00 & 3,00 \\
\hline 5 & $T_{1}$ & $\mathrm{~T}_{2}$ & $\mathrm{~T}_{1}$ & $T_{1}$ & $\mathrm{~T}_{2}$ & $\mathrm{~T}_{2}$ & 10,67 & 12,33 & $-1,67$ \\
\hline 6 & $T_{1}$ & $\mathrm{~T}_{2}$ & $\mathrm{~T}_{1}$ & $\mathrm{~T}_{2}$ & $\mathrm{~T}_{1}$ & $\mathrm{~T}_{2}$ & 11,33 & 11,67 & $-0,33$ \\
\hline 7 & $T_{1}$ & $\mathrm{~T}_{2}$ & $\mathrm{~T}_{1}$ & $\mathrm{~T}_{2}$ & $\mathrm{~T}_{2}$ & $\mathrm{~T}_{1}$ & 12,33 & 10,67 & 1,67 \\
\hline 8 & $T_{1}$ & $\mathrm{~T}_{2}$ & $\mathrm{~T}_{2}$ & $T_{1}$ & $\mathrm{~T}_{1}$ & $\mathrm{~T}_{2}$ & 11,00 & 12,00 & $-1,00$ \\
\hline 9 & $T_{1}$ & $\mathrm{~T}_{2}$ & $\mathrm{~T}_{2}$ & $T_{1}$ & $\mathrm{~T}_{2}$ & $T_{1}$ & 12,00 & 11,00 & 1,00 \\
\hline 10 & $T_{1}$ & $\mathrm{~T}_{2}$ & $\mathrm{~T}_{2}$ & $\mathrm{~T}_{2}$ & $T_{1}$ & $T_{1}$ & 12,67 & 10,33 & 2,33 \\
\hline 11 & $T_{2}$ & $T_{1}$ & $T_{1}$ & $\mathrm{~T}_{1}$ & $\mathrm{~T}_{2}$ & $T_{2}$ & 10,33 & 12,67 & $-2,33$ \\
\hline 12 & $\mathrm{~T}_{2}$ & $T_{1}$ & $T_{1}$ & $T_{2}$ & $T_{1}$ & $\mathrm{~T}_{2}$ & 11,00 & 12,00 & $-1,00$ \\
\hline 13 & $\mathrm{~T}_{2}$ & $T_{1}$ & $\mathrm{~T}_{1}$ & $\mathrm{~T}_{2}$ & $\mathrm{~T}_{2}$ & $T_{1}$ & 12,00 & 11,00 & 1,00 \\
\hline 14 & $\mathrm{~T}_{2}$ & $T_{1}$ & $\mathrm{~T}_{2}$ & $T_{1}$ & $T_{1}$ & $\mathrm{~T}_{2}$ & 10,67 & 12,33 & $-1,67$ \\
\hline 15 & $T_{2}$ & $T_{1}$ & $\mathrm{~T}_{2}$ & $\mathrm{~T}_{1}$ & $T_{2}$ & $T_{1}$ & 11,67 & 11,33 & 0,33 \\
\hline 16 & $\mathrm{~T}_{2}$ & $T_{1}$ & $\mathrm{~T}_{2}$ & $\mathrm{~T}_{2}$ & $T_{1}$ & $\mathrm{~T}_{1}$ & 12,33 & 10,67 & 1,67 \\
\hline 17 & $\mathrm{~T}_{2}$ & $T_{2}$ & $T_{1}$ & $\mathrm{~T}_{1}$ & $\mathrm{~T}_{1}$ & $\mathrm{~T}_{2}$ & 10,00 & 13,00 & $-3,00$ \\
\hline 18 & $\mathrm{~T}_{2}$ & $\mathrm{~T}_{2}$ & $T_{1}$ & $T_{1}$ & $\mathrm{~T}_{2}$ & $T_{1}$ & 11,00 & 12,00 & $-1,00$ \\
\hline 19 & $\mathrm{~T}_{2}$ & $\mathrm{~T}_{2}$ & $\mathrm{~T}_{1}$ & $\mathrm{~T}_{2}$ & $\mathrm{~T}_{1}$ & $\mathrm{~T}_{1}$ & 11,67 & 11,33 & 0,33 \\
\hline 20 & $\mathrm{~T}_{2}$ & $\mathrm{~T}_{2}$ & $\mathrm{~T}_{2}$ & $T_{1}$ & $T_{1}$ & $T_{1}$ & 11,33 & 11,67 & $-0,33$ \\
\hline
\end{tabular}

Tabela 2.1. Distribuição das 20 possíveis configurações de 6 pacientes dispostos em dois grupos de 3 . 
Tabela 2.2. Distribuições de probabilidade e probabilidade acumulada de $\left|\mathbf{M}_{1}-\mathbf{M}_{2}\right|$

\begin{tabular}{lcc}
\hline$\left|\mathbf{m}_{1}-\mathbf{m}_{2}\right|$ & probabilidade & $\begin{array}{c}\text { probabilidade } \\
\text { acumulada }\end{array}$ \\
\hline 3,00 & $3 / 20$ & $3 / 20$ \\
2,33 & $2 / 20$ & $5 / 20$ \\
1,67 & $3 / 20$ & $8 / 20$ \\
1,00 & $6 / 20$ & $14 / 20$ \\
0,33 & $6 / 20$ & $20 / 20$ \\
\hline
\end{tabular}

\subsubsection{Vícios de Seleção (Vícios do Observador)}

Segundo Byar (1991), a razão mais importante para que haja aleatorização em um experimento clínico é evitar vícios de seleção de pacientes nos grupos a serem comparados. A aleatorização assegura que nem o paciente nem o médico viciem o resultado através da decisão de participar ou não do estudo (Breslow, 1982). Vícios podem tornar os grupos não-comparáveis, invalidando um experimento. Se houver evidência estatística de diferença entre respostas de dois grupos de um experimento clínico, gostariamos de atribuí-la exclusivamente aos diferentes efeitos dos tratamentos em estudo. O processo de aleatorização assegura que a diferença entre dois grupos não seja, por exemplo, devida a alguma tendência do investigador em, consciente ou inconscientemente, escolher, digamos, o tratamento $\mathrm{A}$ justamente para os pacientes de pior prognóstico.

\section{Exemplo de Vício de Seleção}

Consideremos o seguinte exemplo de um pesquisador desejando testar o efeito de um determinado colirio na diminuição da pressão intra-ocular (PIO) de individuos com determinada doença oftalmológica. Para tanto, ele mediu a PIO em ambos os olhos de $\underline{n}$ individuos antes e após a aplicação 
do colirio. A seleção do grupo experimental - i.e. do olho que receberia colírio - foi feita pelo paciente, ou seja, o médico solicitava que cada paciente escolhesse "aleatoriamente" ${ }^{\text {10 }}$ um de seus olhos para pingar colírio. O outro olho necessariamente receberia soro (placebo) e seria considerado o grupo controle. $O$ médico imaginou que esta seria uma forma descompromissada de selecionar os grupos. Foram medidas a PIO nos dois olhos, antes e após a aplicação de colirio/soro.

O resultado obtido a partir deste estudo foi o seguinte : PIO do grupo de olhos tratados com colírio "surpreendentemente" maior do que a PIO dos olhos que receberam placebo, sugerindo que o colírio foi ineficaz para diminuir a PIO dos olhos experimentais em relação aos olhos controle.

Não satisfeito com o resultado, o pesquisador decide avaliar a PIO após a aplicação do colírio dos olhos tratados em relação à PIO antes da aplicação no mesmo grupo e não mais em relação ao grupo controle. Observa-se então que a PIO do grupo experimental (olhos que receberam colírio) após a aplicação do colírio era realmente menor que antes da aplicação, sugerindo, opostamente, que o colírio foi eficaz em diminuir a PIO. Já no grupo controle, situação inversa ocorreu, sendo a PIO pós-aplicação do soro semelhante à PIO anterior à aplicação do placebo.

A figura 2.2 apresenta as médias e respectivos desvios-padrão da PIO dos dois grupos, nas situações antes e após aplicação do colírio/soro. Como pode ser observado, a PIO do grupo experimental era superior à do grupo controle antes dos olhos terem recebido qualquer tratamento. A explicação para este fato é justamente a ocorrência de um vício de seleção. Quando solicitado aos pacientes que escolhessem um de seus olhos para fazer parte do grupo experimental, a grande maioria escolheu justamente o olho cuja PIO era mais elevada. Isso fez com que o grupo experimental (de olhos tratados com colírio) não fosse comparável ao grupo controle antes do colirio, pois possuia PIO mais elevada desde o começo do experimento.

\footnotetext{
${ }^{10}$ neste caso, o termo "aleatoriamente" foi empregado com um sentido irônico, uma vez que o paciente não está acostumado a esta linguagem.
} 


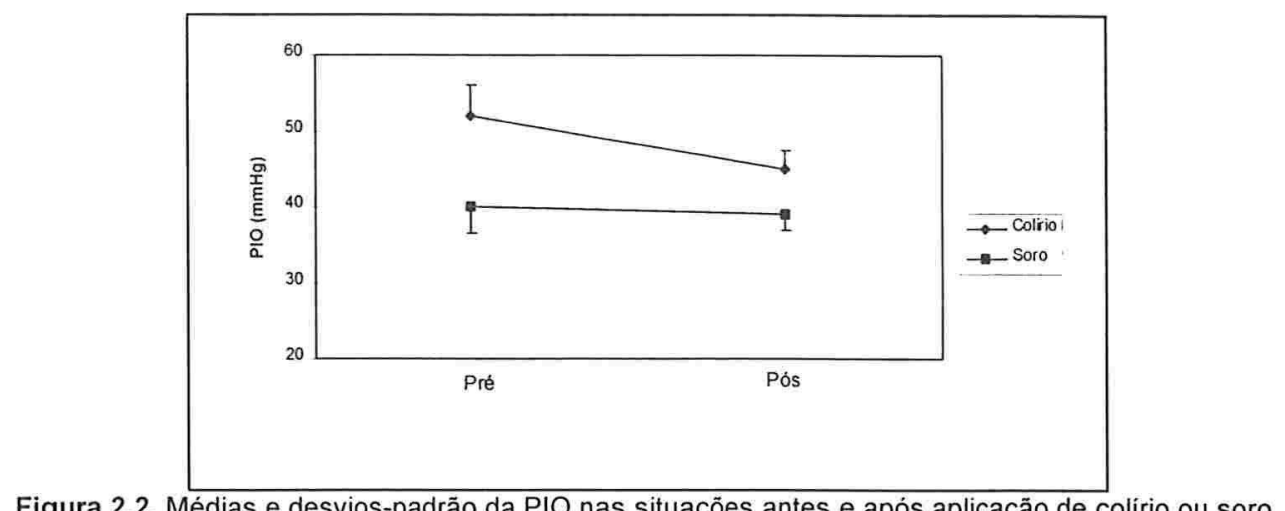

Figura 2.2. Médias e desvios-padrão da PIO nas situações antes e após aplicação de colírio ou soro.

A seleção (supostamente aleatória) dos olhos levou a um nitido vício de seleção que invalidou o experimento, pois a diferença entre os grupos devia-se também ao fato de um grupo ter começado o experimento com PIO evidentemente mais elevada que o outro.

\subsubsection{Covariáveis}

A aleatorização tende a equilibrar os grupos com relação a fatores que influenciam o prognóstico, sejam eles conhecidos ou não, distribuindo-os igualmente. A aleatorização não garante que os grupos serão comparáveis, mas tende a equilibrá-los com relação a covariáveis (Royall, 1991). Por exemplo, no caso de uma variável como idade; dois grupos selecionados de forma aleatória podem apresentar distribuições de idades distintas, de modo que o grupo experimental seja, em média, mais velho que o grupo controle. Mas o mais provável é que a aleatorização evite estas diferenças. Em todo caso, podem ser feitos ajustes estatísticos através de técnicas estatísticas que utilizam covariáveis, como na análise de covariância. Mas a maior vantagem de aleatorizar está nas covariáveis que são desconhecidas ou, impossíveis de serem medidas, para as quais um ajuste estatístico seria impossível.

A aleatorização pode servir para equilibrar os grupos com relação a variáveis que podem ser fatores de confusão para o resultado do experimento, pois tende a 
equilibrar os grupos com relação a todos os fatores, inclusive os que são desconhecidos ou impossiveis de serem medidos. É evidente que, quanto maior for o tamanho amostral, maior será a chance dos grupos serem equilibrados (apesar da aleatorização não garantir este equilíbrio). Em um experimento que planeja estudar 20 pacientes, dos quais 10 receberão o tratamiento $A$ e os 10 restantes receberão o tratamento B, a aleatorização pode produzir uma distribuição de 5 homens e 5 mulheres para cada grupo. Com uma chance menor, porém não nula, a aleatorização poderia produzir um 'desequilíbrio' de 10 mulheres e nenhum homem recebendo o tratamento A e o inverso para o tratamento B. Quando um fator gera confusão quanto ao resultado do estudo e este fator foi medido, ajustes estatísticos podem ser feitos. $\mathrm{O}$ grande problema ocorre quando este(s) fator(es) são desconhecidos, isto é, insuspeitos. Neste caso, ajustes estatísticos são impossíveis de serem realizados.

\subsection{Aspectos Formais da Aleatorização}

Kadane e Seidenfeld (1990) utilizam o conceito de ancilaridade e estatística suprimivel para argumentar contra a aleatorização quando aplicada a três diferentes situações: na inferência, na modificação ou redução dos dados e no planejamento. No primeiro exemplo, a inferência aleatorizada depende de informação totalmente irrelevante. No segundo exemplo, onde a aleatorização é utilizada para modificar ou reduzir os dados, informação ancilar não suprimível é ignorada . Estas são duas formas distintas de violação do Princípio da Verossimilhança. No terceiro exemplo, ao validarse a aleatorização, censura-se evidência ancilar não suprimível. 


\section{Estatística Ancilar}

Seja $\theta$ o parâmetro de interesse; $d$, os novos dados; $p($.$) , a opinião a priori sobre$ $\theta ; \quad p_{d}($.$) , a probabilidade a posteriori sobre \theta$, dado $d$ e, $p(d /$.$) , a função de$ verossimilhança gerada por $d$. A estatística $T$ é ancilar se $p(t / \theta) \equiv p(t)$, ou seja, $T$ é ancilar se sua distribuição independe de $\theta$. Pela regra de Bayes, podemos ver que a distribuição de estatísticas ancilares são irrelevantes, pois a distribuição a posteriori de $\theta$ dado $t$ ancilar independe de $\mathrm{t}$.

$$
\mathrm{p}_{\mathrm{t}}(\theta) \underset{\substack{\text { regra de Bayes } \\ \propto}}{\propto} \mathrm{p}(\mathrm{t} / \theta) \mathrm{p}(\theta) \underset{\text { tancilar }}{=} \mathrm{p}(\mathrm{t}) \mathrm{p}(\theta) \propto p(\theta)
$$

\section{Estatística Suprimível}

Suponhamos agora que os dados possam ser decompostos em duas estatísticas S e $T, d=(S, T)$, com $T$ ancilar para $\theta$; então, pela regra de Bayes, a probabilidade atualizada para $\theta$ depende dos dados apenas através da verossimilhança de $\theta$, gerada por s, dado $\mathrm{T}=\mathrm{t}$.

$$
\begin{aligned}
\mathrm{p}_{\mathrm{d}}(.) \stackrel{\text { notação }}{=} \mathrm{p}_{\mathrm{d}}(\theta) \propto \mathrm{p}(\mathrm{d} / \theta) \mathrm{p}(\theta) & =\mathrm{p}(\mathrm{s}, \mathrm{t} / \theta) \mathrm{p}(\theta)=\mathrm{p}(\mathrm{s} / \mathrm{t}, \theta) \mathrm{p}(\mathrm{t} / \theta) \mathrm{p}(\theta) \stackrel{\text { tancilar }}{=} \\
& =\mathrm{p}(\mathrm{s} / \mathrm{t}, \theta) \mathrm{p}(\mathrm{t}) \mathrm{p}(\theta) \propto \mathrm{p}(\mathrm{s} / \mathrm{t}, \theta) \mathrm{p}(\theta)= \\
& =\mathrm{p}(\mathrm{s} / \mathrm{t}, .) \mathrm{p}(.) \\
\text { notação } &
\end{aligned}
$$

Assim sendo, o que há de relevante nos dados d para o parâmetro $\theta$, está contido na estatística $\mathrm{s}$, dados os dados ancilares t. Portanto, o valor $\mathrm{t}$ de uma estatística ancilar importa para a inferência, pois $p(\theta / d) \propto p(\theta) p(s / t, \theta)$. A irrelevância de T ancilar dá-se na situação a seguir: 
A estatística $T$ é suprimível na presença de $\mathrm{S}$ para $\theta$, quando é ancilar e a distribuição de $\mathbf{S}$, condicional a $T$ e $\theta$, independe de $T$, ou seja $p(s / t, \theta)=p(s / \theta)$. Neste caso, os dados podem ser contraídos em $s$, pois $p(\theta / s, t) \propto p(\theta / s)$, conforme demonstrado a seguir.

$$
p(\theta / s, t) \propto p(s / t, \theta) p(\theta) \underset{\text { t suprimivel }}{=} p(s / \theta) p(\theta)=p(\theta / s) p(s) \propto p(\theta / s)
$$

\section{Suficiência}

Quando T é suprimível na presença de S para $\theta$, S é suficiente para $\theta$, pois:

$$
p(d / s, \theta)=p(t / s, \theta) \underset{\text { Bayes }}{=} \frac{p(s / t, \theta) p(t / \theta)}{p(s / \theta)} \underset{\text { tancilar }}{=} \frac{p(s / t, \theta) p(t)}{p(s / \theta)} \underset{\text { t suprimivel }}{=} p(t)=p(d / s)
$$

Um exemplo que ilustra claramente o papel de uma estatística ancilar é dado por O’Hagan (1994, pg. 71). Uma urna contém um número q desconhecido de bolas vermelhas. Um dado é lançado e seu resultado $x_{1}\left(x_{1}=1,2, \ldots, 6\right)$ é utilizado para determinar o número de bolas brancas que serão adicionadas à urna. Esta, por sua vez, é misturada e uma bola é extraída; se esta for vermelha, $x_{2}=1$, caso contrário, $\mathrm{x}_{2}=0$. Evidentemente $\mathrm{x}_{1}$ é uma estatística ancilar e a distribuição a posteriori é dada por:. A inferência ainda fará uso do número conhecido de bolas brancas na urna, mas irá desprezar o mecanismo aleatório pelo qual $x_{1}$ foi obtido. A mesma inferência teria sido obtida se $x_{1}$ fosse fixado desde o início.

\subsubsection{Na Inferência}


Neste exemplo A de Kadane e Seidenfeld (1990), a aleatorização é aplicada à inferência com o intuito de melhorar o poder estatístico de um teste ao simular continuidade para uma variável aleatória discreta. Esta é uma operação matemática que não tem sentido algum para a inferência estatística. Além do mais, os autores rejeitam a aleatorização quando utilizada para realizar inferência, pois a dependência de evidências totalmente irrelevantes (definidas acima como estatísticas suprimíveis) violam o Princípio da Verossimilhança.

Quando os dados têm uma distribuição discreta, nem sempre é possível construir um teste não-aleatorizado (simples) que tenha tamanho $\alpha$. Por exemplo, suponha que se deseja testar a seguinte hipótese: $H_{0}: p=0,2$ versus $H_{1}: p=0,4$, onde $f_{0}(x) \sim \operatorname{Bin}(n ; 0,2)$ e $f_{1}(x) \sim \operatorname{Bin}(n ; 0,4)$ são as distribuições binomiais associadas respectivamente a hipóteses nula e alternativa.

Seja $\delta_{1}$ um teste da seguinte forma:

$$
\delta_{1}:\left\{\begin{array}{l}
\text { rejeita } H_{0} \text { se } x>4 \\
\text { aceita } H_{0} \text { se } x \leq 4
\end{array}\right.
$$

Supondo $n=10$, este teste tem tamanho dado por:

$$
\alpha=P\left(\text { rejeitar } \mathrm{H}_{0} / \mathrm{H}_{0}\right)=P(x>4 / p=0,2)=\sum_{k=5}^{10}\left(\begin{array}{c}
10 \\
k
\end{array}\right) 0,2^{k} 0,8^{10-k}=0,033
$$

O teste que tem o próximo maior tamanho, ou seja,

$$
\delta_{2}:\left\{\begin{array}{l}
\text { rejeita } H_{0} \text { se } x>3 \\
\text { aceita } H_{0} \text { se } x \leq 3
\end{array}\right.
$$

tem tamanho dado por: $\alpha=P(x>4 / p=0,2)=\sum_{k=4}^{10}\left(\begin{array}{c}10 \\ k\end{array}\right) 0,2^{k} 0,8^{10-k}=0,121$ 
Não existe, portanto, um teste para esta hipótese que tenha tamanho exatamente igual, por exemplo, $\alpha=0,05$. Apesar de não ter utilidade prática nenhuma, os testes aleatorizados resolveriam o problema matemático de criar um teste com tamanho exatamente igual a 0,05. Suponha, por exemplo, o seguinte teste aleatorizado:

$$
\delta_{3}:\left\{\begin{array}{c}
\text { rejeita } H_{0} \text { se } x>4 \\
\text { sorteia com prob. } \gamma, \text { se } x=4, \text { onde } \gamma=0,193 \\
\text { aceita } H_{0} \text { se } x<4
\end{array}\right.
$$

O tamanho do teste $\delta_{3}$ é dado por:

$$
\alpha=P(x>4 / p=0,2)+P(x=4 / p=0,2) \gamma=0,033+\left(\begin{array}{c}
10 \\
4
\end{array}\right) 0,2^{4} 0,8^{6} \times 0,193=0,05
$$

Além de servir como ferramenta matemática para fornecer testes de hipóteses com tamanhos $\alpha$ determinados, a aleatorização pode servir para aumentar o poder estatístico de um teste mantendo o mesmo $\alpha$.

Considere, por exemplo, as seguintes hipóteses: $H_{0}: \theta=\theta_{0}$ versus $H_{1}: \theta=\theta_{1}$ onde $\quad p_{0}(0)=0,05$ e $p_{0}(k)=\frac{k 0,019}{1,1}, k=1, \ldots, 10$. é a distribuição de $\theta$ sob $H_{0}$ e $p_{1}(0)=0,50$ e $p_{1}(k)=\frac{k 0,010}{1,1}, k=1, \ldots, 10 . \quad$ é a distribuição de $\theta$ sob $H_{1}$. Então, $p_{0}(1)=\frac{1 \times 0,019}{1,1}=0,017$ e $p_{1}(1)=\frac{1 \times 0,010}{1,1}=0,009$

Sendo assim, o teste $\delta_{4}:\left\{\begin{array}{l}\text { rejeita } \mathrm{H}_{0}, \text { se } x=1 \\ \text { aceita } \mathrm{H}_{0}, \text { se } x \neq 1\end{array}\right.$

tem tamanho $\alpha=P\left(\right.$ rejeitar $\left.\mathrm{H}_{0} / \mathrm{H}_{0}\right)=P_{0}(x=1)=0,017 \mathrm{e}$ poder $1-\beta=1-P\left(\right.$ aceitar $\left.\mathrm{H}_{0} / \mathrm{H}_{1}\right)=P\left(\right.$ rejeitar $\left.\mathrm{H}_{0} / \mathrm{H}_{1}\right)=P_{1}(x=1)=0,009$ 
A probabilidade de rejeitar $\mathrm{H}_{0}$ quando ela é falsa é menor que a probabilidade de rejeitar $\mathrm{H}_{0}$ quando ela é verdadeira: isto é um absurdo!

$$
\text { Considere o teste } \delta_{5}:\left\{\begin{array}{c}
\text { rejeita com prob. } \gamma, \text { se } x=0 \\
\text { aceita } \mathrm{H}_{0} \text { se } x>0
\end{array} \text {, onde } \gamma=0,40\right.
$$

O tamanho deste teste é dado por: $\alpha=P_{0}(x=0) \gamma=0,05 \times 0,40=0,02$, e o seu poder, por: $1-\beta=P_{1}(x=0) \gamma=0,50 \times 0,40=0,20>0,009$ ! Sendo assim, os testes $\delta_{4}$ e $\delta_{5}$ têm o mesmo tamanho, porém o teste aleatorizado $\delta_{5}$ tem maior poder.

O lema de Neyman-Pearson garante que, se existir um teste $\delta^{*}$ que rejeita $\mathrm{H}_{0}$ se $R V(x)=\frac{f_{1}(x)}{f_{0}(x)}>k$ e aceita caso contrário, então este teste tem poder maior ou igual a qualquer outro teste que tenha tamanho menor ou igual ao tamanho de $\delta^{*}$.

Lema de Neyman-Pearson: Se existe um teste $\delta^{*}$ que rejeite $\mathrm{H}_{0}$ se $R V(x)>k$, então $1-\beta\left(\delta^{*}\right) \geq 1-\beta(\delta), \forall \delta \operatorname{com} \alpha(\delta) \leq \alpha\left(\delta^{*}\right)$.

No exemplo, o lema de Neyman-Pearson se aplica, pois a razão de verossimilhança assume apenas dois valores conforme $x=0$ ou $x>0$, e portanto, 0 teste é do tipo $\delta^{*}$ que rejeita $\mathrm{H}_{0}$ se $R V(x)>k$ :

$$
\left\{\begin{array}{c}
R V(x)=\frac{f_{1}(x)}{f_{0}(x)}=\left(\frac{k 0,010}{1,1}\right) /\left(\frac{k 0,019}{1,1}\right)=0,53, \text { se } x>0 \\
R V(x)=\frac{f_{1}(x)}{f_{0}(x)}=\frac{0,50}{0,05}=10,00, \text { se } x=0
\end{array}\right.
$$


Suponha, $k=0,60$; neste caso, o teste é dado por:

$$
\delta_{6} *:\left\{\begin{array}{c}
\text { rejeita } H_{0} \text { se } R V(x)>0,60 \\
\text { aceita } H_{0} \text { se } R V(x)<0,60 \\
\text { rejeita ou aceita } H_{0} \text { se } R V(x)=0,60
\end{array}\right.
$$

e corresponde ao teste $\delta_{5}$, cujo poder é maior ou igual a qualquer teste que tenha tamanho menor ou igual a $\alpha=0,02$. O teste $\delta_{4}$ tem poder menor que o teste $\delta_{5}$, por não ser do tipo que rejeita $\mathrm{H}_{0}$ se $R V(x)>k$.

A quantidade $\gamma$ no teste $\delta_{5}$ corresponde a um sorteio de um dígito $\mathrm{y} \in$ sorteado aleatoriamente do conjunto $\{0,1,2,3\}$. É evidente que y é uma estatística ancilar à hipótese de interesse, uma vez que sua distribuição é totalmente conhecida e constante. Assim sendo, a estatística y não deveria ter sido levada em conta ao se fazer inferência.

\subsubsection{Na Modificação ou Redução dos Dados}

Além da violação do Princípio da Verossimilhança, Kadane e Seidenfeld (1990) mostram no exemplo B uma situação onde a aleatorização (supostamente) fornece uma base para níveis de confiança exatos, desconsiderando os fatores 'nuisance'. Aqui, evidência ancilar não suprimível é ignorada.

Seja $\left\{x_{i}\right\}$ uma sequência de $n$ variáveis identicamente distribuídas com distribuição $\operatorname{Normal}\left(\mu_{x}, \sigma_{x}^{2}\right)$ e $\left\{y_{i}\right\}$ outra sequência de $\mathrm{n}$ variáveis identicamente com distribuição normal $\left(\mu_{y}, \sigma_{y}^{2}\right)$. O parâmetro de interesse é $\delta=\mu_{x}-\mu_{y}$ e as variâncias populacionais são parâmetros 'nuisance' $\left(\sigma_{x}^{2}, \sigma_{y}^{2}\right)$. Suponhamos que se utilize números 
aleatórios do conjunto $\{1,2, \ldots, n\}$ para a construção de $n$ pares $\left(x_{j}, y_{j}\right)$ aleatoriamente e seja $z_{j}=x_{j}-y_{j}$. A variável aleatória $z_{j}$ possui distribuição normal com parâmetros $\left(\delta, \sigma_{x}^{2}+\sigma_{y}^{2}\right)$. Um intervalo de confiança exato para $\delta$ é criado a partir do teste t-Student usual, baseado nos dados $z_{j}$ (esta análise corresponde a uma solução de teste de permutação para o problema de Behrens-Fisher). Com a ajuda da aleatorização, a análise ortodoxa despreza o parâmetro 'nuisance' $\sigma_{x} / \sigma_{y}$.

Como funciona este teste? A solução de um teste t utiliza a estatística $\frac{(\bar{z}-\delta)}{\mathrm{s}_{z} \sqrt{n-1}}$, reduzindo os dados à estatística $\left(\overline{\mathrm{z}}, \mathrm{s}_{\mathrm{z}}^{2}\right)$. Alterações no pareamento, ou seja no resultado da aleatorização, modificariam $\mathrm{s}_{\mathrm{z}}^{2}$, mas não $\overline{\mathrm{z}}$. Há $\mathrm{n}$ ! possíveis pareamentos dos dados e, portanto, há $n$ ! possíveis valores para $\mathrm{s}_{\mathrm{z}}^{2}$, que são ordenados pela sua magnitude. A aleatorização seleciona um destes possíveis valores, com probabilidade $1 / n !$, gerando a estatística ancilar $t=p o s t o\left(s_{z}^{2}\right)$. Ou seja, a evidência disponível está em $\mathrm{s}=\left(\overline{\mathrm{z}}, \mathrm{s}_{\mathrm{z}}^{2}\right)$ e $\mathrm{t}=\operatorname{posto}\left(\mathrm{s}_{\mathrm{z}}^{2}\right)$, que é esta última uma estatística ancilar na qual um dentre os $\mathrm{n}$ ! possíveis postos de $s_{z}^{2}$ é selecionado. Porém, t é ancilar sem ser suprimível e, $p(\delta / s, t) \propto$ $p(s / \delta, t) p(\delta) \neq p(s / \delta) p(\delta)$

Portanto, conclui-se que o teste t desta forma aleatorizado, baseado em $\mathrm{p}(\mathrm{s} / \delta)$ apenas, não é válido, pois ele considera a escolha aleatória ancilar de t como sendo suprimivel. O uso da aleatorização para eliminar o parâmetro 'nuisance' não é válido sob o ponto de vista bayesiano. Dado resultado da estatística $t$, a posteriori $p(\delta / s, t)$ continua dependendo da opinião a respeito da razão desconhecida $\sigma_{x} / \sigma_{y}$, o que significa que a aleatorização não teve sucesso em eliminar o parâmetro 'nuisance'. 
Tabela 2.2. Distribuição das 6 possiveis configurações de 3 pares valores $(x, y)$.

\begin{tabular}{cccccccccccc}
\hline & par 1 & par 2 & par 3 & & $z_{1}$ & $z_{2}$ & $z_{3}$ & $\bar{z}$ & $s_{z}$ & $\frac{(\bar{z}-\delta)}{s_{2} \sqrt{n-1}}$ \\
\hline 1 & $(13,9)$ & $(12,11)$ & $(10,14)$ & & 4 & 1 & -4 & & 0,33 & 4,04 & 0,058 \\
2 & $(13,9)$ & $(12,14)$ & $(10,11)$ & & 4 & -2 & -1 & & 0,33 & 3,21 & 0,073 \\
3 & $(13,11)$ & $(12,9)$ & $(10,14)$ & & 2 & 3 & -4 & & 0,33 & 3,79 & 0,061 \\
4 & $(13,11)$ & $(12,14)$ & $(10,9)$ & & 2 & -2 & 1 & & 0,33 & 2,08 & 0,115 \\
$\mathbf{5}$ & $(13,14)$ & $(12,9)$ & $(10,11)$ & & -1 & 3 & -1 & & 0,33 & 2,31 & 0,101 \\
6 & $(13,14)$ & $(12,11)$ & $(10,9)$ & & -1 & 1 & 1 & & 0,33 & 1,15 & 0,203 \\
\hline
\end{tabular}

Suponhamos, por exemplo que $n=3, x=(13,12,10)$ e $y=(9,11,14)$. Os 6 possiveis pares que podem ser formados, bem como as estatísticas $\overline{\mathrm{z}}$ e $\mathrm{s}_{\mathrm{z}}^{2}$ estão descritos na tabela 2.2. Se o resultado da aleatorização fosse o correspondente à $5 a$. linha (em negrito) da tabela 2.2, o nível descritivo deste teste seria $p=0,923$, ou seja, não rejeitaríamos $\mathrm{H}_{0}$.

\subsubsection{No Planejamento}

Por fim, a última situação onde a aleatorização pode ser aplicada, é no planejamento de um experimento. Particularmente, a atribuição do tratamento quando realizada segundo uma aleatorização, caracteriza o experimento clínico aleatorizado. Nesta situação, apesar de ainda haverem críticas desfavoráveis por parte dos bayesianos, há uma ressalva no que se trata da divulgação de um trabalho científico que seja um estudo do tipo 'experimento-para-provar'.

Kadane e Seidenfeld (1990) usam o exemplo das xícaras de chá com leite proposto por Fisher (1935), para mostrar uma situação onde evidência ancilar não suprimível é ignorada. 
O famoso exemplo de Fisher trata de uma Dama que afirma ser capaz de distinguir se o leite ou o chá foi colocado primeiramente em uma xícara. Para testar esta afirmação, Fisher planeja o seguinte experimento: serão misturados chá com leite em 8 xícaras, metade na ordem leite-chá e metade na ordem chá-leite. Estas serão apresentadas à Dama, que emitirá o seu palpite. A Dama conhece o seguinte aspecto: existem 4 xícaras de cada tipo que foram preparadas em uma ordem aleatória. Sua tarefa é apontar, dentre as 8 xícaras, quais receberam o tratamento 'leite-chá' e quais, 'chá-leite'.

Há um total de 70 diferentes sequências destas xícaras que podem ser arranjadas (combinação de 8 xícaras, 4 a 4). Sob a hipótese nula (Ho: a Dama não sabe distinguir entre os dois tratamentos: 'leite-chá' e 'chá-leite'), há uma distribuição estatística simples para o resultado experimental: o número de xícaras que a Dama acertar, $X$, segue uma distribuição hipergeométrica com parâmetros $N=8, A=4$ e $n=4$. A distribuição de X é dada por:

$$
P_{H_{0}}(X=x / N, A, n)=\frac{\left(\begin{array}{c}
A \\
x
\end{array}\right)\left(\begin{array}{c}
N-A \\
n-x
\end{array}\right)}{\left(\begin{array}{l}
N \\
n
\end{array}\right)}, x=0,1,2,3,4 .
$$

Sendo assim, sob $\mathrm{H}_{0}$, a probabilidade da Dama acertar todas as 4 xícaras é 1/70; a de acertar 3 e errar 1 xícara, 16/70 e a de acertar 2 e errar 2, 36/70. Outra forma de escrever a hipótese nula é: Ho: A distribuição de $X$ é dada por $P_{H_{0}}(X=x / N, A, n)$. A região crítica que inclui apenas o ponto $\mathrm{x}=0$ produz um nivel descritivo de significância de $\alpha=1 / 70 \cong 1,4 \%$. 
Três são os argumentos que justificam a aleatorização no planejamento neste tipo de situação:

1. Ao apresentar as xícaras em uma ordem aleatória, o pesquisador garante ao leitor que não houve nenhuma influência sua com relação à resposta da Dama para demonstrar a sua hipótese.

2. A ordem aleatória protege o experimento contra a influência de fatores incontroláveis (desconhecidos ou impossiveis de serem medidos)

3. A ordem aleatória garante a existência de uma distribuição de probabilidade correspondente à hipótese nula, possibilitando assim a inferência (frequentista).

O primeiro argumento foi abordado na seção 2.5 .2 , ou seja, a aleatorização tende a evitar os vícios de seleção que podem ser introduzidos pelo pesquisador em um experimento. Na seção 2.5.3 foi abordado o segundo argumento, onde covariáveis podem influenciar a resposta do experimento e a aleatorização tende a equilibrar os grupos com relação a fatores que podem influenciar a resposta, sejam eles conhecidos ou não, distribuindo-os igualmente. Estes fatores poderiam ser, por exemplo, a textura das xícaras, suas cores, a temperatura do chá ou do leite, etc. Em maior ou menor grau de intensidade, estes fatores poderiam eventualmente influenciar a resposta da Dama.

Finalmente, o terceiro argumento trata de algo que é a diferença última entre bayesianos e frequentistas: o conceito de probabilidade! Fisher, em sua visão frequentista, considera que a única forma através da qual as leis da probabilidade são explicitamente introduzidas em um teste de hipóteses é a partir da distribuição de frequências sob a hipótese nula, ou seja, a partir da aleatorização (seção 2.5.1). Já 
para os bayesianos, este argumento não tem valor algum, pois probabilidade é um conceito pessoal e subjetivo que poderá ser introduzido em um problema a todo instante que haja algo desconhecido.

É evidente que a estatística T das xícaras que foram tratadas com 'chá-leite' e as que foram tratadas com 'leite-chá' (o resultado da alocação) é uma estatística ancilar, pois sua distribuição é totalmente conhecida e depende exclusivamente do modo como foi realizado o sorteio para a alocação das xícaras. A estatística $T$, apesar de ser ancilar, não é suprimível na presença de $X$. No entanto, o resultado da aleatorização é ignorado ao se assumir o modelo da hipótese nula, pois $P_{H_{0}}(X=x / N, A, n)$ depende apenas de $\mathrm{X}$ e independe de $\mathrm{T}$.

Kadane e Seidenfled (1990) consideram que, no exemplo da Dama, a aleatorização e posterior censura não produziram um modelo estatístico sob a hipótese alternativa, uma vez que a Dama tem alguma habilidade em identificar as xícaras tratadas com 'leite-chá'. Assim sendo, os fatores 'nuisance' tais como o efeito da textura da xícara ou de sua cor na resposta da Dama, foram eliminados - assim como o $\sigma_{x} / \sigma_{y}$ foi eliminado no exemplo 2.7.2. Outra crítica, pelos mesmos autores, é o fato de que nenhum destes argumentos é válido uma vez que o pesquisador (ou o leitor) ficar a par do resultado (ancilar) da aleatorização.

Ao comentar este exemplo, os autores (Kadane e Seidenfeld) fazem uma analogia com os experimentos clínicos aleatorizados considerando que a Dama faz o papel dos pacientes, o preparador é o pesquisador, que, por sua vez, deseja provar ao 
leitor (ou espectador) sua hipótese (científica) de que a Dama sabe distinguir as duas situações (hipótese alternativa).

Sob a aleatorização, tanto o leitor quanto o pesquisador acreditam que a capacidade de discernimento da Dama independe de sua capacidade de distinguir outros aspectos, ainda que inconscientemente. É evidente que, se não houver relação entre o pesquisador e os pacientes (Dama), este problema não existe (por exemplo, no caso de lotes de terra). Kempthorne (1977) aponta que o papel da aleatorização está relacionado à natureza das unidades experimentais disponíveis. Se fosse possível "fabricar" unidades idênticas, não haveria necessidade de aleatorização para evitar os vícios de seleção (seção 2.5.2) e a influência de covariáveis (seção 2.5.3).

\subsection{O Que Pensam os Bayesianos a Respeito da Aleatorização}

Há motivos de natureza distinta pelos quais aleatorização não é bem vista : o primeiro refere-se à ética médica, que será discutida no capítulo 3 , o segundo está relacionado com o conceito de coerência: aleatorizar não é racional, e o terceiro está relacionado com o Princípio da Verossimilhança. Por outro lado, há apenas um forte argumento a favor da aleatorização: quando se trata da divulgação de um experimentopara-provar.

\subsubsection{Aleatorizar Não é Racional}

Para toda decisão aleatorizada sempre há decisões não-aleatorizadas com utilidade esperada igual ou superior. Sejam $d_{1}, d_{2}$ e $d_{3}$ decisões cujas respectivas utilidades são representadas por $U_{\theta}\left(d_{1}\right)$, e $U_{\theta}\left(d_{2}\right)$ e $U_{\theta}\left(d_{3}\right)$. Sejam $\theta_{1}$ e $\theta_{2}$ os possíveis 
estados da natureza, com priori $p\left(\theta_{1}\right)$ e $p\left(\theta_{2}\right)$ respectivamente. A utilidade esperada da decisão $i$ é dada por: $E\left(d_{i}\right)=p\left(\theta_{1}\right) U_{\theta 1}\left(d_{i}\right)+p\left(\theta_{2}\right) U_{\theta 2}\left(d_{i}\right)$. Assim sendo, a decisão ótima d* é aquela maximiza $E\left(d_{i}\right)$. Se houver mais de uma decisão que satisfaça esta condição, qualquer uma delas é ótima.

Sob este enfoque, aleatorizar é considerado desnecessário. Em um experimento clínico, o pesquisador deve tomar a decisão de que tratamento atribuir a cada paciente. Cada uma das decisões tem uma utilidade esperada. Se uma delas tem uma utilidade esperada maior que as demais, esta é a decisão ótima (ou decisão de Bayes). Se várias decisões apresentarem utilidades esperadas iguais, a seleção de qualquer uma delas é uma decisão ótima, não importando se esta seleção for feita aleatoriamente, ou por qualquer outro método. Então, sob este enfoque, aleatorizar é desnecessário e algumas vezes, subótimo (Kadane e Seidenfeld, 1990).

\subsubsection{Aleatorizar Viola o Princípio da Verossimilhança}

Por outro lado, também após a experimentação, os autores bayesianos negam que a aleatorização seja uma necessidade para a análise estatística do experimento. 0 aprendizado com os dados deve ser feito em obediência ao Princípio da Verossimilhança (Inoue, 1994), independentemente do particular método de atribuição dos tratamentos.

Quanto à utilização de testes de permutação e concretização de distribuições de probabilidade em geral, o argumento que defende a aleatorização com este propósito não tem nenhum valor, uma vez que testes de permutação violam o Princípio da 
Verossimilhança. Os testes de permutação baseiam-se na distribuição de resultados que poderiam ter ocorrido, mas não ocorreram (Kadane e Seidenfeld, 1990).

Inoue (1994) fornece um histórico a respeito do Principio da Verossimilhança (PV) e sua importância, além de apresentá-lo, tanto de modo informal, quanto através de desenvolvimento axiomático (devido a Birnbaum 1962).

Princípio da Verossimilhança: "Toda a informação fornecida por um experimento a respeito de uma quantidade desconhecida $\theta$ está contida na função de verossimilhança para $\theta$ gerada pelos dados. Se duas funções de verossimilhança para $\theta$ forem proporcionais entre si (podendo ser provenientes do mesmo experimento ou até de experimento distintos), então elas contém a mesma informação a respeito de $\theta . "$ (Berger e Wolpert, 1988)

O PV e sua relação com a inferência bayesiana são discutidos por Inoue (1994). Se por um lado a inferência bayesiana implica a obediência ao PV, por outro lado, a recíproca não é verdadeira: este princípio não requer a adoção da inferência bayesiana, pois existem outras inferências que satisfazem o PV, como a inferência de verossimilhança.

Para os bayesianos, adeptos do PV, o único aspecto relevante de uma amostra já observada refere-se aos dados efetivamente obtidos. A análise baseia-se na distribuição corrente para os parâmetros, dadas as informações disponíveis. A análise, após a realização da amostra, independe de aspectos de planejamento do experimento, regras de parada, protocolos, etc. (Inoue 1994). 
Este fato evidentemente não significa que o planejamento de um experimento deva ser mal feito, ou que não deva existir. A diferença é que outros aspectos podem ser levados em consideração sob um planejamento que não possua tantas restrições. A questão da aleatorização, por exemplo, é um ponto onde bayesianos e frequentistas diferem enormemente. Sob o enfoque bayesiano, uma vez que a análise independe de aspectos do planejamento, aleatorizar é desnecessário. O pesquisador poderá utilizar qualquer método de seleção de tratamentos para os pacientes, inclusive um que leve em conta os interesses do próprio paciente - fato este que concorda plenamente com os aspectos da ética pessoal (ver capítulo 3). Opostamente, o enfoque frequentista menospreza um experimento cujo método de seleção dos tratamentos não tenha sido aleatorizado, uma vez que a análise depende deste sorteio.

A aleatorização por si só, quando realizada no planejamento, não viola o Princípio da Verossimilhança, desde que seu resultado não seja utilizado para realizar inferência, ou para modificar/reduzir os dados.

\subsubsection{Defendendo a Aleatorização}

Kadane e Seidenfeld (1990) valorizam a aleatorização quando se trata de imperfeição humana. Referem-se à imperfeição humana em situações de experimentos clínicos, onde o pesquisador tem uma tendência natural a introduzir um vício ao selecionar os pacientes que receberão cada tratamento. "Enquanto pesquisadores, é a surpreendente verdade que nos tornará famosos. Então, cada pesquisador deve ter (ou deve ser suspeito de ter) um motivo para exagerar a verdade. Nós não estamos escrevendo sobre falsificação flagrante e deliberada, mas sobre os meios mais sutis 
através dos quais nós podemos enlouquecer a nós mesmos e tentar enlouquecer os outros".

De um certo modo, a aleatorização oferece uma segurança metodológica contra o vício do observador. Estes autores apresentam duas formas de se abordar este argumento. A primeira concentra-se no pesquisador e em experimentos onde este deseja aprender - experimentos-para-aprender. A segunda abordagem enfoca a relação pesquisador-leitor como uma situação de tomada de decisão em grupo: os experimentos-para-provar (seção 3.1.4). Para Kadane e Seidenfeld (1990), em experimentos-para-aprender a aleatorização não é bem vista, uma vez que esta priva o pesquisador de maximizar a informação a ser obtida em um estudo de seu interesse. A justificada tendência de qualquer pesquisador em exagerar a verdade com o intuito de provar a eficácia de determinado tratamento torna a aleatorização uma boa alternativa como método de seleção dos tratamentos.

Em experimentos-para-provar, a tomada de decisão em grupo é vista do seguinte modo: por um lado, o pesquisador tem como utilidade uma função que reflete seu desejo de provar a hipótese formulada a respeito da eficácia de determinado tratamento; por outro lado, o leitor tem uma legitima fonte de preocupação na forma como foi planejado e conduzido o experimento. Se o pesquisador deseja que seu trabalho seja lido e divulgado, ou seja, se ele deseja demonstrar a sua hipótese aos leitores, não deveria ser permitida sua intervenção na atribuição dos tratamentos aos pacientes. Stone (1969) argumenta que a aleatorização é a única solução para este problema. Kadane e Seidenfeld (1990) também consideram que a aleatorização resolve este problema, apesar de não usarem-na como o único método. Para estes autores, 
existem outros métodos que fazem o papel de proteger o experimento contra o vício do observador. Um exemplo seria um esquema de seleção que maximizasse a informação a ser obtida, atribuindo os tratamentos aos pacientes conforme suas características mensuráveis pré-estabelecidas no protocolo do estudo (não havendo, obviamente a possibilidade do pesquisador introduzir vício de seleção referente à covariáveis insuspeitas).

Algumas vezes, pode ser eficiente buscar o acordo interpessoal sobre o que os dados apontam, usando-se um planejamento aleatorizado simples ao invés de um experimento que otimize o que o pesquisador (sozinho) pode aprender. Neste tipo de estudo há um obstáculo para o consenso: uma limitação naquilo que o pesquisador pode conseguir demonstrar (Kadane e Seidenfeld, 1990).

Kadane e Seidenfeld (1990) citam Savage (1961): "Ao aplicarmos a teoria da probabilidade pessoal, ingenuamente concluímos que a aleatorização não tem valor algum para a estatística. Esta conclusão não parece correta, e não está correta. Um exame mais detalhado do caminho desta conclusão indefensável leva a novas idéias em relação ao papel e limitações da aleatorização, mas esta não deixa de ter uma importante função na estatística." e Savage (1962): "Apesar de todos nós pensarmos que a aleatorização é uma invenção importante, a teoria da probabilidade subjetiva nos lembra que nós ainda não a entendemos completamente... A necessidade da aleatorização está na imperfeição humana e, talvez, no fato de que mais de uma pessoa esteja preocupada com uma investigação." ${ }^{11}$

\footnotetext{
${ }^{11}$ grifos da autora.
} 
Apesar de todas as críticas bayesianas ingênuas, Kadane e Seidenfled (1990), citando Savage (1961 e 1962), reforçam o valor da aleatorização quando se trata da divulgação de um trabalho científico. Em experimentos-para-provar, estes autores aprovam e inclusive apoiam o uso da aleatorização na fase do planejamento do experimento. Para uma ilustração prática desta posição, veja o experimento clínico conduzido por Kadane e descrito em detalhes no capítulo 6, onde considerações éticas e estatísticas foram encaminhadas em direção a um consenso. No artigo intitulado "Randomization: A Bayesian Perspective" (1990) estes autores entendem que "... a aleatorização é uma ferramenta (que pode servir) para a melhora da comunicação interpessoal", sendo, portanto, sociologica e epistemologicamente importante. 


\section{CAPÍTULO 3 - O DILEMA ÉTICO}

3.1. A Seleção dos Tratamentos

\subsubsection{Aleatorização}

3.1.2. Seleção do Tratamento Segundo o Paciente

3.1.3. Controles Concorrentes (a proposta de Royall)

3.1.4. Experimentos-para-aprender e Experimentos-para-provar

3.2.O Princípio da Atenção Pessoal

3.3. Estado de Equiparação

3.4. O Consentimento Informado

3.5. Os Momentos de um Experimento Clínico onde Pode Surgir o Dilema Ético

\subsection{A Seleção dos Tratamentos}

Basicamente, o maior problema dos experimentos clínicos está no método de seleção dos tratamentos, ou seja, como é tomada a decisão de qual será o tratamento atribuído a cada paciente. Nesta seção consideraremos os aspectos éticos e científicos de vários métodos de seleção de tratamentos: aleatorização (3.1.1), seleção do tratamento realizada pelo próprio paciente (3.1.2) e a proposta de Royall (1991) de controles concorrentes (3.1.3). Além disso, a seção 3.1.4 trata do dilema ético enfocado na seleção do tratamento em dois tipos de experimentos. 


\subsubsection{Aleatorização}

Um dos problemas da aleatorização em experimentos clínicos é o fato destes envolverem seres humanos. O paciente que participa de um experimento clínico aleatorizado deve concordar com o fato de que o tratamento que ele receberá será escolhido por meio de um sorteio, ou seja, que haverá aleatorização. Quando um paciente vai ao médico, o que ele procura na maior parte das vezes é a opinião do médico a respeito do que fazer para curar sua doença. Ora, se o médico der sua opinião a respeito de qual é o melhor tratamento para este paciente, então não haverá aleatorização. Em outras palavras, em determinadas situações, aleatorizar um paciente para receber um determinado tratamento ou outro pode representar um erro ético.

Suponhamos uma situação onde a comunidade médica realmente não saiba qual é o melhor tratamento para uma determinada doença. Neste caso, não seria antiético o médico alegar isto ao paciente e selecionar um tratamento aleatoriamente. Após alguns pacientes tratados, o médico deveria ter adquirido mais experiência e poderia ter mudado de opinião. Então, para os próximos pacientes, aleatorizar tratamentos passaria a ser uma atitude anti-ética.

A discordância entre especialistas médicos é (ou, pelo menos, deveria ser) uma condição inerente à decisão de se conduzir um experimento clínico. Se não houver desacordo, ou incerteza a respeito do melhor tratamento, não há motivos para se conduzir um experimento clínico. $\mathrm{O}$ argumento que um médico pode dar a um paciente pode ser atenuado por esta discordância, dizendo que a comunidade médica diverge quanto ao melhor tratamento. Só que isto não significa que o médico não tenha opinião 
a este respeito. Na maior parte das vezes, o que um paciente procura quando vai a um médico especialista é sua opinião, e não a opinião da comunidade médica.

\subsubsection{Seleção do Tratamento Segundo o Paciente}

Permitir que os pacientes escolham o seu próprio tratamento não é uma boa solução para o dilema ético. Se, em um experimento clínico, paciente e médico conjuntamente tomassem a decisão da escolha do tratamento, este esquema não violaria os direitos do paciente, pois este estaria recebendo o que fosse o melhor para os seus interesses. Por outro lado, como poderiam ser analisados separadamente os efeitos devido ao tratamento e os efeitos devidos às pessoas que os escolheram?

O esforço de se conduzir um experimento clínico não teria nenhum valor se estes dados não pudessem ser utilizados cientificamente. Se, em nome da proteção ao paciente, ele próprio fosse privado da possibilidade do avanço médico científico através do uso de dados provenientes de experimentos clínicos, este estudo não teria valor científico. O que se busca, é um meio termo entre o que se considera um bom negócio para o paciente que participa do experimento clínico aleatorizado e, por outro lado, que se obtenha dados interpretáveis para a comunidade cientifica (Kadane, 1986).

\subsubsection{Controles concorrentes (a proposta de Royall)}

Aleatorizar pode ser necessário para que o resultado do estudo seja convincente para a sociedade. Royall (1991) propõe, como solução alternativa à aleatorização, que sejam feitos estudos com controles concorrentes. Estes estudos seriam análogos aos experimentos clínicos aleatorizados, porém, o tratamento controle seria aplicado a 
pacientes de outros hospitais com características semelhantes aos do grupo experimental.

Tanto Royall (1991) quanto Herman (1995) apontam que algumas das intervenções mais benéficas já conhecidas foram introduzidas sem o uso da metodologia de experimentos clínicos aleatorizados: vacinação contra sarampo, hormônio da tireóide, insulina, penicilina, aspirina, digoxina, anestesia e até mesmo cirurgia da artéria coronária.

Para Byar (1991), este argumento é fraco. Em epidemiologia, geralmente os fatores de exposição não são escolhidos com o objetivo de afetar alguma variável resposta. O mesmo não acontece com tratamentos, que são escolhidos propositadamente com o intuito de afetar resultados relevantes. Portanto, o fenômeno de confusão em estudos observacionais é mais provavelmente um problema sério e, talvez, um problema intransponível quando se deseja avaliar eficácia de tratamentos. Os estudos observacionais envolvem problemas que podem ter sido subestimados por Royall ao sugerir esta proposta.

Green e Byar (1984) resumiram a sua hierarquia sobre a força de evidência com relação à eficácia de tratamentos gerada a partir de vários tipos de estudos. Em ordem crescente, os menos convincentes são os estudos de relato de casos, séries de casos sem controles ou com controles da literatura. A seguir vêm os estudos provenientes de bancos de dados computacionais, estudos do tipo caso-controle, estudos observacionais e séries com controles históricos. Por fim, os mais convincentes são os experimentos clínicos aleatorizados, especialmente quando mais de um estudo sobre o mesmo tratamento produz o mesmo resultado. Acima de todos estes estão as meta- 
análises, que são estudos que procuram analisar dados de todos os experimentos clínicos aleatorizados bem conduzidos a respeito de um mesmo assunto. Este tipo de estudo tem tamanho amostral grande, justamente por reunir vários outros estudos, e, portanto, seu poder estatístico é também muito grande.

Apesar desta classificação dos vários tipos de estudo, existem controvérsias. Herman (1995) comenta a divergência entre resultados de dois artigos de meta-análise que tratam do mesmíssimo assunto. Ora, a meta-análise foi criada justamente para superar as dificuldades que os experimentos clínicos aleatorizados apresentam de vários estudos poderem levar a resultados inconclusivos ou conflitantes, através de um maior poder estatístico para avaliar subgrupos (devido ao tamanho amostral acumulado). Este exemplo sugere que, nem mesmo as meta-análises são convincentes.

Várias críticas surgem contra a abordagem de controles concorrentes: um estudo com controles em outros hospitais não teria nenhuma credibilidade por parte da comunidade médica. Além disto, um estudo deste tipo não aliviaria o dilema ético, uma vez que o tratamento convencional (ou o experimental) continuaria sendo atribuído a alguns pacientes. A única diferença para um estudo aleatorizado é que estes pacientes seriam de outros hospitais. Bartlett e Cornell (1991) são completamente contrários à visão de Royall de que estudos não-aleatorizados também podem ser convincentes.

Byar (1991) não aceita a idéia de controles concorrentes não aleatorizados. Na sua visão, é óbvio que todos os médicos não podem estar certos quanto ao melhor tratamento, a menos que eles sejam equivalentes. Portanto, seria anti-ético conduzir 
um estudo onde pacientes recebessem o tratamento inferior, ainda que em outros hospitais. Esta proposta menospreza a importância de se evitar vícios de seleção.

\subsubsection{Experimentos-para-aprender e Experimentos-para-provar}

Há dois tipos de experimentos que um pesquisador pode executar para estudar a eficácia de um tratamento. O primeiro é um tipo de estudo onde o interesse principal está em adquirir novos conhecimentos a respeito do tratamento. Estes estudos onde o enfoque do pesquisador está em aprender são denominados experimentos-paraaprender. Neste caso, aleatorizar é inaceitável, pois priva o pesquisador do conhecimento em uma situação onde seu interesse é justamente adquirir conhecimento. O segundo tipo é um experimento cujo objetivo é demonstrar, ou provar, ou convencer que este tratamento é eficaz. Supõe-se que nestes experimentos-paraprovar (ou experimentos-para-convencer) o pesquisador já conhece a eficácia do tratamento, mas a realização de um experimento é necessária para que esta eficácia seja demonstrada à comunidade médica.

A discussão das implicações éticas do método de seleção de tratamentos tornase um pouco diferente nos dois tipos de estudo. Em experimentos-para-aprender, a aleatorização parece ser mais intolerável que nos experimentos-para-demonstrar. Neste último tipo de experimento, a aleatorização tem a função de facilitar a comunicação interpessoal, através de aspectos introduzidos no planejamento, de modo a assegurar ao leitor que não houve vício de seleção ou influência de covariáveis (Kadane e Seidenfeld, 1990). Este aspecto foi discutido nas seções 2.5.2 e 2.5.3. 
Byar (1991) sugere que alguns critérios sejam considerados ao se decidir se um estudo não-aleatorizado é justificável (sob o ponto de vista ético). É necessário que haja dados suficientes para assegurar que pacientes que não receberem a nova terapia tenham mau prognóstico, que efeitos colaterais que desclassifiquem a nova terapia não sejam esperados, que o benefício esperado seja suficientemente grande de tal forma que a interpretação dos resultados seja inambígua e que a justificativa científica para o estudo seja tão forte que um resultado positivo seja amplamente aceito.

Estes critérios sugerem que os experimentos que forem planejados apenas para demonstrar para os outros os benefícios de uma terapia que já se pensa ser eficaz sejam realmente anti-éticos.

\subsection{O Princípio da Atenção Pessoal}

Foi denominado por Royall (1991) de Princípio da Atenção Pessoal (PAP) o que Fried (1974) descreveu como a "obrigação do médico em colocar os interesses do paciente acima de tudo no seu relacionamento profissional".

Segundo o juramento médico que consta da declaração de Geneva adotada pela Associação Médica Mundial, (World Medical Association, 1948): "a saúde do meu paciente será minha primeira consideração". A obrigação profissional do médico com seu paciente, ou seja, a percepção do médico do que é bom para seu paciente, entra em conflito com as necessidades do experimento quando se aleatoriza um tratamento para um dado paciente. O PAP aparece explicitamente na declaração do Conselho de Pesquisa Médica da Grã-Bretanha (Medical Research Council, 1964) a respeito da responsabilidade em investigações em seres humanos: “... qualquer médico que 
participar de um experimento clínico tem a obrigação de excluir um paciente do estudo, e instituir qualquer tratamento que julgar necessário, se, na sua opinião, isto for o melhor interesse do paciente". Se o médico acredita que um tratamento é melhor que os demais para um determinado paciente, então não deve haver aleatorização.

Um exemplo seria o de um estudo onde o pesquisador deseja investigar três doses diferentes de uma droga. O esquema terapêutico de cada paciente será escolhido através de um mecanismo de chances, ou seja, este é um experimento clínico aleatorizado. Se ao longo de algum período surgirem evidências de melhores resultados no grupo que recebeu a maior dose (ou piores resultados no grupo que recebeu a menor dose), o pesquisador deveria aumentar a dose dos demais pacientes.

\subsection{Estado de Equiparação}

Outra base de preocupação quanto à ética médica em experimentos clínicos é a verdadeira existência do estado de equiparação individual, ou pelo menos a equiparação clínica (vide seção 1.5). A realização de um experimento clínico é ética desde que esteja presente o estado de equiparação individual. Alguns autores mais flexivelmente consideram que a equiparação clínica por si só é suficiente para que um experimento clínico aleatorizado seja considerado ético. Em outras palavras, basta haver discordância entre os investigadores quanto ao melhor tratamento, não necessariamente havendo um estado de genuína incerteza de cada pesquisador.

Byar (1991), em oposição ao estado de equiparação (seção 1.5), enuncia o Princípio da Incerteza, onde é enfatizada a incerteza individual ao invés da incerteza do grupo: os estudos devem ser abertos somente aos pacientes onde houver uma 
genuína incerteza sobre qual tratamento recomendar. O principio está relacionado com o conceito de estado de equiparação; porém, ao invés de enfocar a incerteza de um grupo, enfoca a incerteza individual. A incerteza refere-se ao indivíduo que está incluindo um paciente no estudo. O paciente somente poderá participar do estudo se seu médico tiver genuína incerteza a respeito de qual seria o melhor tratamento para seu caso.

Byar (1991) comenta a idéia de valorizar a opinião do médico. Este autor não considera ético que cada um faça o que achar melhor em situações onde haja discordância entre os profissionais. "Ao invés de sempre deixar os médicos sempre fazerem o que acharem melhor parece-me preferível encorajá-los a reconhecer as limitações de seus conhecimentos e conduzir experimentos clínicos aleatorizados". Quando um experimento é proposto, isto geralmente significa que os médicos beminformados diferem quanto às suas opiniões e que uma abordagem honesta da evidência não é convincente. Neste tipo de situação, conduzir um experimento clínico aleatorizado pode ser mais ético do que simplesmente negar a incerteza e fazer o que o médico individualmente pensa que é melhor.

\subsection{O Consentimento Informado}

Segundo as regras e regulamento do Departamento de Saúde e Serviços Humanos (DHHS, 1981, pg. 8382), o consentimento informado tem o dever de "comunicar os pacientes, em uma linguagem acessivel a eles, informações que estes devam desejar possuir ao considerar se devem ou não participar do estudo". Schaffner (1996) levanta o aspecto que, nesta frase, não está claro se detalhes do planejamento 
experimental - tais como a aleatorização - devem constar do consentimento informado. Levine e Lebacqz (1979) vêem o envolvimento de um paciente em um experimento clínico aleatorizado como dependente do seu consentimento informado. O consentimento informado é derivado do princípio ético de respeito pelo ser humano, que requer que se respeite o direito do próximo à autodeterminação, ou seja, o direito da liberdade de escolha. O consentimento informado é considerado correto somente se contiver uma descrição completa e honesta de toda informação relevante para que o paciente possa tomar esta decisão. Se a aleatorização for vista como relevante neste sentido, então fica sendo obrigatório constar do consentimento informado.

Kadane (1986) introduz o artigo intitulado "Progress Toward a More Ethical Method for Clinical Trials" descrevendo o dilema ético e apontando que alguns tipos de soluções não são adequadas. Primeiramente, em uma seção intitulada "Do patients get a fair shake in current clinical trials?", o autor posiciona o paciente de um lado e o pesquisador de outro, demonstrando que os pacientes não levam uma parte justa neste pacto que é o experimento clínico aleatorizado. O consentimento informado é uma espécie de contrato oferecido pelo médico ao paciente. Alguns aspectos do contexto que envolve a assinatura deste contrato: 1) muitas vezes, o paciente pode não compreender bem o conteúdo daquilo que ele está assinando e 2) outra situação não menos frequente é caracterizada pelo prejuízo causado ao paciente pela doença, seja ele emocional ou físico. Mais forte do que estes argumentos, é o fato deste contrato não ser igualmente vantajoso para ambas as partes. Segundo Kadane (1996), "o consentimento informado é raramente informado e nem sempre consentido". 
O paciente deve assinar um consentimento informado, concordando em participar do estudo e, consequentemente, em receber um tratamento que será escolhido de forma aleatória. Neste 'contrato' oferecido pelo médico ao paciente, ambas as partes deveriam ter o mesmo poder, ou seja, este contrato deveria ser vantajoso (pelo menos em algum sentido) para ambas as partes. Muitos pacientes interpretam este documento como sendo mais um formulário que deve ser preenchido para que eles possam receber o tratamento. Em algumas situações, o paciente considera que esta seja a única forma através da qual ele poderá ser tratado por uma instituição de saúde.

O médico deve zelar pelos interesses do paciente, uma vez que este pode não ser capaz de fazê-lo em determinado momento. É rídiculo utilizar o pretexto de que o paciente assinou o documento para receber um tratamento que é evidentemente desvantajoso.

Fleming (1994) propõe sigilo dos resultados parciais ("blindness") para que o médico não introduza nenhum tipo de vício no experimento ao acumular experiência e tomar conhecimento dos resultados preliminares. Kadane (1986) considera isto totalmente anti-ético, pois apenas com o intuito de justificar a aleatorização, o médico e também o paciente seriam privados do conhecimento de informação. O paciente não está em uma posição favorável para se defender da afirmação (injusta) de que ele deve ajudar a ciência. Isto deveria estimular os estatísticos a pensar em planejar experimentos que diminuam ao máximo o fardo destes pacientes. 


\subsection{Os Momentos de um Experimento Clínico onde Pode Surgir o Dilema Ético}

Em um experimento clínico, há vários momentos em que pode surgir o dilema ético. Na figura 3.1, podemos observar que o fluxograma começa com uma questão: É ético iniciar o experimento clínico aleatorizado? Se os investigadores considerarem que não é ético, este fluxograma termina e restam dúvidas científicas, pois, o experimento clínico aleatorizado seria a forma mais confiável de se estudar a eficácia de um tratamento (ver seção 1.2). Se o estado de equiparação estiver presente, e os investigadores considerarem ético o início deste experimento, outra vez o dilema surge à medida que se acumula experiência e dados: Será ético continuar incluindo pacientes em um experimento que já sugeriu alguma evidência de que um dos tratamentos é superior? Em outras palavras, este estudo já sugeriu alguma evidência? Se sim, o estudo termina e estes resultados estão sujeitos a críticas de leitores que poderão considerar que o término foi precoce. Se não, o estudo continua incluindo mais pacientes, o que implica em custos, tanto financeiros, quanto de ordem ética.

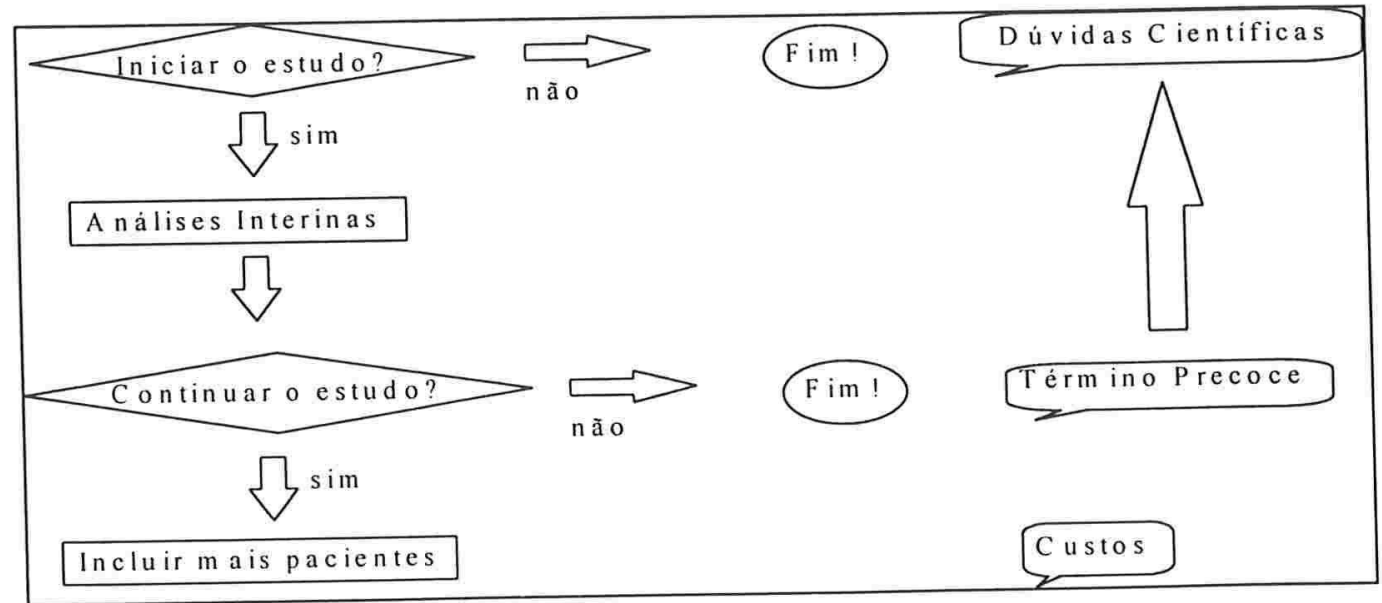

Figura 3.1. Momentos onde pode surgir o dilema ético em um experimento clínico aleatorizado. 
Sob um ponto de vista bastante clássico, Fleming (1994) propõe que existam Comissões de Controle dos Dados que controlem as análises parciais de modo que o experimento continue sendo ético enquanto as análise confidenciais desta Comissão não forem publicadas. Em outras palavras, enquanto o pesquisador não conhece os resultados ainda que parciais do experimento, este continua sendo ético. Usando o conceito de equiparação, poderíamos dizer que a Comissão, ao não publicar os resultados parciais, teoricamente mantém o pesquisador em seu estado inicial de equiparação individual onde havia uma honesta incerteza a respeito de qual dos tratamentos é o mais recomendado para cada paciente. $\mathrm{Na}$ prática, o médico vai intuitivamente formando uma opinião à medida em que ele adquire mais experiência com os tratamentos em estudo e, na prática, a Comissão omite informação. 


\section{CAPÍTULO 4 - MÉTODOS DE ATRIBUIÇÃO DE TRATAMENTOS}

\subsection{Introdução}

4.2. Métodos de Atribuição de Tratamentos

4.3. Planejamentos Adaptativos

4.4. O Planejamento Play-the-Winner Aleatorizado (PWA)

4.5. O Primeiro Experimento ECMO (Bartlett et al. 1985)

4.5.1. Descrição do Experimento

4.5.2. O Dilema Ético

4.5.3. O Método de Seleção dos Tratamentos

4.5.4. Resultados do Estudo

4.5.5. O Consentimento Informado

4.6. O Segundo Experimento ECMO (Ware et al. 1989)

4.6.1. O Dilema Ético

4.6.2. O Método de Seleção dos Tratamentos

4.6.3. Resultados do Estudo

\subsection{Introdução}

Em um experimento clínico há várias formas de se selecionar o tratamento que será atribuído a cada paciente, conforme discutido na seção 3.1. A seção 4.2 descreve alguns dos métodos de atribuição que utilizam a aleatorização. Os planejamentos adaptativos, discutidos na seção 4.3 , são de particular interesse por terem realizado um avanço em direção à questão da ética médica. Em especial, o planejamento play-the- 
winner aleatorizado, proposto por Zelen (1969), será abordado na seção 4.4 e ilustrado na seção 4.5, através de um experimento clínico que estudou um novo tratamento para hipertensão pulmonar persistente em recém-nascidos. Continuando com o exemplo, a seção 4.6 descreve outro experimento onde foi estudado o mesmo tratamento e aplicado o planejamento adaptativo sequencial em dois estágios.

\subsection{Métodos de Atribuição de Tratamentos}

A figura 4.1, descrita por Emrich e Sedransk (1996, pg. 268), mostra como funciona o esquema de atribuição dos tratamentos após a entrada de um paciente em um típico experimento clínico aleatorizado.

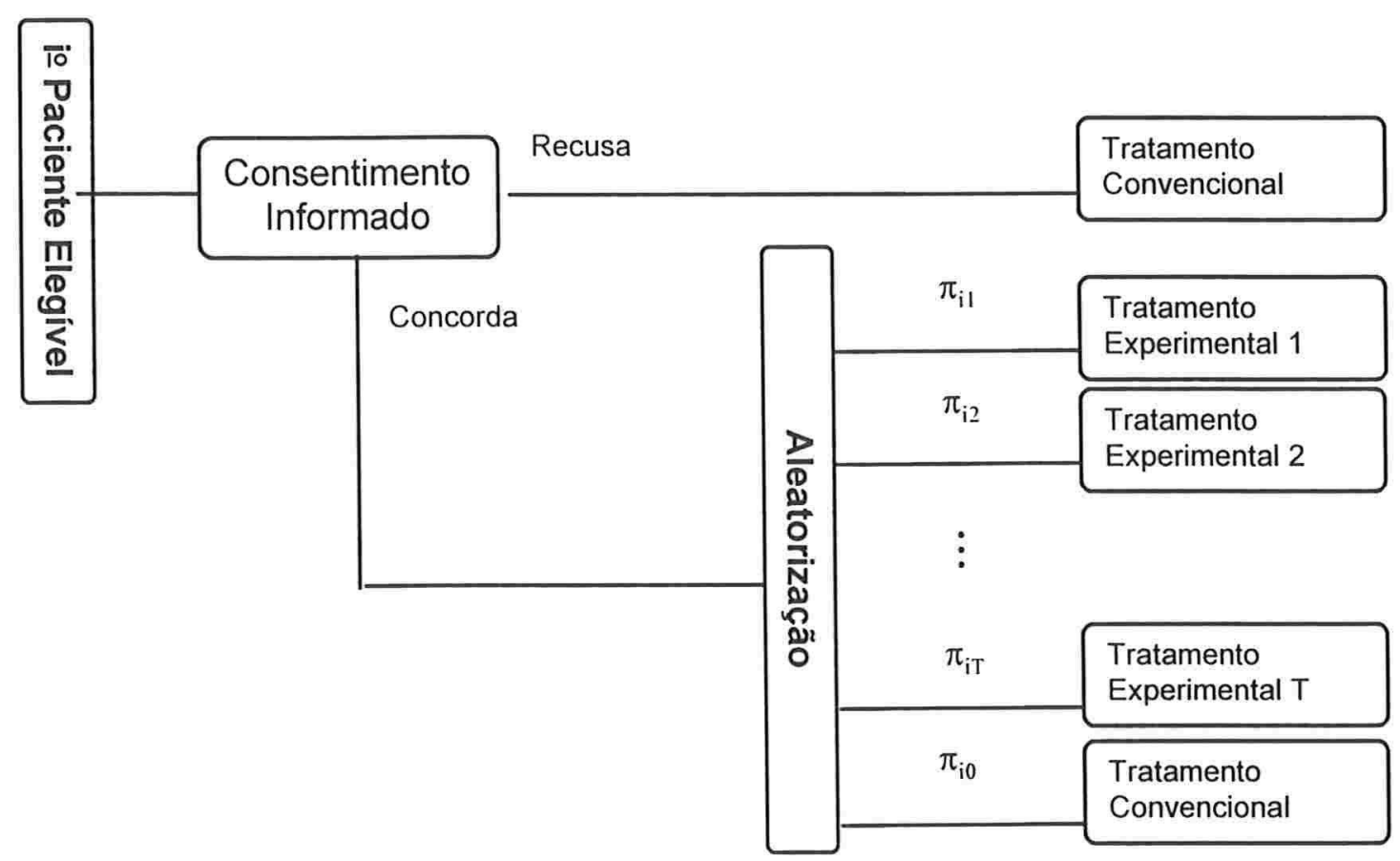

Figura 4.1. Esquema de atribuição dos tratamentos em um experimento clínico. 
Após o consentimento informado, o paciente $i$, se concordar em participar do estudo, receberá o tratamento $t(t=0,1, \ldots, T)$ com probabilidade $\pi_{\text {it }}$. Em alguns estudos, $\pi_{\mathrm{i} 0}$ é nula, pois não há tratamento convencional, ou grupo controle.

A figura 4.2 mostra vários métodos de atribuição de tratamentos baseados na aleatorização. A alocação aleatorizada simples caracteriza-se por $\pi_{\mathrm{it}}=\pi_{\mathrm{it}}, \mathrm{t} \neq \mathrm{t}^{\prime}, \quad \mathrm{t}, \mathrm{t}^{\prime}=$ $0,1, \ldots, T$. Este processo é análogo ao do lançamento de uma moeda honesta, ou de um dado equilibrado, onde a probabilidade de um paciente receber um dos tratamentos é a mesma. Dependendo do número de lançamentos, não é raro uma moeda honesta produzir um número de caras e coroas desproporcional, o que corresponderia a uma quantidade desproporcional de pacientes que receberia cada tratamento. Isto pode ser prejudicial para a análise estatística, cujo resultado é mais eficiente quando os grupos possuem tamanhos iguais. Por este motivo, algumas modificações foram introduzidas neste método de alocação de tratamentos. O planejamento de blocos aleatórios permutados quebra a sequência de alocação dos tratamentos em blocos. Em um estudo com $\mathrm{T}$ tratamentos experimentais e um controle, os blocos podem ter tamanhos $b(T+1)$. Desta forma, b alocações para cada tratamentos serão embaralhadas e atribuídas em uma ordem aleatória para as alocações de um bloco. Então, a cada $b(T+1)$ pacientes, exatamente o mesmo número de pacientes será submetido a cada tratamento.

Outra variação deste planejamento é o da moeda desonesta. Este método permite que seja utilizado o método de alocação aleatória simples enquanto a diferença entre o número de pacientes atribuídos para o tratamento mais frequente e o menos 
frequente, estiver dentro de algum limite de tolerância. Quando a diferença ultrapassar este limite, as probabilidades $\pi_{\text {it }}$ são ajustadas para que a chance de atribuição do tratamento menos frequente seja aumentada. Uma vez que o equilíbrio é atingido, as probabilidades são novamente ajustadas para $\pi_{\mathrm{i} 0}=\pi_{\mathrm{i} 1}=\ldots=\pi_{\mathrm{iT}}$.

Usando a mesma lógica da moeda desonesta, o modelo de urnas é um planejamento mais preciso, onde as probabilidades $\left\{\pi_{\mathrm{it}}\right\}$ são ajustadas após cada atribuição a favor dos tratamentos não atribuídos.

Os planejamentos adaptativos pertencem à uma classe de planejamentos que levam em conta os resultados dos tratamentos em pacientes anteriores para atualizar estas probabilidades (ver seção 4.3). Estas iniciam com $\pi_{10}=\pi_{11}=\ldots=\pi_{1 \mathrm{~T}}$ e as probabilidades $\left\{\pi_{\mathrm{it}}\right\}$ alteram-se ao longo do experimento conforme o número de sucessos de cada tratamento. Por exemplo, se um paciente $i$ receber o tratamento t e tiver sucesso, a probabilidade $\pi_{i+1, t}$ será maior que $\pi_{i t}$. As demais probabilidades permanecem inalteradas cada uma em relação à outra. Um caso particular de planejamento adaptativo é o play-the-winner aleatorizado proposto por Zelen (1969), que será descrito na seção 4.4 .

Segundo Sedransk (1996), para que uma análise estatística válida possa ser realizada com os dados gerados pelo estudo, a seguinte condição deverá ser satisfeita: a distribuição de probabilidades de atribuição do tratamento $T$ ao paciente $i$ dados o vetor de características observadas deste paciente antes do tratamento e a evidência passada até o paciente $i-1$ (tratamento atribuído, resultado do 
tratamento e características observadas) - não deve depender da quantidade de interesse $\theta$. Esta notação será descrita na seção 5.2. São, pela autora, considerados razoáveis a maior parte dos planejamentos com métodos de seleção baseados em aleatorização.

Segundo Sedransk (1996), todos os métodos de seleção apresentados nesta seção permitem uma interpretação estatística válida, pois parece óbvio que o lançamento de uma moeda não oferece nenhuma informação a respeito de qualquer aspecto (taxa de cura, sobrevida mediana, etc.) relacionado aos efeitos dos tratamentos em estudo. Nesta particular discussão obviamente não estão sendo consideradas as questões éticas, mas somente a condição proposta por Sedransk (1996).

\begin{tabular}{||l|l|l||}
\hline Método de Atribuição & Probabilidade de Atribuição & Características \\
\hline \hline $\begin{array}{l}\text { Alocação aleatorizada } \\
\text { simples }\end{array}$ & $\pi_{\mathrm{it}}=\pi_{\mathrm{it}}=1 /(\mathrm{T}+1), \mathrm{t} \neq \mathrm{t}^{\prime}, \mathrm{t}, \mathrm{t}^{\prime}=0,1,2, \ldots, \mathrm{T}$ & $\begin{array}{l}\text { Os grupos podem ter tamanhos } \\
\text { muito diferentes }\end{array}$ \\
\hline $\begin{array}{l}\text { Blocos aleatórios } \\
\text { permutados }\end{array}$ & $\begin{array}{l}\text { Quebra a sequência de alocaçäo dos } \\
\text { tratamentos em blocos de tamanhos } \mathrm{b}(\mathrm{T}+1)\end{array}$ & $\begin{array}{l}\text { Garante o balanceamento dos } \\
\text { grupos }\end{array}$ \\
\hline Moeda desonesta & $\begin{array}{l}\text { Enquanto o balanceamento entre os grupos } \\
\text { estiver dentro de um limite de tolerância, } \\
\pi_{\mathrm{i} 0}=\pi_{\mathrm{i} 1}=\ldots=\pi_{\mathrm{iT}} \\
\text { Quando houver desbalanceamento, }\left\{\pi_{\mathrm{it}}\right\} \text { são } \\
\text { ajustadas } \\
\text { Quando atingir o equilibrio, novamente } \\
\pi_{\mathrm{i} 0}=\pi_{\mathrm{i} 1}=\ldots=\pi_{\mathrm{iT}}\end{array}$ & $\begin{array}{l}\text { As probabilidades são ajustadas, } \\
\text { conforme o desbalanceamento } \\
\text { dos grupos }\end{array}$ \\
\hline Modelo de urnas & $\begin{array}{l}\text { As probabilidades }\left\{\pi_{\mathrm{it}}\right\} \text { são ajustadas após } \\
\text { cada atribuição a favor dos tratamentos não } \\
\text { atribuídos }\end{array}$ & $\begin{array}{l}\text { Este é um planejamento mais } \\
\text { preciso, baseado no da moeda } \\
\text { desonesta }\end{array}$ \\
\hline $\begin{array}{l}\text { Planejamentos } \\
\text { adaptativos }\end{array}$ & $\begin{array}{l}\text { Iniciam com } \pi_{\mathrm{i} 0}=\pi_{\mathrm{i} 1}=\ldots=\pi_{\mathrm{iT}} \\
\text { Alteram-se ao longo do experimento } \\
\text { conforme o número acumulado de sucessos } \\
\text { de cada tratamento }\end{array}$ & $\begin{array}{l}\text { Levam em conta os resultados } \\
\text { dos tratamentos em pacientes } \\
\text { anteriores para atualizar estas } \\
\text { probabilidades }\end{array}$ \\
\hline
\end{tabular}

Figura 4.2. Os diferentes métodos de atribuição aleatória dos tratamentos em um experimento clínico. 


\subsection{Planejamentos Adaptativos}

A busca por um tipo de experimento clínico mais ético não é uma novidade. Esta procura parece ter sido motivada e motivadora do desenvolvimento dos experimentos sequenciais na década de 50 e também pelos planejamentos adaptativos nos anos de 1960 e 1970 (Schaffner, 1996).

Os planejamentos adaptativos são aqueles cujo método de seleção de tratamentos incorpora a informação que surge no desenrolar do experimento às probabilidades de atribuição dos tratamentos aos pacientes. Com este tipo de planejamento, procura-se atribuir a mais pacientes o tratamento que está se saindo melhor até aquele ponto do experimento.

A probabilidade de um indivíduo receber um tratamento cuja eficácia (medida pela ocorrência de sucessos) é menor diminui à medida que esta evidência surja ao longo do experimento. Há um processo dinâmico de mudança das probabilidades de atribuição dos tratamentos. Isto é um esforço no sentido de aliviar o dilema ético relativo a esta situação. Com isso, tenta-se atribuir o tratamento que tem menor eficácia com uma probabilidade (e portanto com uma frequência) cada vez menor ao longo do experimento. Por outro lado, se um tratamento não se mostrar pior que o outro, as probabilidades de atribuição dos tratamentos continuarão equilibradas. Se, contrariamente, o tratamento em questão mostrar-se superior ao outro, ele será atribuído a um grande número de pacientes.

Este é um esforço por parte dos pesquisadores que consideram anti-ética a atribuição de um determinado tratamento (aquele com menor eficácia) à aproximadamente metade dos indivíduos do experimento. Por outro lado, vamos tentar 
entender a origem da questão da ética médica neste tipo de situação: os médicos acreditam, por exemplo, que o tratamento convencional tem uma chance de sucesso bastante inferior ao novo tratamento. Se a questão se encerrasse neste ponto, nem existiria dilema, pois bastaria tratar todos os novos pacientes com o novo tratamento. $\mathrm{O}$ problema está no fato deste juízo basear-se em informações consideradas nãocientíficas, ou não-convincentes, por não terem sido extraídas de experimentos clínicos aleatorizados, e sim de séries isoladas na literatura sem grupos controles (dados históricos). Surge então a necessidade de se conduzir um experimento clínico aleatorizado que prove a eficácia do novo tratamento.

Alguns autores apostaram neste tipo de planejamento como um passo em direção à solução do dilema ético (Bartlett et al. (1985), Ware et al. (1989)).

\subsection{O Planejamento Play-the-Winner Aleatorizado (PWA)}

Consideremos primeiramente uma urna com uma bola de cada cor representando cada um dos tratamentos A e B. O primeiro paciente do estudo receberá o tratamento A se a bola extraída da urna for preta e B se for branca. Neste passo, a chance de atribuição dos tratamentos é de 50\%, representando o estado de equiparação individual (seção 1.5) dos pesquisadores.

No segundo passo, a urna conterá as duas bolas iniciais, além de uma bola extra que será preta $(A)$ ou branca $(B)$, conforme o resultado do primeiro paciente. Assim, se o primeiro paciente do estudo teve sucesso tendo sido tratado por A , a urna conterá uma bola branca e duas bolas pretas; se teve fracasso tendo sido tratado por $A$, a urna 
conterá uma bola preta e duas bolas brancas, e assim por diante, simetricamente com o tratamento $B$.

Para o segundo paciente, a chance de receber o tratamento $A$ será $2 / 3$ caso o primeiro tenha tido sucesso com este tratamento (ou fracasso com o tratamento B) e $1 / 3$ caso o primeiro tenha tido fracasso com $A$ (ou sucesso com $B$ ). À medida que os sucessos do tratamento $A$ ocorrem, mais bolas pretas serão adicionadas à urna, de modo que a chance de recebê-lo aumentará (com a chance de receber tratamento $B$ diminuindo).

A probabilidade de atribuição do tratamento $\mathrm{A}$ ao paciente $i, \pi_{\mathrm{i}, \mathrm{A}}$, depende da probabilidade de atribuição do tratamento $A$ ao paciente anterior, $\pi_{i-1, A}$, do resultado do tratamento no paciente anterior, $O_{i-1}$ e do tratamento efetivamente recebido por este paciente, $T_{i-1}$. Assim sendo, a expressão de $\pi_{\mathrm{i}, \mathrm{A}}$ pode ser escrita da seguinte forma:

$$
\begin{gathered}
\pi_{i, A}=\frac{i \pi_{i-1, A}+O_{i-1} T_{i-1}+\left(1-O_{i-1}\right)\left(1-T_{i-1}\right)}{i+1}, \text { onde } \\
\left\{\begin{array}{l}
O_{i} \text { indicador (sucesso no paciente } i \text { ) } \\
T_{i} \text { indicador (paciente } i \text { receber tratamento A) }
\end{array}\right.
\end{gathered}
$$

$$
\pi_{1, A}=\pi_{1, B}=1 / 2
$$

Para melhor entendermos esta fórmula, vejamos que $i \pi_{i-1, A}$ representa o número de bolas pretas $(A)$ contidas na urna antes de ser escolhido um tratamento ao paciente $i$; o numerador $(i+1)$ representa o número total de bolas na urna após o resultado do paciente $i$ e, a parcela $O_{i-1} T_{i-1}+\left(1-O_{i-1}\right)\left(1-T_{i-1}\right)$ é um conjunto de indicadores de 
sucesso do tratamento $A$ que, combinados, indicam o número de bolas que serão adicionadas à urna após o resultado $O_{i-1}$ do paciente $i$-1 submetido ao tratamento $\mathrm{T}_{i-1}$.

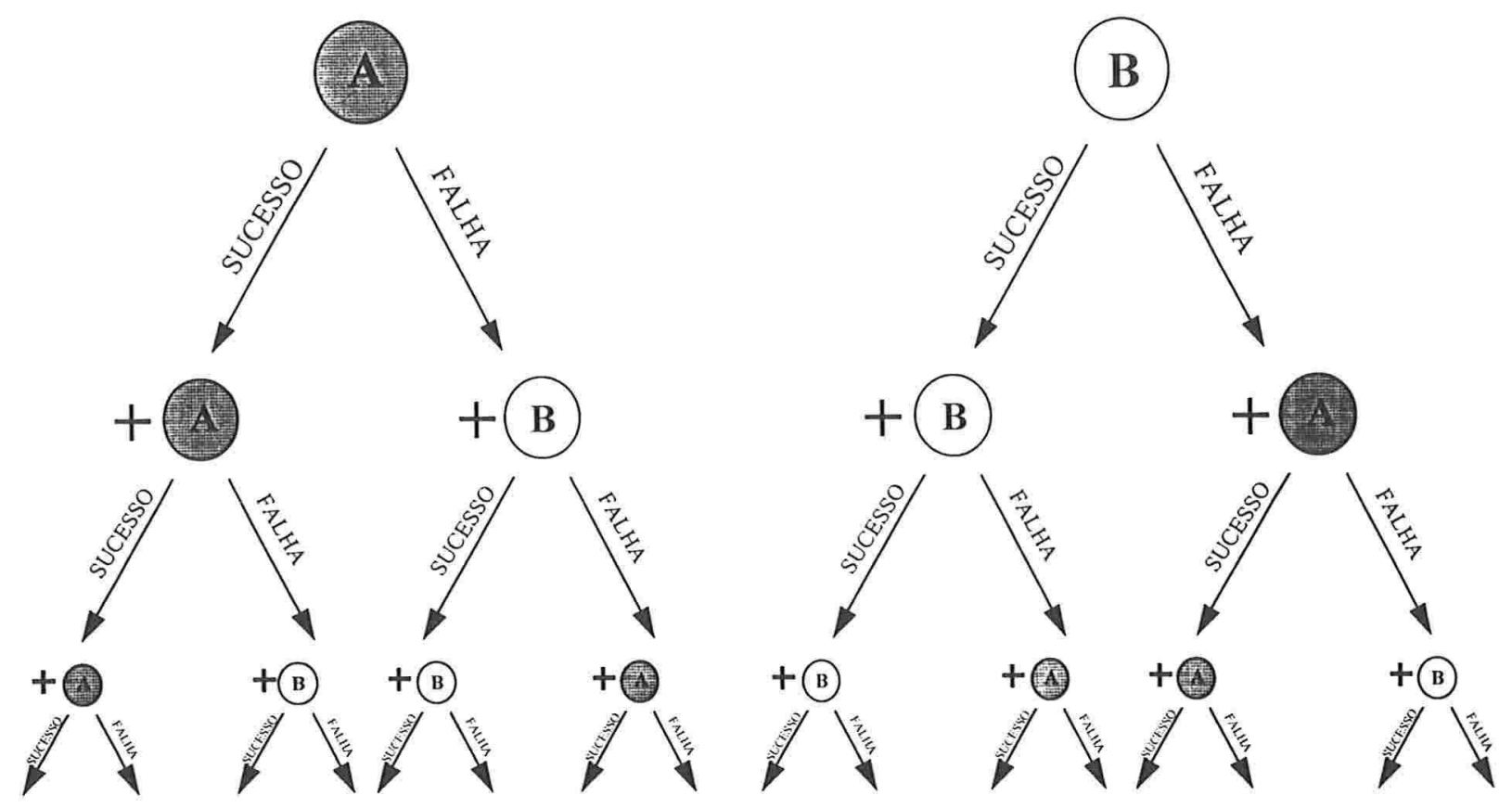

Figura 4.3. Desenho esquemático do planejamento Play-the-winner

\subsection{O Primeiro Experimento ECMO (Bartlett et al. 1985)}

\subsubsection{Descrição do experimento}

Neste artigo Bartlett et al. (1985) tratam da avaliação de uma nova intervenção (ECMO) para o tratamento de hipertensão pulmonar persistente do recém-nascido. A sigla ECMO quer dizer "extra-corporeal membrane oxygenation", ou oxigenação extracorpórea através de uma membrana, que é um sistema externo para a oxigenação do sangue baseado em tecnologia de transpassagem cardiopulmonar desenvolvida para cirurgias cardíacas. Com grande frequência, estas cirurgias necessitam da interrupção do trabalho cardíaco. Para manter o funcionamento e a vitalidade do organismo, é necessária a utilização de um sistema de circulação extra-corpórea para o 
bombeamento e a oxigenação do sangue. Como sugere o termo "extra-corpórea", o sangue é removido do corpo (via linha venosa) e passado para uma máquina, onde através de uma membrana é exposto a grandes concentrações de oxigênio. É então reaquecido e devolvido à aorta, então transpassando funcionalmente por ambos, pulmão e coração. As trocas gasosas realizadas no pulmão passam a ser realizadas pela máquina, para que o coração não precise bombear o sangue e, assim, pare de bater durante o tempo necessário.

A circulação extra-corpórea era um procedimento já utilizado em cirurgia cardíaca. Surgiu, em 1977, a proposta de utilizar a oxigenação extra-corpórea com membrana para o tratamento de recém-nascidos com problemas respiratórios graves. Em 1985, vários centros já haviam reportado taxas de sobrevivência de $80 \%$ ou mais em crianças tratadas com ECMO (Wetmore, McEwen, O'Connor e Bartlett, 1979; Bartlett, Andrews, Toomasian et. al., 1982; Kirckpatrick et. al., 1983), e a experiência com este tipo de paciente mostrava uma taxe de sobrevida de aproximadamente $20 \%$.

\subsubsection{O Dilema Ético}

Parecia evidente o fato do tratamento com ECMO ser superior, mas como não havia até então sido conduzido um experimento clínico aleatorizado, este fato ainda não estava "cientificamente" comprovado. As informações anteriores provinham de pequenas séries isoladas.

Em 1982, época em que se iniciou o primeiro ensaio clínico do ECMO para esta doença, ainda não havia um número suficiente de casos de recém-nascidos com doença pulmonar submetidos a este tratamento. Bartlett e Cornell (1991), justificando 
posteriormente a validade ética deste experimento, julgam que este fato implica a existência de uma incerteza com relação à superioridade de um ou outro tratamento para esta doença: "... O fato das probabilidades (de sucesso) terem sido estimadas antes do estudo não implica na existência de um vício (preferência quanto a um determinado tratamento). Todo ensaio clínico começa com estimação de probabilidades, seja para fins de cálculo de tamanho amostral, ou para formulação de hipóteses". Além disto, na visão destes autores, não é necessário que haja estado de equiparação - nem individual, nem institucional - para se planejar e conduzir um experimento clínico válido.

Apesar das expectativas de que o ECMO fosse superior à terapia convencional, Bartlett e Cornell (1991) alegam, que "não poderiam ter certeza de que isto aconteceria em um experimento clínico aleatorizado". A incerteza é justamente o motivo principal de um experimento clínico aleatorizado: se não houvesse incerteza, nem haveria um experimento clínico aleatorizado.

Bartlett e Cornell (1991) reconhecem que o dilema ético realmente existiu e que o fato de terem usado o planejamento do tipo PWA não resolveu o dilema, tendo porém suavizado-o de modo a prevalecer o argumento prático citado por Royall que maximiza a utilidade total: o sacrifício dos pacientes do presente em benefício aos pacientes do futuro.

\subsubsection{O Método de Seleção dos Tratamentos}

O planejamento do estudo foi feito segundo o PWA descrito na seção 4.4 . 


\subsubsection{Resultados do Estudo}

O primeiro paciente foi sorteado (com $\left.\pi_{1, \mathrm{ECMO}}=\pi_{1, \mathrm{CIRURGIA}}=1 / 2\right)$ para receber $\mathrm{O}$ tratamento experimental ECMO e sobreviveu. Em função deste resultado, foi adicionada à urna uma bola branca correspondendo ao tratamento ECMO. A urna, à esta altura do experimento, continha 2 bolas brancas (ECMO) e uma preta (convencional). O segundo paciente foi sorteado (agora com uma chance de 1/3) para receber o tratamento convencional e não sobreviveu. Adicionou-se mais uma bola branca à urna, devido ao insucesso do tratamento convencional. Para o terceiro paciente do estudo, a chance de receber o tratamento ECMO era 3/4 (e a de receber o convencional, 1/4). Este paciente e os 7 seguintes foram sorteados para receber o tratamento ECMO (com chances $4 / 5,5 / 6,6 / 7,7 / 8,8 / 9$ e $9 / 10$, respectivamente) e todos sobreviveram. Por motivo de falha de comunicação entre os investigadores dos diferentes centros, mais dois pacientes foram tratados (aleatoriamente) com ECMO, mesmo após ter sido atingido o número de pacientes que havia sido previsto para este estudo. Estes dois últimos pacientes também sobreviveram. A tabela 4.1 mostra os resultados deste estudo.

Em resumo, este estudo produziu o seguinte resultado: dos 12 pacientes avaliados, apenas 1 recebeu o tratamento convencional e não sobreviveu e os 11 restantes receberam ECMO e sobreviveram. Há necessidade de análise estatística para se convencer de que ECMO é superior? 
Tabela 4.1. Resultados do primeiro experimento clínico do ECMO (Bartlett et al. 1985).

\begin{tabular}{rcccccc}
\hline $\boldsymbol{i}$ & $\boldsymbol{O}_{i}$ & $T_{i}$ & $\boldsymbol{O}_{i} T_{i}$ & $\left(1-\boldsymbol{O}_{i}\right)\left(1-\mathrm{T}_{i}\right)$ & $\pi_{i, \mathrm{ECMO}}$ & $\pi_{i, \mathrm{CONV}}$ \\
\hline 1 & 1 & 1 & 1 & 0 & $1 / 2$ & $1 / 2$ \\
2 & 0 & 0 & 0 & 1 & $2 / 3$ & $1 / 3$ \\
3 & 1 & 1 & 1 & 0 & $3 / 4$ & $1 / 4$ \\
4 & 1 & 1 & 1 & 0 & $4 / 5$ & $1 / 5$ \\
5 & 1 & 1 & 1 & 0 & $5 / 6$ & $1 / 6$ \\
6 & 1 & 1 & 1 & 0 & $6 / 7$ & $1 / 7$ \\
7 & 1 & 1 & 1 & 0 & $7 / 8$ & $1 / 8$ \\
8 & 1 & 1 & 1 & 0 & $8 / 9$ & $1 / 9$ \\
9 & 1 & 1 & 1 & 0 & $9 / 10$ & $1 / 10$ \\
10 & 1 & 1 & 1 & 0 & $10 / 11$ & $1 / 11$ \\
11 & 1 & 1 & 1 & 0 & $11 / 12$ & $1 / 12$ \\
12 & 1 & 1 & 1 & 0 & $12 / 13$ & $1 / 13$ \\
\hline $\boldsymbol{O}_{i}:$ resultado observado no paciente $\boldsymbol{i}($ sucesso=1, fracasso $=0)$ \\
$T_{i}$ : tratamento recebido pelo paciente $\boldsymbol{i}(\mathrm{A}=1, \mathrm{~B}=0)$
\end{tabular}

\subsubsection{O Consentimento Informado}

Neste experimento, os pais e familiares destas crianças recém-nascidas em UTI passaram por uma situação que, por si só, é muito delicada. Qualquer decisão que tivesse que ser tomada pelos pais da criança era uma responsabilidade gigante. Assinar um documento permitindo a experimentação de um tratamento em um filho doente seria, em alguns casos, um stress desnecessário. A assinatura do consentimento informado visa conscientizar os pais de que o bebê participaria do estudo, no caso um experimento clínico aleatorizado, e seria atribuído ao acaso a um dos tratamentos sob estudo. 
$\mathrm{Na}$ prática, ao assinar este documento, os pais estariam permitindo a aleatorização e não necessariamente a introdução de um novo tratamento experimental, pois poderia o paciente ser sorteado para receber o tratamento convencional. Baseado nesta idéia, este estudo utilizou o consentimento informado aleatorizado (seção 1.4), onde os pais seriam submetidos ao stress de permitir algo, ou de assinar algo, apenas se este bebê fosse sorteado para receber o tratamento diferente do convencional (neste caso, o ECMO). Se o bebê fosse sorteado para receber o tratamento convencional, os pais seriam poupados de tomarem esta decisão. Além do mais, com as taxas de sucesso que se conhecia no momento, o tratamento convencional implicaria em óbito com uma grande chance.

Royall (1991) critica a utilização do consentimento informado aleatorizado, alegando que os pais do único bebê que morreu não tiveram a oportunidade de saber da existência de um novo tratamento totalmente promissor.

\subsection{O Segundo Experimento ECMO (Ware, 1989)}

\subsubsection{O Dilema Ético}

Este experimento foi conduzido a partir de 1986, por James Ware, em Harvard. A esta altura, o primeiro experimento já havia sido publicado fazia um ano e, portanto, mais evidências já existiam a favor deste tratamento relativamente ao convencional. Apesar disto, os argumentos dos autores do segundo ECMO giram em torno da falta de demonstração "científica" de que este tratamento fosse superior ao convencional. Os autores admitem que o estudo anterior (Bartlett, 1985: primeiro ECMO), realizado em Michigan, tenha fornecido informações encorajadoras sobre as taxas de sobrevida dos 
pacientes tratados com ECMO, porém as informações a respeito das taxas de sobrevida na mesma população tratada com a terapia convencional foram consideradas escassas. Experiências históricas são desprezadas pelo grupo de Harvard (segundo ECMO), que sentiu-se sem base científica para justificar o uso rotineiro do ECMO no tratamento de recém-nascidos com hipertensão pulmonar persistente.

Neste momento, a literatura não estava mais controversa. Todos concordavam que a ECMO era melhor que o tratamento convencional, só que isto ainda não havia sido demonstrado "cientificamente" (com um experimento clínico aleatorizado), pois a única tentativa que havia sido feita anteriormente fôra frustrada (seção 4.5). Por ser um estudo sequencial e adaptativo, ao final do estudo, apenas 1 criança havia sido submetida ao tratamento convencional. Estudos anteriores ao primeiro ECMO eram questionáveis com relação a heterogeneidade dos pacientes (diferentes tipos de patologias) e até mesmo quanto aos resultados estatísticos devido ao tamanho amostral. Neste ponto, teria sido muito importante usar toda a informação disponível possivel que pudesse auxiliar na tomada de decisão de sacrificar mais vidas em nome da ciência, conduzindo um experimento clínico aleatorizado.

Tanto na primeira quanto na segunda tentativa em que se estudou a ECMO através de um experimento clínico aleatorizado, existiam informações a priori que foram simplesmente ignoradas. Em 1985, ainda havia o argumento da heterogeneidade dos pacientes quanto a variáveis importantes como tipo de doença, etc. Mas no segundo experimento, estavam sendo estudados recém nascidos graves portadores da mesma patologia, já se tinha pelo menos a informação a respeito do primeiro experimento. Isso 
sequer não foi nem cogitado! Ter conduzido o primeiro ECMO em 1985 (Bartlett et al.) já foi bastante anti-ético; quanto mais o segundo ECMO em 1989 (Ware).

Por outro lado, este experimento enquadra-se na definição da seção 3.1 .4 de um experimento-para-provar, embora os argumentos que defendem sua validade ética parecem muito fracos (a não ser o argumento de que, apesar de toda a discussão em torno do primeiro ECMO, a comunidade médica ainda não estava convencida de que ECMO fosse superior e se sentiu obrigado a conduzir um experimento clínico aleatorizado).

Bartlett e Cornell (1991) questionam o artigo de Ware (segundo ECMO) com o seguinte argumento: "Na época em que o primeiro ECMO foi publicado, em 1985, vários autores, inclusive Ware e Epstein, autores do segundo ECMO (1989) fizeram sérias críticas ao planejamento adaptativo utilizado neste estudo. Apesar disto, um planejamento também adaptativo foi utilizado no segundo ECMO, publicado por Ware em 1989. Porque?". Além disto, quando o segundo ECMO foi iniciado, já existia a seguinte fonte de informação: em 1988, 715 casos haviam sido reportados com uma taxa de sobrevida de $81 \%$ pelo registro Neonatal de ECMO da Universidade de Michigan. Em resumo, Bartlett e Cornell (1991) demonstram que Ware (1989) passou pelo mesmo dilema que eles, alguns anos depois, e também conduziram um experimento clínico aleatorizado. Isto mostra que a sugestão de Royall de se usar controles concorrentes não teria mesmo nenhuma credibilidade.

Apesar de muitos estatísticos não terem gostado e criticado o planejamento deste estudo, para Bartlett e Cornell (1991), muitos médicos gostaram e acreditaram que o ECMO era superior e passaram a recomendá-lo para seus próximos pacientes. A 
única entidade que não se conformou com os resultados e precisou conduzir ainda mais estudos foi Harvard (Ware, 1989).

Ware passou pela situação mencionada por Royall de controles concorrentes não aleatorizados: em 1989, ele tinha à disposição os dados da Harvard de 82 e 83 de 11/13 óbitos de recém-nascidos tratados com o esquema convencional; além do estudo de Michigan (Bartlett e Cornell 1985). Isto não foi suficiente... e eles sentiram-se na obrigação de conduzir um novo estudo (aleatorizado).

\subsubsection{O Método de Seleção dos Tratamentos}

Neste experimento, também foi utilizado um planejamento adaptativo: o planejamento sequencial de dois estágios. Num primeiro estágio foi feita uma alocação em blocos aleatórios permutados com tamanho 4. Este estágio duraria até que ocorressem $r$ óbitos em um dos grupos. No segundo estágio, todos os pacientes receberiam o tratamento que não teve $r$ óbitos no primeiro estágio, até que ocorressem róbitos (ao todo neste grupo), ou até que o número de sobreviventes neste grupo fosse suficiente para estabelecer a superioridade deste tratamento.

A idéia deste planejamento era que houvesse um número suficiente de pacientes para a comparação entre os dois grupos no primeiro estágio. Este número não pode ser tão grande a ponto de colocar em risco a vida de muitos pacientes e nem tão pequeno que não seja possivel se fazer inferência com "segurança" (Ware, 1989).

No segundo estágio, após alguma evidência de qual seria o melhor tratamento, estuda-se mais pacientes submetidos ao tratamento considerado até então superior. A atribuição do tratamento considerado "pior" seria muito mais anti-ética (menos ética) no 
segundo estágio do que no primeiro, pois acumulou-se evidência da superioridade de um deles. Em outras palavras, no segundo estágio já se sabe "oficialmente" que um dos tratamentos é melhor do que o outro, ao passo que no primeiro estágio este conhecimento ainda não era "oficial".

\subsubsection{Resultados do Estudo}

Dentre as 18 primeiras crianças, metade recebeu o tratamento convencional, dentre as quais 3 resultaram em óbito; e nenhuma das 9 restantes que foram submetidas ao tratamento experimental (ECMO) foi a óbito. A décima-nona criança foi sorteada para o tratamento convencional e morreu, completando assim a regra de parada da primeira fase do estudo (4 óbitos em qualquer um dos grupos). Na segunda fase, dezenove crianças recém-nascidas com hipertensão pulmonar persistente foram tratadas com ECMO e apenas uma foi a óbito. A tabela 4.2 mostra estes resultados.

Tabela 4.2. Resultados das duas fases do experimento ECMO (Ware, 1989).

\begin{tabular}{|c|c|c|c|c|}
\hline \multirow[b]{2}{*}{ Tratamento } & \multicolumn{2}{|c|}{ 1a. fase (aleatorizada) } & \multicolumn{2}{|c|}{ 2a. fase (não aleatoriz) } \\
\hline & \# Pacientes & \# Óbitos & \# Pacientes & \# Óbitos \\
\hline Convencional & 10 & 4 & & \\
\hline ЕСмо & 9 & 0 & 20 & 1 \\
\hline Total & 19 & 4 & 20 & 1 \\
\hline
\end{tabular}




\section{CAPÍTULO 5 - UM PLANEJAMENTO BAYESIANO}

5.1. Introdução

5.2. Notação

5.3. O Planejamento KSS

5.4. Utilizando o Conceito de Qualidade de Vida no Planejamento KSS

\subsection{INTRODUÇÃO}

O que define um estatístico bayesiano é a adoção da postura subjetivista, que está baseada no conceito de probabilidade subjetivista. Quando vista meramente como um teorema do cálculo de probabilidades, a fórmula de Bayes não gera controvérsias. Alguns estatísticos, no entanto, utilizam-na como formalização do processo de aprender com os dados: os bayesianos encaram o teorema de Bayes como um guia para a atualização de opiniões à luz de novas evidências experimentais.

Probabilidade a posteriori da hipótese $H$, dada a evidência $E$ $\propto$

(Priori para $\mathrm{H}$ ) $\mathrm{X}$

(Verossimilhança para $\mathrm{H}$, gerada por $\mathrm{E}$ )

O aspecto mais controverso talvez seja o uso da noção de probabilidade a priori. Estatísticos não-bayesianos criticam o uso de prioris por julgarem-na representantes de um bias subjetivo.

O Princípio da Verossimilhança (citado na Seção 2.7.2) é outro aspecto de divergência. Segundo este princípio, toda evidência experimental é captada pela função de verossimilhança. Por este motivo, a aleatorização é irrelevante para a análise 
estatística, e o acompanhamento sequencial dos dados não teve ter nenhum efeito sobre a inferência. Portanto, para um bayesiano um experimento clínico é um processo através do qual novos dados permitem uma revisão contínua da opinião a priori sobre um tratamento. Algumas vantagens em relação aos planejamentos de experimentos clássicos: não há um ponto final em especial; o tamanho do experimento pode depender de vários fatores; não há níveis de significância ou erros de qualquer tipo envolvidos (no máximo, odds relativos do sucesso de dois tratamentos, que são julgados posteriormente à aquisição de novos dados). A principal vantagem da visão bayesiana está na sua flexibilidade no que se refere ao planejamento e execução de um experimento.

A inferência bayesiana pode ser mergulhada dentro de um contexto de teoria da decisão de uma forma muito natural. Este contexto permite a atribuição de valores (função utilidade) às várias alternativas, e então optar pela ação que maximizar a utilidade esperada. Os bayesianos são capazes de elaborar uma abordagem poderosa e flexível para a tomada de decisões quando há incerteza.

Kadane (1986) discute as responsabilidades das pessoas que planejam um experimento clínico, para com os pacientes através do seguinte exemplo hipotético: suponhamos que exista um grupo de médicos que são considerados os maiores especialistas em determinada doença. Um paciente que tenha condições financeiras certamente desejará consultá-los para ouvir os seus conselhos. Kadane sugere que, de alguma forma, um experimento clínico proporcione ao paciente esta oportunidade. Outra sugestão é que se use a informação que surge ao longo do experimento para o benefício dos próximos pacientes. É evidente que o uso da informação que surge no 
desenrolar do estudo deve ser utilizada sem que se sacrifique a validade científica deste estudo, ou seja, sem a introdução de nenhum tipo de vício de seleção.

Neste capitulo serão apresentados métodos bayesianos que abordam estas questões. A seção 5.2 mostra a notação utilizada por Kadane e Seidenfeld (1996), e a seção 5.3 apresenta o primeiro artigo onde surge uma proposta bayesiana de planejamento de um experimento clínico (Kadane e Sedransk, 1980) e também uma extensão deste trabalho (Kadane, 1986). Este tipo de planejamento será denominado KSS. A seguir, na seção 5.4, apresentamos uma variação deste planejamento, onde a função utilidade pode basear-se em um conceito amplo como a qualidade de vida do paciente.

\subsection{NOTAÇÃO}

Consideremos a seguinte notação introduzida por Kadane e Seidenfeld (1996), com intuito de formalizar uma restrição imposta à metodologia de seleção dos tratamentos. Os pacientes entram consecutivamentoe no estudo e são indexados por $i=1,2, \ldots, I$. O vetor de características observadas do paciente antes do tratamento é representado por $\mathrm{X}_{\mathrm{i}}$ e, $\mathrm{T}_{\mathrm{i}}$ é o tratamento atribuído ao paciente $i$. $\mathrm{O}$ resultado do tratamento no paciente $i$ é dado por $\mathrm{O}_{i}$. Seja $\theta$ o vetor de parâmetros de interesse, que determina as probabilidades dos resultados $O_{i}$ para um paciente $i$, dadas as características $X_{i}$ e o tratamento $T_{i}$. Finalmente, seja a evidência passada de todos os pacientes anteriores a $i$, incluindo o paciente $i$, representada por $\mathrm{P}_{\mathrm{i}}=\left(\mathrm{O}_{\mathrm{i}}, \mathrm{T}_{\mathrm{i}}, \mathrm{X}_{\mathrm{i}}, \mathrm{O}_{\mathrm{i}-1}, \mathrm{P}_{\mathrm{i}}\right.$ $\left.{ }_{1}, X_{i-1}, \ldots, O_{1}, T_{1}, X_{1}\right) . P_{i}$ é ordenado da direita para a esquerda, na ordem em que 
surgiu a informação: características $\left(\mathrm{X}_{1}\right)$, tratamento recebido $\left(\mathrm{T}_{1}\right)$ e resultado $\left(\mathrm{O}_{1}\right)$ do primeiro paciente; características $\left(\mathrm{X}_{2}\right)$, tratamento recebido $\left(\mathrm{T}_{2}\right)$ e resultado $\left(\mathrm{O}_{2}\right)$ do segundo paciente e assim por diante, até o i-ésimo paciente.

A partir desta notação, a função de verossimilhança para $\theta$ gerada pelos dados, pode ser escrita como $L_{P_{i}}(\theta)=f_{\theta}\left(P_{i}\right)$. Usando a definição de probabilidade condicional, podemos escrever:

$$
\begin{aligned}
f_{\theta}\left(P_{i}\right) & =\prod_{i=1}^{l} f_{\theta}\left(O_{i} \mid T_{i}, X_{i}, P_{i-1}\right) f_{\theta}\left(T_{i} \mid X_{i}, P_{i-1}\right) f_{\theta}\left(X_{i} \mid P_{i-1}\right) \\
& =\prod_{i=1}^{l} f_{\theta}\left(O_{i} \mid T_{i}, X_{i}, P_{i-1}\right) \prod_{i=1}^{l} f_{\theta}\left(T_{i} \mid X_{i}, P_{i-1}\right) \prod_{i=1}^{l} f_{\theta}\left(X_{i} \mid P_{i-1}\right)
\end{aligned}
$$

A seguir, discutiremos cada um dos três produtos que compõem a função de verossimilhança em (5.2.1). O primeiro termo, $\prod_{i=1}^{l} f_{\theta}\left(O_{i} \mid T_{i}, X_{i}, P_{i-1}\right)$, é o que contém a principal fonte de informação a respeito de $\theta$. O fator $f_{\theta}\left(O_{i} \mid T_{i}, X_{i}, P_{i-1}\right)$ independe da evidência passada $P_{i-1}$, pois, dado $\theta$, a probabilidade do resultado $O_{i}$ independe do resultado obtido para os pacientes anteriores. Desta forma,

$$
f_{\theta}\left(O_{i} \mid T_{i}, X_{i}, P_{i-1}\right)=f_{\theta}\left(O_{i} \mid T_{i}, X_{i}\right), \quad 1 \leq i \leq \mathrm{I}
$$

Então, o primeiro termo pode ser reescrito da seguinte forma:

$$
\prod_{i=1}^{l} f_{\theta}\left(O_{i} \mid T_{i}, X_{i}, P_{i-1}\right)=\prod_{i=1}^{l} f_{\theta}\left(O_{i} \mid T_{i}, X_{i}\right)
$$

Alguns experimentos clínicos não consideram as características $\left(X_{i}\right)$ dos pacientes antes do tratamento. Neste caso, (5.2.2) pode ser escrito como: $f_{\theta}\left(O_{i} \mid T_{i}, X_{i}\right)=f_{\theta}\left(O_{i} \mid T_{i}\right)$. O tipo de planejamento proposto na seção 5.3 (KSS), que se preocupa com o método de atribuição dos tratamentos, considera uma análise que 
despreza $X_{i}$ anti-ética, pois não leva em conta as características individuais de cada paciente ao escolher o tratamento para ele. Segundo Kadane e Seidenfeld (1996), o cuidado adicional em modelar esta dependência é um dos preços estatísticos pagos por esta nova classe de experimentos.

O segundo termo da expressão (5.2.1), $\prod_{i=1}^{1} f_{\theta}\left(T_{i} \mid X_{i}, P_{i-1}\right)$ está diretamente ligado ao método de atribuição dos tratamentos. Em alguns experimentos clínicos, esta função é determinística, assumindo o valor 1 para alguns tratamentos e, o valor 0, para o tratamento escolhido para o paciente i. Em experimentos que envolvem aleatorização, desde que respeitadas as restrições éticas (tratamentos admissiveis, ver seção 5.3), esta é uma distribuição uniforme, onde $f_{\theta}\left(T_{i} \mid X_{i}, P_{i-1}\right)=\frac{1}{\# \text { trats. admissiveis }}$. Vale a pena ressaltar que no planejamento KSS (seção 5.3) esta função independe de $\theta$. Esta restrição é importante e foi discutida na seção 4.2, onde define-se que métodos de seleção de tratamentos não são válidos quando $f_{\theta}\left(T_{i} \mid X_{i}, P_{i-1}\right)$ depende de $\theta$.

Finalmente, o terceiro termo de (5.2.1), $\prod_{i=1}^{l} f_{\theta}\left(X_{i} \mid P_{i-1}\right)$ também não depende de $\theta$, pois as características do paciente $i$ independem da evidência passada $P_{i-1}$. Em outras palavras, as características iniciais do paciente $i$ independem das características iniciais ou de resultados, de pacientes passados $1,2, \ldots, i-1$.

Com estas análises, concluímos que a função de verossimilhança depende de $\theta$ apenas através do primeiro termo de (5.2.1). Assim sendo, para os experimentos clínicos do tipo KSS (seção 5.3), podemos escrever: 


$$
L_{P_{i}}(\theta)=f_{\theta}\left(P_{i}\right) \propto \prod_{i=1}^{l} f_{\theta}\left(O_{i} \mid T_{i}, X_{i}\right)
$$

\subsection{O Planejamento KSS}

A base da inferência estatística subjetivista é que ela lida com opiniões e, neste caso, com opiniões médicas. Um dos tópicos da pesquisa moderna bayesiana refere-se à expressão de opiniões sob a forma de distribuições de probabilidade (Kadane e colaboradores 1980). Em um processo de identificação da priori, pergunta-se a um especialista questões a respeito por exemplo de sua mediana para uma quantidade em função de alguns valores específicos de outras. Estas medianas são inseridas em modelo que estima a resposta de um especialista com relação a qualquer questão deste tipo. Este modelo permite, portanto, o estudo de semelhanças e divergências entre vários especialistas quanto às respectivas visões sobre um determinado assunto. Além disto, estas opiniōes atualizadas podem ser utilizadas para o benefício dos pacientes sem que estes tenham que, fisicamente, consultar o especialista.

Kadane e Sedransk (1980) fazem uma proposta de um experimento clínico que representa uma melhora em direção à solução deste dilema ético. Os requisitos necessários para se aplicar esta proposta são:

1. a indicação de um pequeno número de especialistas na doença e tratamentos que estão sendo estudados

2. este grupo deve estar de acordo com relação a um único indicador de um resultado (a curto prazo) que seja razoável para o paciente no estudo 
3. este grupo deve estar de acordo com relação a alguns indicadores diagnósticos que estejam possivelmente ligados ao resultado que, por sua vez, será medido através do indicador estabelecido no item 2 acima

4. expressão da opinião de cada especialista sobre o indicador de resultado como uma função (probabilística) dos indicadores diagnósticos e do tratamento

5. este grupo deve estar de acordo com relação a uma função de verossimilhança para atualizar as funções dos especialistas à medida em que os dados vão se disponibilizando

6. atualização destas opiniões através do uso da fórmula de Bayes

A partir dos dados de cada paciente novo que entra no estudo, um ou mais tratamentos são considerados admissiveis para os próximos pacientes. A mistura entre os dados existentes no passado e as opiniões dos especialistas através da fórmula de Bayes indicam se cada tratamento é admissível para cada novo paciente. A opinião dos especialistas é ponderada de tal forma que, se pelo menos um especialista do grupo considerar um determinado tratamento recomendável para um paciente, este tratamento é considerado admissível.

Diferentes conjuntos de tratamentos podem ser considerados admissíveis para cada paciente. Dentre os tratamentos considerados admissíveis para um paciente, qualquer mecanismo de seleção de tratamentos poderá ser utilizado, inclusive a aleatorização. O grande avanço deste tipo de abordagem com relação à ética médica é o compromisso entre o dever de tratar o paciente com o melhor tratamento disponivel e a necessidade de se obter dados interpretáveis sob o ponto de vista científico. 
Kadane e Sedransk (1980) propõem uma solução que incorpora a nova informação à medida que esta é gerada pelo experimento, numa tentativa de proteger pacientes de tratamentos que possam ser desaconselháveis.

A opinião de cada um dos especialistas a respeito dos tratamentos pode ser expressa através de uma distribuição de probabilidades para a medida de eficácia condicionando nos fatores prognósticos (item 3 desta seção) considerados por um ou mais pesquisadores. A variável eficácia assume valores $e_{1}, e_{2}, \ldots, e_{k}$ e a distribuição de probabilidades; $p_{1}, p_{2}, \ldots, p_{k}$. Uma vez expressas em termos de distribuição de probabilidades, a cada nova informação gerada pelo experimento, as opiniões podem ser atualizadas levando assim a opiniões presentes.

Há dois tipos de perdas (utilidades) em um experimento clínico: a do paciente e a do estudo. Queremos maximizar a utilidade do estudo em termos de cumprir seus objetivos chegando a um consenso sobre qual é o melhor tratamento (ou ganhando experiência a respeito deles). Por outro lado, queremos também maximizar a utilidade do paciente (minimizar a perda), em termos de tratá-lo com o que é considerado o melhor tratamento para seu caso. Neste caso, a utilidade do paciente pode ser expressa em termos dos resultados terapêuticos; seja pelo médico (em nome do paciente) ou pelo próprio paciente. Esta é a importância do artigo de Kadane e Sedransk (1980): há uma preocupação em zelar pelos direitos do paciente com relação ao Princípio da Atenção Pessoal (seção 3.2).

Estes autores propõem usar a utilidade (ou perda) do paciente para definir um conjunto de tratamentos ADMISSÍVEIS para este e, a partir deste conjunto, selecionar o melhor tratamento de acordo com os objetivos do estudo - sem ferir, portanto, os 
direitos do pacientes de receber o que for melhor para ele. Um tratamento é admissivel para um paciente se este, de alguma forma, maximizar seus interesses, que por sua vez são expressos em termos de uma função de utilidade ou uma função de perda.

O paciente poderia, por si só, expressar uma função de perda, ou então alguém poderia fazer isso por ele. Em ambos os casos, a função perda deve refletir sua própria opinião mesclada com a opinião do especialista que o paciente consultou. Seguindo o costume de procurar uma segunda opinião quando estamos doentes, há um conjunto de funções perda formado pelas várias opiniões dos médicos que estão envolvidos no experimento. Em outras palavras, estaremos representando a opinião de cada médico (pelo paciente) a respeito de cada tratamento através de uma função perda. Sendo assim, para cada médico há uma perda esperada, ou um risco associado a cada tratamento. Seja $\theta$ o estado desconhecido da natureza com $\theta_{1}$ : óbito e $\theta_{2}$ : cura, $L(\theta)$, a função perda e $\mathrm{R}(\mathrm{t})$, a perda esperada para o tratamento $\mathrm{t}: R_{p}(t)=E(L(\theta))$.

DEFINIÇÃO : O tratamento t é ADMISSÍVEL se existir um conjunto convexo de pesos $\left\{\mathrm{w}_{\mathrm{p}}\right\}$ tal que $\sum_{p} R_{p}(t) w_{p} \leq \sum_{p} R_{p}\left(t^{\prime}\right) w_{p}$ para todos os outros tratamentos $\mathrm{t}^{\prime}$.

Em outras palavras, o tratamento t é admissivel se, de alguma forma, seu risco ponderado (pelos médicos) é menor ou igual ao risco ponderado de todos os outros tratamentos. A proposta é de uma definição de tratamento admissível para o paciente de acordo com seu interesses (que são expressos pela função perda). 


\subsection{Utilizando o Conceito de Qualidade de Vida no Planejamento KSS}

Esta proposta trata de Teoria da Decisão no contexto da pesquisa médica. Considere a seguinte situação na prática médica: Um paciente sentado em frente ao médico esperando para saber que tratamento ele receberá após o diagnóstico de sua doença. É uma situação de tomada de decisão, onde o médico deve escolher o melhor tratamento para um doente. Usualmente vários aspectos são considerados ao se fazer esta escolha: eficácia do tratamento, custos, viabilidade... Além destes, atualmente a Qualidade de Vida (QV) do paciente também é um aspecto a ser considerado.

Cox e colaboradores (1992) ressaltam a importância da resposta do paciente com relação a sua qualidade de vida: "A essência da abordagem de QV é a expressão de um ponto de vista subjetivo e, portanto, o principal respondente deve sempre ser o paciente". O interesse e a importância da mensuração da QV do paciente têm crescido rapidamente em muitas áreas da saúde. Qualidade de Vida é um conceito multidimensional, sendo, portanto extremamente difícil de ser medido. O artigo de Cox et al. enfatiza muitos aspectos complexos deste assunto, especialmente no que se refere à mensuração de Qualidade de Vida.

A opinião do médico em relação ao resultado clínico do tratamento é extremamente importante para o paciente. Geralmente, a responsabilidade desta decisão pertence muito mais ao médico do que ao paciente, em uma relação assimétrica.

Esta proposta sugere que a escolha do melhor tratamento para um paciente, segundo o conceito bayesiano de Teoria da Decisão, seja baseada em três elementos: um índice de qualidade de vida, as preferências do paciente e a opinião do médico. As 
três partes envolvidas neste processo de tomada de decisão são: dados passados de QV, o médico e o paciente.

O dados passados de QV representam o conhecimento anterior a respeito da QV de pacientes semelhante aos que estamos estudando (no sentido de seu estado de saúde antes do tratamento). Para resumir os dados passados pode ser utilizada qualquer quantidade que represente QV.

O que pode ser muito importante para um determinado paciente, pode não ser tão importante para outro. Por exemplo, se para um paciente as atividades sociais são importantes, para outro, as expectativas com relação ao tratamento podem ser mais importantes. Por este motivo, as preferências do paciente devem ser consideradas neste modelo. O paciente terá a oportunidade de atribuir pesos às dimensões de QV de modo a expressar suas preferências.

Cada tratamento, $T$, tem sua utilidade para o paciente. A função utilidade será representada como uma média ponderada dos dados passados ao longo de todas as dimensões de QV, onde os pesos são as preferências dos pacientes dentre estas dimensões. A função utilidade depende de $\theta$, a quantidade desconhecida que representa o resultado clínico. Consideremos $\theta$ como sendo um indicador de cura. Sendo assim, a função utilidade é dada por:

$$
U_{T}(\theta)=\sum_{k=1}^{d} w(k, \theta) \times Q V_{T}(k)
$$


onde,

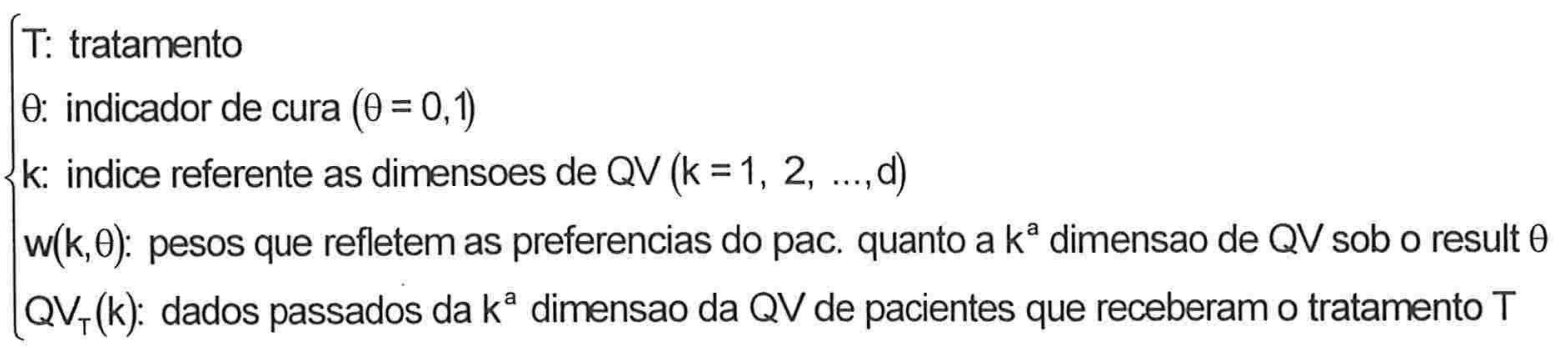

A mesma idéia poderia ser aplicada para outros aspectos da vida do paciente, ou mesmo, outros exames do paciente. Por exemplo, no caso de transplante cardíaco, o paciente é avaliado por uma equipe multiprofissional que, baseada em inúmeras avaliações (clínica, laboratorial, psicológica, social, Tc), decide se o paciente está apto ou não para receber o novo coração. Neste caso, o índice de Qualidade de Vida $\mathrm{QV}_{\mathrm{T}}(\mathrm{k})$ - poderia ser substituído por outro índice que expressasse o resultado de cada uma destas avaliações. As preferências do pacientes - $w(k, \theta)$ - poderiam ser investigadas quanto aos vários tipos de avaliações.

Porque as pessoas vão ao médico, se não para ouvir a sua opinião baseado em experiência passada? A opinião do médico tem que entrar no modelo. O estatístico poderá auxiliá-lo a expressar esta opinião através de uma medida de probabilidade. Por exemplo, o médico poderia atribuir probabilidades aos possíveis resultados: cura ou óbito. Estas são modificadas a cada novo resultado através da fórmula de Bayes. Sendo assim, são obtidas probabilidades atualizadas.

O resultado clínico $\theta$ do paciente, seja por um tratamento ou por outro, é desconhecido. Obviamente que, se o médico soubesse com certeza qual seria o resultado, não haveria uma situação de tomada de decisão. A incerteza do médico 
quanto ao resultado do tratamento é o motivo pelo qual sua opinião deve ser expressa através de probabilidade, $p(\theta)$.

Para cada tratamento, cada possível resultado clínico está associado com um valor da função utilidade. Sendo assim, seria razoável calcular a Utilidade Esperada para cada tratamento.

$$
\mathrm{E}(\mathrm{U}(\mathrm{T}))=\sum_{\theta} \mathrm{U}_{\mathrm{T}}(\theta) \times \mathrm{P}(\theta)
$$

Finalmente, o tratamento que produzir a melhor utilidade esperada será o escolhido para este paciente. Concluindo esta proposta, a Teoria da Decisão foi aplicada ao problema de seleção de tratamento para um paciente, misturando-se os seguintes elementos: 1) a probabilidade do médico, sua opinião a respeito do resultado clínico, 2) as evidências de dados passados para cada aspecto da vida do paciente (sejam eles dimensões de qualidade de vida ou outro tipo de avaliação) e cada tratamento em pacientes permutáveis com este que está sendo estudado e 3) as preferências dos pacientes dentre os aspectos avaliados no item anterior. Este método de seleção de tratamentos escolhe apenas os tratamentos admissíveis para um paciente. 


\section{CAPÍTULO 6 - UMA APLICAÇÃO PRÁTICA}

6.1. Introdução

6.2. Objetivo do Estudo Verapamil versus Nitroprussiato (VENI)

6.3. A Aprovação do Protocolo pela Comissão de Ética

6.4. Aspectos Computacionais do Estudo

6.5. A Experiência dos Especialistas - A Identificação de Prioris

6.6. O Método de Seleção de Tratamentos Utilizado no VENI

6.7. Erros que Ocorreram durante o VENI

6.8. Resultados do Estudo - Análise Bayesiana

\subsection{Introdução}

Kadane (1986) relata a experiência com o experimento clínico conduzido com médicos anestesistas do hospital Johns Hopkins. Em 1994, outro artigo é publicado com resultados mais definitivos a respeito deste mesmo experimento. Em 1996, Kadane publica um livro intitulado "Bayesian Methods and Ethics in a Clinical Trial Design", onde desenvolve conjuntamente com outros autores, 9 capítulos de tópicos práticos e teóricos a respeito deste estudo nos capítulos 5 a 13, que serão discutidos a seguir. Galway (1996) considera inovador o fato do tratamento de um dado paciente ser determinado através de aleatorização além de dados acumulados dos pacientes anteriores. O planejamento PWA, discutido na seção 4.4, também tem estas mesmas características. O inovador no planejamento KSS é sua formulação bayesiana, e não apenas o fato de considerar dados de pacientes anteriores. 


\subsection{Objetivo do Estudo Verapamil versus Nitroprussiato (VENI)}

Heitmiller e Blanck (1996) dão uma introdução médica ao problema. Frequentemente na cirurgia cardíaca é empregado um mecanismo chamado circulação extra-corpórea (CEC), onde, no ponto em que o sangue entra no coração (átrio esquerdo), ele é desviado do corpo através de tubos para um oxigenador, que assume as funções do pulmões em oxigenar o sangue e devolvê-lo ao corpo via outro conjunto de tubos para a aorta (de onde o sangue sai do coração). Este procedimento fornece ao cirurgião meios de parar os batimentos cardíacos de tal forma que ele tenha um campo com pouco fluxo sanguíneo para suturar as pontes, enquanto os outros órgãos do corpo continuam recebendo o fluxo de sangue. Após o término da sutura das pontes, o coração do paciente é estimulado a bater e então retoma suas funções usuais. Neste ponto a CEC é interrompida. Pacientes que são submetidos a este tipo de cirurgia costumam desenvolver aumento da pressão sanguínea após a interrupção da CEC, mesmo que não tenham história de hipertensão antes da cirurgia. Pressão elevada a este momento é indesejável por estar associada a maiores sangramentos e derrames. Desta forma, esta hipertensão aguda deverá ser tratada com drogas que tenham ação rápida e confiável.

O objetivo do estudo VENI é a comparação dos tratamentos Verapamil e Nitroprussiato para o controle da hipertensão aguda após cirurgia cardíaca. Este evento pode ocorrer no intervalo de meia hora após a cirurgia, quando o tratamento é administrado e o resultado é obtido após alguns minutos. Por este motivo, há informação que pode ser coletada e utilizada para o benefício dos próximos pacientes. Este tipo de situação, onde o resultado do tratamento pode ser observado em um curto 
espaço de tempo, é ideal para a aplicação do planejamento (bayesiano) do tipo KSS (apresentado na seção 5.3)

\subsection{A Aprovação do Protocolo pela Comissão de Ética}

Heitmiller e Blanck (1996) discutem aspectos médicos deste estudo, narrando a história da aprovação do protocolo pela comissão de ética do local onde os pacientes foram tratados. Nos Estados Unidos, um órgão federal - o departamento de Saúde e Recursos Humanos do Food and Drug Administration (FDA) - exige que a aprovação de qualquer protocolo de pesquisa em seres humanos seja aprovado pela comissão de ética (Institutional Review Board) da respectiva instituição. Particularmente no Hospital Johns Hopkins, hospital onde foi realizado este estudo, esta comissão é denominada de Joint Committee on Clinical Investigations (JCCl) e é formada por 19 membros (1 chefe, 1 pesquisador-não médico, 1 enfermeiro(a), 2 membros não afiliados à instituição e 15 médicos que representem as várias especialidades médicas).

A $\mathrm{JCCl}$ tem a responsabilidade de rever e aprovar toda pesquisa em seres humanos conduzida por pesquisadores da Escola de Medicina e todas as pesquisas que envolvem pacientes do Hospital Johns Hopkins. Por pesquisa, a JCCl entende que seja "... uma investigação formal planejada para desenvolver ou contribuir para o conhecimento generalizável...". Suas principais preocupações para com os pacientes são que: " os direitos e bem-estar dos sujeitos sejam adequadamente protegidos; os riscos para os sujeitos sejam compensados pelos potenciais benefícios da pesquisa; um consentimento informado bem elaborado seja obtido e, quando adequado, documentado..." 
Em julho de 1983, o primeiro protocolo do VENI foi aprovado pelo JCCI. Em 10 meses, apenas 5 pacientes entraram no estudo. De um total de 16 pacientes candidatos ao estudo, 11 não passaram pelos critérios de seleção, ou recusaram-se a participar do estudo. Para justificar a recusa em participar do estudo, alguns pacientes alegavam estarem muito assustados, ou que não queriam ser cobaias da pesquisa, alguns pacientes preferiram receber 0 tratamento convencional $e$ alguns, especificamente contra a aleatorização faziam questão que o respectivo médico optasse pelo tratamento.

Em junho de 1984, os pesquisadores submeteram ao $\mathrm{JCCl}$ o protocolo revisado propondo a metodologia bayesiana de alocação dos tratamentos (planejamento KSS, seção 5.3). O JCCl, por sua vez, respondeu com três questões fundamentais:

1. Decisões terapêuticas feitas por "prevailing opinions" têm tantas variáveis que os resultados são difíceis de serem analisados. A aleatorização tende a balancear estas variáveis. Como este novo planejamento lida com esta questão?

2. Como este novo método garante que as conclusões sejam atingidas apropriadamente, em um período de tempo viável, uma vez que este não determina um número mínimo de pacientes para atingir certos limites de confiança?

3. Os dados coletados e analisados deste estudo através de um planejamento bayesiano serão relatados de uma forma aceitável para publicação?

Com relação a primeira questão, a atribuição dos tratamentos neste planejamento é baseada nas características individuais do paciente, além da opinião dos médicos. Com relação à questão da viabilidade do estudo em termos de tempo, este planejamento tem maiores chances de ser viável do que um planejamento 
clássico, uma vez que a velocidade de recrutamento dos pacientes deve aumentar quando a abordagem do consentimento informado incorporar a preocupação do médico com os interesses do paciente atribuindo-lhe apenas tratamentos que sejam admissíveis para ele. Por último, ser aceitável para publicação é um aspecto que dependerá mais do editor da revista onde será publicado este estudo do que propriamente da qualidade do mesmo. A comunidade científica e, portanto os jornais e revistas médicas, estão muito "acostumados" a lerem artigos cujo planejamento é o clássico experimento clínico aleatorizado.

$\mathrm{Na}$ realidade, a aprovação do protocolo revisado pelo $\mathrm{JCCl}$ não dependeu das respostas a estas três perguntas; simplesmente o $\mathrm{JCCl}$ considerou este protocolo como um experimento que estivesse desenvolvendo um novo planejamento e não encontrou razões éticas para se opor a ele. Uma nova versão do consentimento informado foi redigida e submetida ao $\mathrm{JCCl}$. Esta incluiu alterações na metodologia de atribuição dos tratamentos e também nos possíveis efeitos colaterais das drogas, uma vez que alguma experiência já havia sido adquirida pelos investigadores.

A aprovação da segunda versão do protocolo foi obtida em setembro de 1984. Os dados obtidos dos primeiros 5 pacientes foram utilizados para estabelecer algumas estimativas para o novo modelo. Dos 71 pacientes que preencheram os critérios de inclusão, o consentimento para a participação no estudo foi obtida em 49; proporção esta muito maior que a obtida na primeira etapa do estudo. Este sucesso provavelmente é o reflexo da nova versão do consentimento informado. Um total de 30 pacientes foram estudados - desconsiderados os que se recusaram ou não satisfizeram 
os critérios de seleção do estudo - dentre os quais, 12 receberam o Nitroprussiato e 18, o Verapamil.

\subsection{Aspectos Computacionais do Estudo}

Galway (1996), escreve um capítulo no livro editado por Kadane (1996) a respeito dos aspectos computacionais do estudo VENI. Antes do início do estudo, opiniões de 5 especialistas na área de anestesia foram expressas através do método descrito por Kadane et al. (1980) quanto à resposta da pressão sangüínea pósoperatória ao Verapamil ou Nitroprussiato, para 16 perfis de pacientes determinados pela presença ou ausência de 4 fatores de risco. Estes fatores foram determinados pelos pesquisadores após algumas discussões:

a. anormalidade dos movimentos das paredes do coração,

b. hipertensão não controlada por betabloqueadores,

c. uso de antagonistas do cálcio e

d. história de doença vascular.

A presença ou ausência de cada um destes fatores em um paciente, juntamente com as opiniões a priori dos especialistas permitiram que, antes da cirurgia, fosse feita uma estimativa do resultado de cada tratamento. Se estas estimativas, realizadas através da fórmula de Bayes, indicassem que nenhuma das duas drogas fosse superior, a alocação era feita de acordo com a tabela 6.1; caso contrário, o paciente receberia o tratamento que tivesse o melhor resultado esperado. Nesta tabela, o primeiro paciente com as características $a, b, c$ e d, ou seja, com todos os fatores de risco, poderia receber o tratamento Verapamil se ambos fossem considerados admissíveis, (por ser um Verapamil o primeiro tratamento da tabela 6.1 na coluna abcd) 
e o tratamento Nitroprussiato, se apenas este fosse admissível. Se o paciente tivesse um aumento de pressão durante a cirurgia, e fosse efetivamente tratado com a droga recomendada, o resultado era utilizado para atualizar as distribuições a priori e dar novas estimativas para os efeitos dos tratamentos nos próximos pacientes. As prioris atualizadas (ou distribuições a posteriori) eram então utilizadas na atribuição dos tratamentos para os novos pacientes. Esta é uma formulação explicitamente bayesiana, onde o aprendizado com os dados é feito através da fórmula de Bayes, e a distribuição a posteriori, utilizada para realizar inferência. O método de alocação dos tratamentos do VENI será descrito com detalhes na seção 6.6.

Tabela 6.1. Lista de aleatorização do estudo VENI para os 16 tipos de pacientes.

\begin{tabular}{|c|c|c|c|c|c|c|c|c|c|c|c|c|c|c|c|c|}
\hline & (1) & $a$ & b & c & d & $a b$ & ac & ad & bc & bd & cd & $a b c$ & abd & acd & bcd & abcd \\
\hline 1 & $\mathrm{~V}$ & $\mathrm{~N}$ & $\mathrm{~N}$ & $\mathrm{~N}$ & $\mathrm{~N}$ & $\mathrm{~V}$ & V & $\mathrm{V}$ & V & $\mathrm{V}$ & $\mathrm{V}$ & $\mathrm{N}$ & $\mathrm{N}$ & $\mathrm{N}$ & $\mathrm{N}$ & V \\
\hline 2 & $\mathrm{~N}$ & V & V & $V$ & V & $\mathrm{N}$ & $\mathrm{N}$ & $\mathrm{N}$ & $\mathrm{N}$ & $\mathrm{N}$ & $\mathrm{N}$ & V & V & V & V & $\mathrm{N}$ \\
\hline 3 & V & $N$ & $\mathrm{~N}$ & $\mathrm{~N}$ & V & V & V & $N$ & V & $\mathrm{N}$ & $\mathrm{N}$ & $\mathrm{N}$ & V & V & V & $\mathrm{N}$ \\
\hline 4 & $\mathrm{~N}$ & V & V & V & $\mathrm{N}$ & $N$ & $N$ & V & $\mathrm{N}$ & V & V & V & $\mathrm{N}$ & $\mathrm{N}$ & $\mathrm{N}$ & V \\
\hline 5 & $\mathrm{~N}$ & V & V & $\mathrm{N}$ & V & $\mathrm{N}$ & V & $\mathrm{N}$ & V & $N$ & V & $\mathrm{N}$ & V & $\mathrm{N}$ & $\mathrm{N}$ & V \\
\hline 6 & V & $\mathrm{N}$ & $\mathrm{N}$ & V & $N$ & V & $\mathrm{N}$ & V & $\mathrm{N}$ & V & $N$ & V & $\mathrm{N}$ & V & V & $\mathrm{N}$ \\
\hline 7 & V & $\mathrm{N}$ & $N$ & V & $\mathrm{N}$ & V & $\mathrm{N}$ & $\mathrm{V}$ & $\mathrm{N}$ & $\mathrm{V}$ & $\mathrm{N}$ & V & $\mathrm{N}$ & V & V & $\mathrm{N}$ \\
\hline 8 & $\mathrm{~N}$ & V & V & $\mathrm{N}$ & V & $\mathrm{N}$ & V & $N$ & V & $N$ & V & $\mathrm{N}$ & V & $\mathrm{N}$ & $\mathrm{N}$ & V \\
\hline 9 & $\mathrm{~N}$ & V & $\mathrm{N}$ & V & V & V & $N$ & $\mathrm{~N}$ & V & V & $N$ & $\mathrm{~N}$ & $\mathrm{~N}$ & V & $\mathrm{N}$ & V \\
\hline 10 & $\mathrm{~V}$ & $\mathrm{~N}$ & V & $\mathrm{N}$ & $\mathrm{N}$ & $N$ & V & V & $\mathrm{N}$ & $N$ & V & V & V & $\mathrm{N}$ & V & $N$ \\
\hline 11 & V & $\mathrm{N}$ & V & $N$ & $\mathrm{~N}$ & $\mathrm{~N}$ & V & V & $\mathrm{N}$ & $N$ & V & V & V & $N$ & V & $\mathrm{N}$ \\
\hline 12 & $\mathrm{~N}$ & V & $\mathrm{N}$ & V & V & V & $N$ & $\mathrm{~N}$ & V & V & $N$ & $\mathrm{~N}$ & $\mathrm{~N}$ & V & $\mathrm{N}$ & V \\
\hline 13 & $N$ & V & V & V & V & $\mathrm{N}$ & $N$ & $N$ & $\mathrm{~N}$ & $\mathrm{~N}$ & $N$ & V & V & V & V & $\mathrm{N}$ \\
\hline 14 & V & $\mathrm{N}$ & $\mathrm{N}$ & $N$ & $\mathrm{~N}$ & V & V & V & V & V & V & $\mathrm{N}$ & $\mathrm{N}$ & $N$ & $\mathrm{~N}$ & v \\
\hline 15 & $\mathrm{~N}$ & V & V & V & V & $N$ & $N$ & $N$ & $N$ & $N$ & $N$ & V & V & V & V & $\mathrm{N}$ \\
\hline 16 & V & $\mathrm{N}$ & $\mathrm{N}$ & $\mathrm{N}$ & $\mathrm{N}$ & V & V & V & V & V & V & $\mathrm{N}$ & $\mathrm{N}$ & $N$ & $\mathrm{~N}$ & V \\
\hline 17 & $\mathrm{~N}$ & V & V & $\mathrm{N}$ & V & $\mathrm{N}$ & V & $\mathrm{N}$ & V & $\mathrm{N}$ & V & $\mathrm{N}$ & V & $\mathrm{N}$ & $N$ & V \\
\hline 18 & V & $\mathrm{N}$ & $\mathrm{N}$ & V & $\mathrm{N}$ & V & $\mathrm{N}$ & V & $N$ & V & $N$ & V & $\mathrm{N}$ & V & $\mathrm{V}$ & $N$ \\
\hline 19 & $\mathrm{~N}$ & $\mathrm{~N}$ & V & V & V & V & V & V & $\mathrm{N}$ & $N$ & $N$ & $N$ & $\mathrm{~N}$ & $\mathrm{~N}$ & V & V \\
\hline 20 & V & V & $\mathrm{N}$ & $\mathrm{N}$ & $\mathrm{N}$ & $\mathrm{N}$ & $\mathrm{N}$ & $\mathrm{N}$ & V & V & V & V & V & V & $\mathrm{N}$ & $\mathrm{N}$ \\
\hline
\end{tabular}

$V=$ Verapamil, $N=$ Nitroprussiato, (1)=sem nenhum fator de risco, a=anormalidades no movimento das paredes do coração,

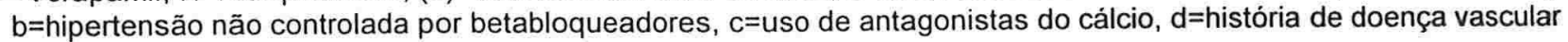


Suponhamos que a reposta ao tratamento seja uma soma de uma função linear dos fatores de risco, mais um erro aleatório cuja distribuição é normal, e que observações de diferentes pacientes sejam condicionalmente independentes e consideremos a seguinte notação: n: número de pacientes considerados; $\mathbf{y}$ : vetor ndimensional contendo as respostas de $n$ pacientes; $X$ :matriz $n \times 5$ composta por 1 s e 0 s representando indicadores dos fatores de risco (uma coluna de 1s considera o fato de que um paciente que não tem nenhum fator de risco também terá uma resposta à droga); m: vetor dos parâmetros lineares, com dimensão $5 \times 1$; w: parâmetro de precisão real não negativo.

A distribuição de $y$ tem a seguinte forma (a menos de uma constante multiplicativa):

$$
f(y / m, w) \propto w^{n / 2} \exp \left[-\left(\frac{w}{2}\right)(y-X m)^{\prime}(y-X m)\right]
$$

A distribuição conjunta de $\mathrm{m}$ e $\mathrm{w}$ a priori escolhida foi a normal-gama, de modo que a distribuição a posteriori também é uma normal-gama, por ser conjugada sob uma verossimilhança normal (pg. 249 a 253; DeGroot, 1970). Assim sendo, m / w tem uma distribuição normal de dimensão 5 com parâmetros $m$ e $\tau$, onde $w \tau$ é a matriz de precisão e $\alpha$ e $\beta$ são os parâmetros da gama. Assim sendo, se $\mu=E(m / w)$, então $E($ resultado de um paciente com características $X)=X^{\prime} \mu$

A priori de cada especialista é definida através dos hiperparâmetros $\mu, \tau, \alpha$ e $\beta$ extraídos de entrevistas com os especialistas (seção 6.5). O programa TRIALS calcula o resultado esperado $X^{\prime} \mu$ para cada paciente e cada droga e usa estes números para a 
atribuição dos tratamentos. Por este motivo, o interesse está no efeito que os resultados acumulados têm no hiperparâmetro $\mu$. A fórmula de Bayes indica uma forma simples de realizar estes cálculos. Os parâmetros da distribuição a posteriori são dados por:

$$
\alpha_{1}=\alpha+\mathrm{n} / 2, \tau_{1}=\tau+\mathrm{X}^{\prime} \mathrm{X}, \beta_{1}=\beta+\frac{1}{2}\left[\left(\mathrm{y}-\mathrm{X}^{\prime} \mu_{1}\right)^{\prime} \mathrm{y}+\left(\mu-\mu_{1}\right)^{\prime} \tau \mu\right]
$$

onde, $\mu_{1}$ deve satisfazer

$$
\left(\tau+\mathrm{X}^{\prime} \mathrm{X}\right) \mu_{1}=\left(\tau \mu+\mathrm{X}^{\prime} \mathrm{y}\right)
$$

\subsection{A Experiência dos Especialistas - A Identificação de Prioris}

Quando o estudo foi proposto para os especialistas, cada um deles foi informado sobre a intenção de resolver alguns conflitos éticos que surgiram quando se tentou realizar um experimento clínico nos moldes tradicionais (ver discussão seção 6.3: a aprovação do protocolo pela comissão de ética). Os especialistas também foram informados a respeito da necessidade de 2 ou 3 entrevistas de "identificação de priori".

Os objetivos da aplicação do planejamento bayesiano foram o aumento da proteção (segurança) do paciente durante o experimento e, a obtenção de uma conclusão estatisticamente válida mais rapidamente (através da inclusão de dados acumulados na escolha dos tratamentos de pacientes novos). Por proteção/segurança do paciente, entende-se que, pelo menos um especialista considere que aquele é o melhor tratamento para um determinado paciente, dado um conjunto de variáveis preditoras, o que é o mesmo que classificar um tratamento em admissível ou nãoadmissível. 
O processo de identificação: O processo consistiu de uma entrevista via telefônica com o Prof. J.B. Kadane, referente à pressão sangüínea esperada em uma intervenção com Verapamil ou com Nitroprussiato em pacientes com certos perfis. Estes perfis eram determinados pelos 4 fatores de risco, descritos na seção 6.4. As entrevistas com cada profissional duraram aproximadamente uma hora e os dados eram digitados no computador simultaneamente pelo entrevistador.

A cada especialista foram solicitados valores para a mediana e percentis 75 e 90 para a variável resposta (o valor mínimo atingido pela pressão arterial média - PAM mínima) para vários valores das variáveis preditoras. O ajuste do modelo gerado pelo computador durante a própria entrevista a partir destes valores era fornecido ao especialista a partir de um número (uma estatística) indicando quão concordante sua opinião era com a do modelo. Esta informação era necessária para que o especialista fosse capaz de modificar sua opinião e esclarecer quaisquer incertezas em seu julgamento.

Na segunda etapa do processo (outra entrevista telefônica), um conjunto de dados eram apresentados ao especialista, que deveria fornecer novamente um valor para a mediana de um conjunto de variáveis preditoras que foram incluídos no mesmo conjunto. O objetivo desta etapa era que os especialistas tivessem um melhor julgamento sobre o efeito de Verapamil e do Nitroprussiato com relação às variáveis preditoras.

Esta etapa foi vista pelos especialistas com pouco entusiasmo, por causa da experiência com a primeira. Um aspecto interessante foi que os dados enviados aos especialistas eram dados hemodinâmicos acumulados até aquele momento e; além 
disso, não foram enviadas análises estatísticas das interações entre as variáveis preditoras e a intervenção farmacológica. Deste modo, os especialistas tiveram o benefício dos dados, porém não das análises.

O que os especialistas acharam disto? Segundo Kadane, os especialistas foram capazes de responder as questões da entrevista, mesmo não conhecendo a natureza do processo e as idéias por trás dele. Para os especialistas, esta era uma situação estranha; eles tiveram que quantificar não somente o efeito das variáveis preditoras na PAM mínima, como também o efeito das interações destas na PAM mínima. De um modo geral, os especialistas (Blanck et al., 1996) acharam que esta foi uma "experiência totalmente nova", no sentido de que houve a necessidade de um novo tipo de raciocínio a respeito de uma interação farmacológica que ocorre normalmente durante a prática clínica. O processo de identificação da priori exigia uma resposta numérica, diferentemente do tipo de resposta que o especialista costuma dar em um contexto puramente clínico. Algumas expressões por eles citadas para descrever o processo de identificação da priori: "chato", "divertido", "interessante", "não vejo onde isto vai dar". Estes autores consideraram esta uma fase crítica deste tipo de experimento clínico.

O receio dos especialistas. Por ter sido esta a primeira vez que os especialistas tiveram que lidar com um planejamento bayesiano em um experimento clínico, surgiram dúvidas a respeito da validade das próprias opiniões enquanto ferramentas estatísticas. Os especialistas não tinham nenhuma garantia de que este planejamento fosse mais eficaz ou mais seguro. Além disso, o processo de 
identificação da priori foi longo, o que os tornou um pouco céticos com relação ao valor deste tipo de abordagem.

Questões preditivas. Com relação ao processo de identificação da priori, Kadane (1996) aponta a dificuldade em extrair de um especialista valores para os parâmetros das distribuições a priori. Por isso, o método proposto pelo próprio autor em 1980 (Kadane e colaboradores, 1980) sugere que se façam questões preditivas aos especialistas. Por exemplo: "Para pacientes que utilizam betabloqueadores e antagonistas do cálcio, que não têm história de hipertensão e nem anormalidades no movimento das paredes do coração, qual seria a sua mediana para um desvio médio de $80 \mathrm{mmHg}$ na PAM da primeira meia hora após a cirurgia? A mediana é o número abaixo do qual você espera que esteja o desvio médio de $80 \mathrm{mmHg}$ de metade dos pacientes."

Estas quantidades são mais familiares aos especialistas do que parâmetros da distribuição a priori, que são mais difíceis de entender. Os métodos de identificação de priori propostos por Kadane utilizam somente estas questões preditivas e permitem que os especialistas revejam suas respostas e façam mudanças, sem que haja necessidade de reiniciar o processo.

\subsection{O Método de Seleção de Tratamentos Utilizado no VENI}

O estudo Verapamil versus Nitroprussiato não tinha apenas o objetivo de investigar o mérito relativo das duas drogas; como também, o de examinar e documentar o novo planejamento desde sua concepção, implementação até sua análise estatística. Por este motivo, os pesquisadores sentiram-se quase que obrigados 
a utilizar um método de seleção de tratamentos que envolvesse o conceito de tratamento admissivel e, simultaneamente, aleatorização. Desta forma, tanto a análise clássica quanto a bayesiana poderiam ser aplicadas, e até mesmo contrastadas.

Conforme citado na seção $6.4,4$ fatores de risco foram considerados para o balanceamento dos grupos:

a. anormalidade do movimento das paredes do coração

b. hipertensão não controlada por betabloqueadores

c. uso de drogas antagonistas do cálcio

d. história de doença vascular

Para cada um dos 16 estratos formados pela presença ou ausência dos 4 fatores de risco $\left(2^{4}=16\right.$ estratos), foi gerada uma sequência aleatória de 20 tratamentos. Esta sequência foi preparada antes do estudo e foi completamente independente da determinação se tratamento para um dado paciente era admissível ou não. Além disso, os médicos não tiveram acesso a esta lista antes do experimento.

O método de seleção consistiu dos seguintes passos:

10: Um novo paciente com certas características entra no estudo

20: O conjunto de tratamentos admissiveis para este paciente é determinado

3o: O primeiro tratamento admissível da sequência de 20 é reservado a este paciente

4o: Se o paciente tiver hipertensão intra-operatória, ele receberá o tratamento descrito no 3o. passo e o tratamento será deletado da sequência.

5o: Se o paciente não tiver hipertensão intra-operatória, o tratamento continuará na sequência para o próximo paciente que tiver as mesmas características que este. 
Suponhamos, por exemplo, que a sequência de 20 tratamentos para um paciente com as características abd seja a seguinte: $\vee \vee N \vee N \vee N \vee V \vee N N N \vee N N$ $\mathrm{N} \vee \mathrm{V}$ (o correspondente à 13a. coluna da tabela 6.1). Quando um paciente com este perfil entra no estudo, se o tratamento $\mathrm{N}$ for o único admissivel para este perfil, os dois primeiros tratamentos serão pulados e o paciente, se tiver hipertensão intra-operatória, receberá o terceiro tratamento da sequência (o Nitroprussiato). Neste caso, a sequência para o próximo paciente com este perfil será: $\vee V \_\vee N \vee N \vee V \vee N N N \vee$ N N N V V. Se, por acaso, mais adiante no estudo, o tratamento $\vee$ tornar-se admissível para este tipo de paciente, um paciente novo receberá o primeiro tratamento admissível da lista corrente. No caso deste exemplo, seria o tratamento Verapamil e, caso ocorresse o evento hipertensão intra-operatória, o paciente receberia o tratamento, que, por sua vez, seria deletado da sequência. A sequência após este paciente ficaria da seguinte forma: _ ${ }_{-}$V N V N V V V N N V N N V V.

O planejamento utilizado no VENI foi o planejamento fatorial balanceado sugerido por Sedransk (1996), no qual são gerados grupos equilibrados com relação ao número de pacientes com os vários perfis. Este tipo de planejamento garante que, se apenas um paciente de cada tipo entrar no estudo, cada fator ( $A, B, C$ e $D)$ será representado o mesmo número de vezes em cada grupo. Além disso, será possível estimar os efeitos da resposta ao tratamento para cada fator utilizado para caracterizar os pacientes. Há também, a garantia de que os pacientes dos dois grupos sejam comparáveis, uma vez que, se muitos pacientes com o mesmo perfil entrarem no estudo em um determinado período de tempo, eles receberão os dois tratamentos em 
números proporcionais. Como um resultado, estimativas das diferenças entre os tratamentos são as mais precisas possíveis, dado o particular conjunto de pacientes que são por fim estudados.

Este equilíbrio em termos do número de pacientes com cada perfil nos dois grupos, incorporado ao novo tipo de experimento clínico (KSS) pode ser destruído quando um tratamento admissível é chamado, porém não atribuído. No entanto, o planejamento fatorial balanceado executa o maior equilíbrio possível no conjunto de pacientes em cada grupo, quando se atribuem apenas tratamentos admissíveis. Outro ponto levantado por Sedransk é que, tanto análises clássicas quanto bayesianas são possíveis por causa da base na aleatorização para o planejamento (seleção de uma permutação aleatoriamente e sequência aleatória de drogas). Além disso, a complexidade do planejamento é, de alguma forma, um obstáculo para a manipulação deliberada do planejamento por parte de qualquer pessoa que esteja ligada ao estudo.

\subsection{Erros que Ocorreram durante o VENI}

Com relação ao aspecto computacional. Os métodos propostos por Kadane et al. (1980) para a identificação de prioris baseados em questões preditivas (seção 6.5) foram implementados em dois sistemas de computadores: o CADA, na época do estudo e o STATLIB, atualmente. Dez anos após o início do estudo e da utilização do sistema CADA, Kadane não parece ter ficado muito satisfeito com seu desempenho e aponta os motivos:

1. O sistema CADA não garante que a matriz de covariâncias dos coeficientes da regressão seja positiva definida. Esta restrição, apesar de constar do método de 
Kadane et al. (1980) não foi implementada no sistema, o que trouxe dificuldades computacionais quando os pesquisadores expressaram matrizes de covariância que não eram positivas definidas. Kadane considera que o aspecto mais difícil da identificação de uma priori conjugada para o modelo normal linear seja encontrar a matriz de covariância dos coeficientes da regressão, que tem que ser positiva definida.

2. O mesmo conjunto de variáveis independentes é utilizado pelo sistema para solicitar a opinião do especialista. Kadane sugere que o sistema poderia escolher valores variados para as variáveis independentes, tornando-se menos mecânico e, portanto melhorando a interface com o usuário (os pesquisadores e os especialistas).

3. Uma tabela errada no programa faz com que os cálculos dos graus de liberdade da priori sejam suspeitos.

Para Kadane esta fase do estudo teve um desempenho razoável, tanto no que se refere ao envolvimento dos especialistas, quanto à parte humana da interface homem-máquina.

Com relação ao andamento do estudo. Vários erros ocorreram durante a realização do experimento. O primeiro tem a ver com a escolha da variável resposta. Inicialmente, foi escolhida uma medida do mínimo valor atingido pela PAM na primeira meia hora após o início do tratamento. Entretanto, após algumas discussões, considerou-se que a utilização da medida do desvio médio da PAM de $80 \mathrm{mmHg}$ durante a primeira meia hora protegeria os interesses do paciente, tanto contra PAMs muito altas, como também, contra PAMs muito baixas - também consideradas indesejáveis para o paciente. Para que fosse efetuada esta mudança de variável 
resposta, novas entrevistas deveriam ser realizadas com os cinco especialistas. Durante este intervalo, a variável resposta utilizada foi a medida do desvio da PAM mínima de $75 \mathrm{mmHg}$. Resumindo, o estudo teve três fases onde as variáveis respostas utilizadas foram, respectivamente:

1. o valor mínimo atingido pela PAM na primeira meia hora após o tratamento

2. o desvio da PAM mínima de $75 \mathrm{mmHg}$ na primeira meia hora após o tratamento

3. o desvio médio de todos os valores da PAM de $80 \mathrm{mmHg}$ na primeira meia hora após o tratamento (PAMDEV)

Segundo Kadane, mesmo com esta mudança na variável resposta, os dados continuaram sendo interpretáveis, uma vez que a atribuição dos tratamentos continuou sendo uma função conhecida das características de cada paciente. A única diferença é que esta função não foi a mesma para todos os pacientes do estudo.

Outro erro que ocorreu durante o estudo, foi relacionado à um grande bug que foi encontrado no programa quando este foi mudado de Pittsburgh para Baltimore. Até um certo ponto, os estatísticos e o computador onde estavam os programas (VAX) do estudo ficaram alocados em Pittsburgh, enquanto os pacientes eram tratados por médicos em Baltimore. A cada paciente que entrava no estudo, o pesquisador telefonava de Baltimore para o centro computacional dizendo as características do paciente. O estatístico dava entrada destes dados no computador, que imediatamente fornecia o tratamento recomendado pelo estudo para este paciente. Em algumas situações onde não havia um profissional para fazer a atribuição do tratamento em Pittsburgh , o paciente era perdido para o estudo. Por este motivo, decidiu-se mover o programa computacional para Baltimore. 
Esta mudança implicou em alterar o sistema, que rodava o sistema operacional VMS em VAX, para DOS em microcomputadores IBM PC. Vários problemas ocorreram nesta fase, tanto de ordem tecnológica, quanto com relação ao programa. Tecnologicamente, na época, os programadores tiveram dificuldades, pois os compiladores de FORTRAN para microcomputadores tinham menos recursos que os compiladores FORTRAN para VMSNAX, e os programas foram reescritos gerando estimativas das probabilidades ligeiramente diferentes. O pior de tudo foi que, quando os programas foram reescritos, descobriu-se um grande bug, cujo efeito foi a atribuição inadequada de tratamentos inadmissiveis para alguns pacientes do estudo.

Infelizmente, este ocorrido impossibilitou uma avaliação do balanceamento dos grupos. Por outro lado, felizmente, o método de atribuição dos tratamentos não tornouse inaceitável com este erro, uma vez que a condição 5.2.1 continuou sendo satisfeita. A atribuição dos tratamentos foi realizada com base somente nas variáveis independentes, ainda que não tenham sido as funções inicialmente planejadas.

O terceiro e último erro reportado por Kadane foi um erro de transcrição nas características de um paciente. Este tipo de situação poderia ter ocorrido em qualquer tipo de experimento clínico.

Kadane finaliza este capítulo do livro, argumentando que as falhas ocorridas neste estudo não servem como pretexto para que pesquisadores isentem-se da responsabilidade ética de tentar proteger os interesses dos pacientes ao máximo na fase de atribuição dos tratamentos. 


\subsection{Resultados do Estudo - Análise Bayesiana}

Nesta seção, apresentaremos os resultados do estudo VENI, segundo uma análise bayesiana. A variável resposta utilizada nesta análise é chamada PAMDEV e representa o desvio médio de $80 \mathrm{mmHg}$ dos valores da PAM durante 30 minutos após o tratamento. Os 16 diferentes perfis de pacientes de acordo com a presença ou ausência de cada uma das variáveis independentes estão representados na tabela 6.2.

Tabela 6.2. Tipos de pacientes de acordo com a presença (1) ou ausência (0) das variáveis independentes.

\begin{tabular}{ccccc}
\hline $\begin{array}{c}\text { Tipo de } \\
\text { Paciente }\end{array}$ & $\begin{array}{c}\text { Doença } \\
\text { Vascular } \\
\text { Prévia }\end{array}$ & $\begin{array}{c}\text { Uso de } \\
\text { Antagonista } \\
\text { do Cálcio }\end{array}$ & $\begin{array}{c}\text { Anormalidade } \\
\text { do Movimento } \\
\text { da Parede }\end{array}$ & $\begin{array}{c}\text { Hipertensão } \\
\text { Prévia }\end{array}$ \\
\hline 1 & 1 & 1 & 1 & 1 \\
2 & 1 & 1 & 1 & 0 \\
3 & 1 & 1 & 0 & 1 \\
4 & 1 & 1 & 0 & 0 \\
5 & 1 & 0 & 1 & 1 \\
6 & 1 & 0 & 1 & 0 \\
7 & 1 & 0 & 0 & 1 \\
8 & 1 & 0 & 0 & 0 \\
9 & 0 & 1 & 1 & 1 \\
10 & 0 & 1 & 1 & 0 \\
11 & 0 & 1 & 0 & 1 \\
12 & 0 & 1 & 0 & 0 \\
13 & 0 & 0 & 1 & 1 \\
14 & 0 & 0 & 1 & 0 \\
15 & 0 & 0 & 0 & 1 \\
16 & 0 & 0 & 0 & 0 \\
\hline
\end{tabular}

As preferências de cada um dos cinco especialistas (representados por A, B, C, D e E) para cada tipo de paciente segundo as distribuições a priori identificadas na primeira fase do estudo (seção 6.5), encontram-se na tabela 6.3. Antes do estudo, a 
preferência dos especialistas A e B era o Nitroprussiato para todos os tipos de pacientes, assim como a preferência do especialista D para quase todos os tipos de pacientes. Opostamente, o Verapamil era preferido pelo especialista $E$ para todos os pacientes. Somente o especialista C pareceu ser mais flexível em suas opiniões a priori antes do início do experimento, preferindo Nitroprussiato para alguns tipos de pacientes e Verapamil para outros.

Tabela 6.3. Preferências dos especialistas com relação ao tratamento segundo as distribuições a priori da PAMDEV.

\begin{tabular}{|c|c|c|c|c|c|}
\hline \multirow[b]{2}{*}{ Tipo de Paciente } & \multicolumn{5}{|c|}{ Especialista } \\
\hline & A & $\mathrm{B}$ & C & D & $E$ \\
\hline 1 & $\mathrm{~N}$ & $\mathrm{~N}$ & V & $\mathrm{N}$ & V \\
\hline 2 & $\mathrm{~N}$ & $N$ & V & $N$ & V \\
\hline 3 & $\mathrm{~N}$ & $\mathrm{~N}$ & V & $\mathrm{N}$ & V \\
\hline 4 & $\mathrm{~N}$ & $\mathrm{~N}$ & $\mathrm{~N}$ & $\mathrm{~N}$ & V \\
\hline 5 & $\mathrm{~N}$ & $\mathrm{~N}$ & V & $N$ & V \\
\hline 6 & $\mathrm{~N}$ & $\mathrm{~N}$ & $\mathrm{~N}$ & $N$ & V \\
\hline 7 & $\mathrm{~N}$ & $\mathrm{~N}$ & V & $N$ & V \\
\hline 8 & $\mathrm{~N}$ & $\mathrm{~N}$ & $\mathrm{~N}$ & $\mathrm{~N}$ & V \\
\hline 9 & $\mathrm{~N}$ & $\mathrm{~N}$ & V & $\mathrm{N}$ & V \\
\hline 10 & $\mathrm{~N}$ & $\mathrm{~N}$ & V & $\mathrm{N}$ & V \\
\hline 11 & $\mathrm{~N}$ & $\mathrm{~N}$ & V & $\mathrm{N}$ & V \\
\hline 12 & $\mathrm{~N}$ & $\mathrm{~N}$ & V & $\mathrm{N}$ & V \\
\hline 13 & $\mathrm{~N}$ & $\mathrm{~N}$ & V & N & V \\
\hline 14 & $\mathrm{~N}$ & $\mathrm{~N}$ & V & $\mathrm{N}$ & V \\
\hline 15 & $\mathrm{~N}$ & $\mathrm{~N}$ & V & V & V \\
\hline 16 & $\mathrm{~N}$ & $\mathrm{~N}$ & $\mathrm{~N}$ & $\mathrm{~N}$ & V \\
\hline
\end{tabular}

As divergências de opiniões dos especialistas com relação à eficácia relativa dos dois tratamentos é típica de um experimento clínico. Se esta divergência não existisse, não haveria necessidade de se conduzir um experimento clínico. A tabela 6.4 mostra as 
preferências dos especialistas atualizadas pelos dados provenientes do estudo. O padrão desta tabela é um pouco diferente da 6.3. Ao final do estudo, os 5 especialistas concordam com relação à superioridade do Verapamil para alguns tipos de pacientes $(1,3,5,7,11$ e 15). Se o estudo continuasse e entrasse um paciente deste tipo, somente o Verapamil seria admissível para ele. Entretanto, esta condição não seria permanente; uma vez que resultados favoráveis com relação ao Nitroprussiato ou resultados desfavoráveis com relação ao Verapamil em futuros pacientes podem alterar a admissibilidade deste tratamento para este tipo de paciente.

Uma característica importante de um planejamentos do tipo KSS é a possibilidade de interrupção do estudo a qualquer momento. Em planejamentos clássicos, muitas vezes nos deparamos com decisões que, por um lado consideram o risco de expor mais pacientes a um tratamento que parece ser inferior, e, por outro lado, a interrupção do estudo leva ao prejuízo de nada se aprender sobre a eficácia relativa dos tratamentos. Por atribuírem automaticamente o tratamento preferido ao se atingir a unanimidade, os planejamentos do tipo KSS evitam esta situação.

As tabelas 6.3 e 6.4 mostram, respectivamente, as preferências a priori e posteriori dos especialistas quanto aos tratamentos Nitroprussiato e Verapamil. Por exemplo, se a probabilidade de sucesso a priori para o Verapamil fosse maior que para o Nitroprussiato, então a preferência deste especialista para este perfil de paciente seria do Verapamil. 
Tabela 6.4. Preferências dos especialistas com relação ao tratamento após o estudo segundo as distribuições a posteriori da PAMDEV

\begin{tabular}{|c|c|c|c|c|c|}
\hline \multirow[b]{2}{*}{ Tipo de Paciente } & \multicolumn{5}{|c|}{ Especialista } \\
\hline & A & B & C & D & $E$ \\
\hline 1 & V & V & V & $\mathrm{V}$ & V \\
\hline 2 & V & $\mathrm{N}$ & $N$ & V & V \\
\hline 3 & V & V & V & V & V \\
\hline 4 & V & V & $\mathrm{N}$ & V & V \\
\hline 5 & V & V & V & V & V \\
\hline 6 & V & $\mathrm{N}$ & $\mathrm{N}$ & V & V \\
\hline 7 & V & V & V & V & V \\
\hline 8 & V & V & $N$ & V & V \\
\hline 9 & $\mathrm{~N}$ & $\mathrm{~N}$ & V & V & V \\
\hline 10 & $\mathrm{~N}$ & $N$ & $\mathrm{~N}$ & $\mathrm{~N}$ & V \\
\hline 11 & V & V & V & V & V \\
\hline 12 & V & $\mathrm{N}$ & $\mathrm{N}$ & $\mathrm{N}$ & V \\
\hline 13 & $N$ & $\mathrm{~N}$ & V & V & V \\
\hline 14 & $\mathrm{~N}$ & $N$ & $\mathrm{~N}$ & $N$ & V \\
\hline 15 & V & V & V & V & V \\
\hline 16 & $\mathrm{~N}$ & $\mathrm{~N}$ & $N$ & $\mathrm{~N}$ & V \\
\hline
\end{tabular}

No entanto, nestas tabelas, a extensão destas preferências não foi quantificada. Kadane e Sedransk (1996) criaram uma figura que mostra a variação após o estudo na preferência de cada especialista representada pela média da PAMDEV. Na figura 6.1, cada gráfico representa um tipo de paciente. Os especialistas são representados por setas, cujas coordenadas da origem são dadas pelos valores esperados da PAMDEV a priori dos tratamentos Nitroprussiato e Verapamil respectivamente. As coordenadas do final da seta são dadas pelos valores esperados das distribuições a posteriori para os tratamentos Nitroprussiato e Verapamil respectivamente. 
Neste gráfico, um ponto que estiver localizado abaixo da linha diagonal tem valor médio da PAMDEV para o tratamento Verapamil menor que para o tratamento Nitroprussiato, o que indica uma preferência do primeiro tratamento, uma vez que é desejável para o paciente o menor valor de PAMDEV possível. Por exemplo, para o paciente do tipo 3 , os especialistas $A, B$ e $D$ tinham uma preferência a priori pelo Nitroprussiato (origem das setas acima da diagonal) e, ao final do estudo, as opiniões atualizadas pelos dados indicam preferência pelo Verapamil (final das setas abaixo da diagonal). Os especialistas $\mathrm{C}$ e $\mathrm{E}$ já tinham preferência pelo Verapamil antes do estudo, porém esta preferência parece ter sido reforçada após os dados.

Os pacientes do tipo $1,3,5,7,9,11,13$ e 15 são aqueles que tem história anterior de hipertensão. Para estes pacientes, há uma forte tendência de todas as setas apontarem para a região direita inferior dos respectivos gráficos, indicando uma mudança de preferência em direção ao Verapamil. Esta mudança não é tão evidente nos pacientes que não sofriam anteriormente de hipertensão. Geralmente, as opiniões a posteriori tendem a se aglomerar mais que as opiniões a priori. À medida que o tamanho amostral aumenta, a verossimilhança tende a concentrar-se mais, o que faz com que as distribuições a posteriori dos especialistas sejam mais similares entre si.

A abordagem bayesiana ainda permite a recuperação de mais informação. Nem todas as prioris e posterioris carregam o mesmo grau de incerteza. Os gráficos da figura 6.2 mostram as distribuições a priori e posteriori de cada especialista para alguns tipos de paciente e cada droga. Para uma avaliação desta figura, observemos os pacientes 9 e 13, que são exceções à generalização de que os especialistas tendem a preferir o Verapamil para pacientes com história anterior de hipertensão. Para estes 
pacientes, os especialistas A e B preferem o Nitroprussiato. O grau de incerteza da opinião de cada um pode ser observado nas distribuições a priori para cada tratamento (linha tracejada para o Nitroprussiato e cheia para o Verapamil). Para os dois especialistas, a distribuição a priori do Nitroprussiato parece estar concentrada em valores da PAMDEV inferiores aos da distribuição do Verapamil. Em ambos os casos, os dados mudaram as visões dos especialistas em direção a valores menores da PAMDEV, mas ambos parecem quase certos das ordenações de suas preferências.

A conclusão deste estudo com relação ao próximo paciente que tiver hipertensão aguda pós cirurgia cardíaca, é a preferência pelo Verapamil se ele tiver um perfil do tipo $1,3,5,7,11$ ou 15 e qualquer um dos dois tratamentos, se ele tiver outro perfil. 
Tipo 1

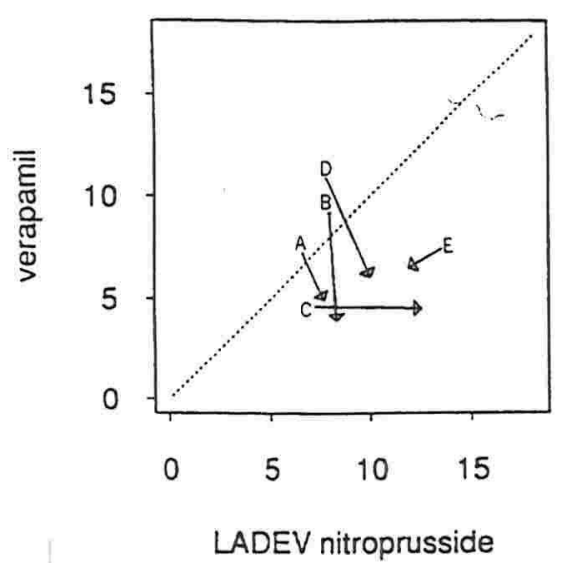

Tipo 5

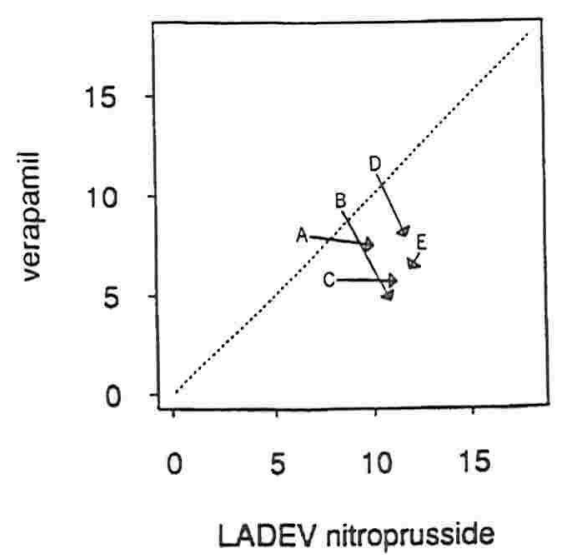

Tipo 2

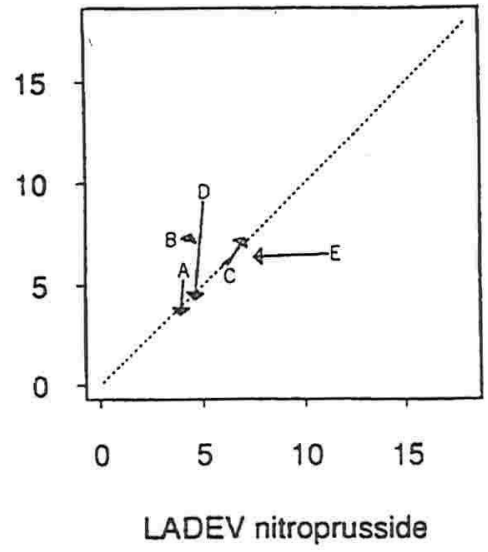

Tipo 6

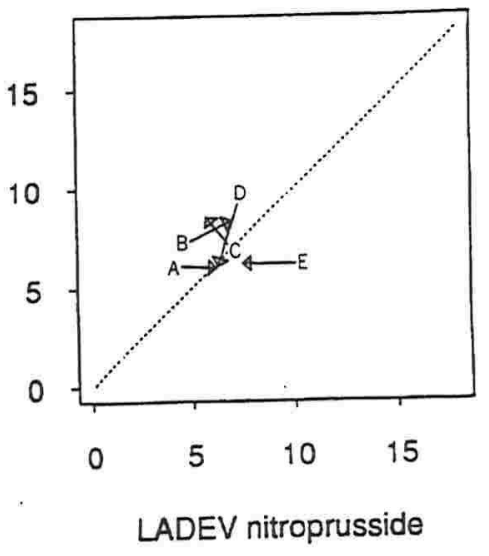

Tipo 3

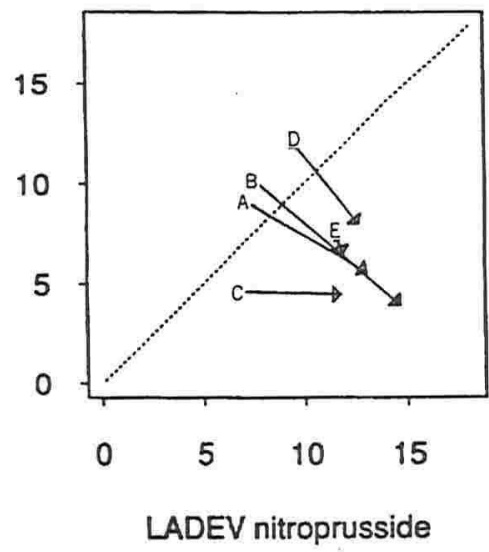

Tipo 7

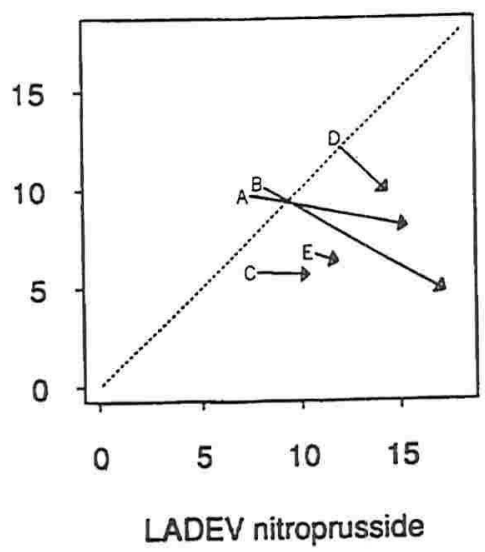

Tipo 4

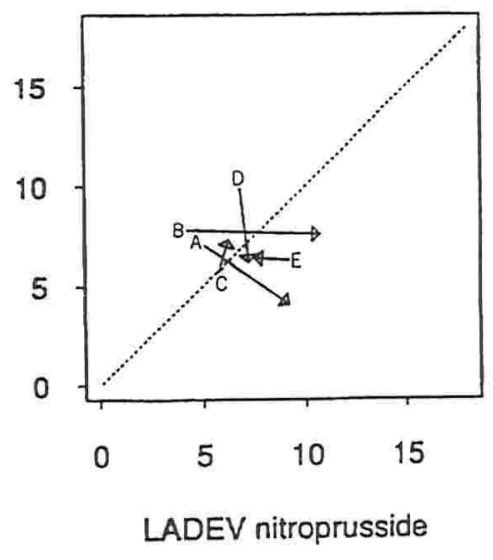

Tipo 8

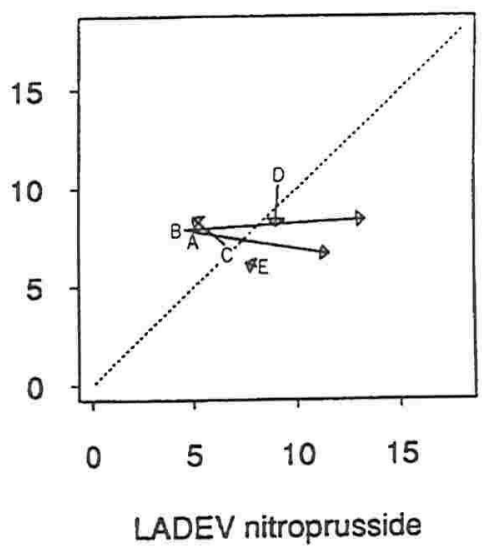

Figura 6.1.a. Médias das distribuições a priori e posteriori da PAMDEV (LADEV) para Nitropussiato e Verapamil, em pacientes dos tipos 1 a 8 


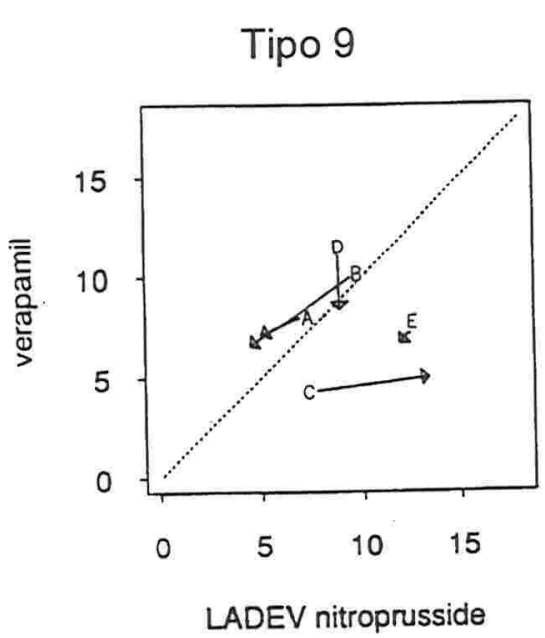

Tipo 13

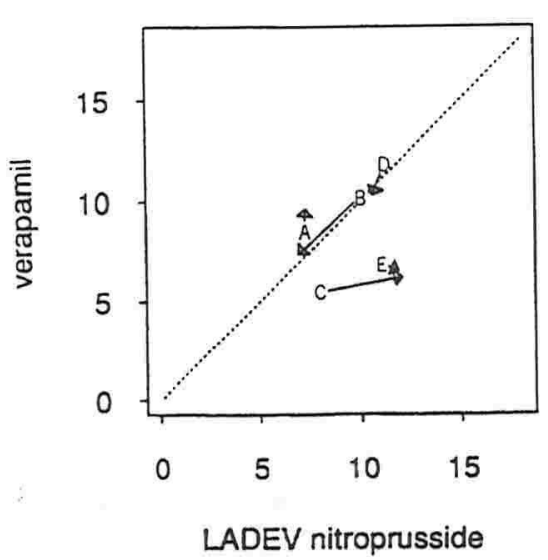

Tipo 10

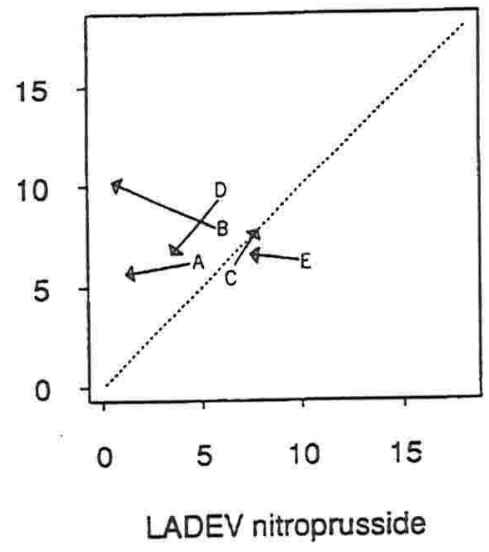

Tipo 14

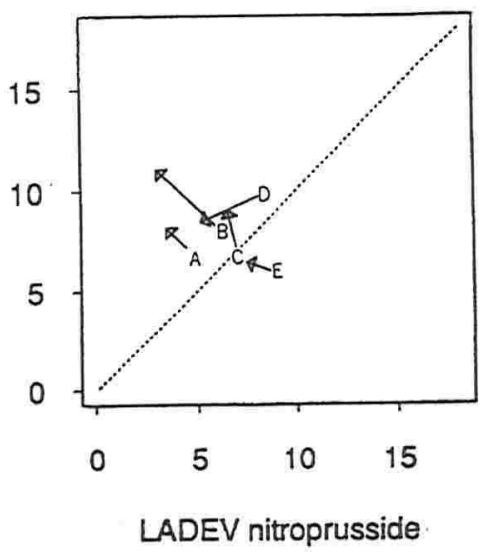

Tipo 11

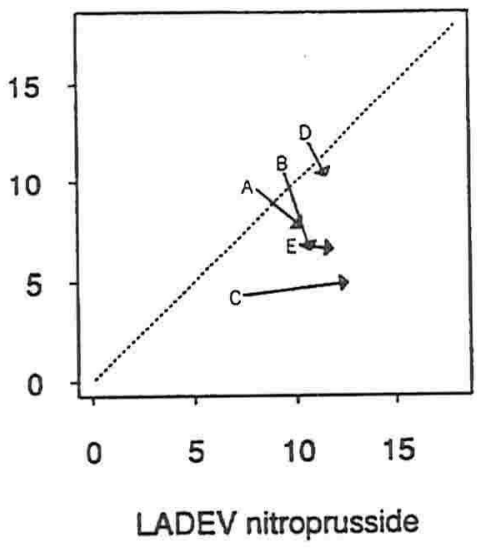

Tipo 15

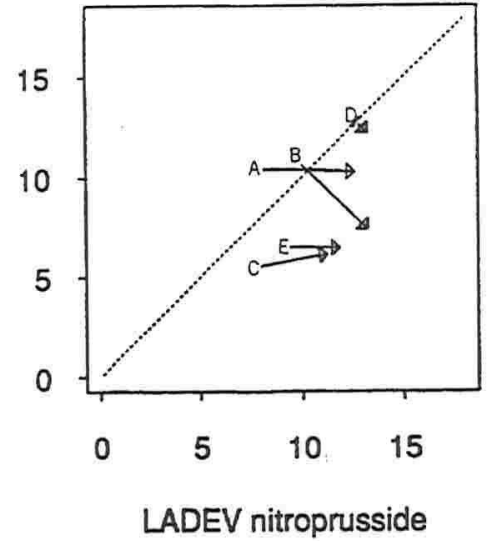

Tipo 12

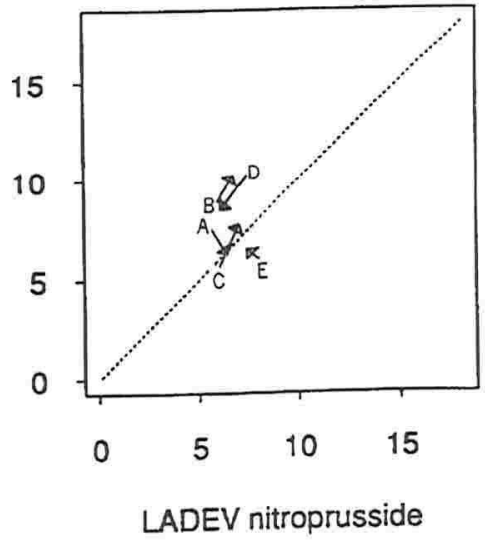

Tipo 16

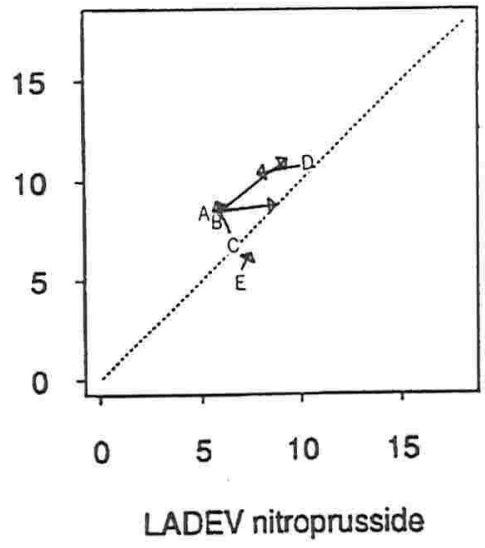

Figura 6.1.b. Médias das distribuições a priori e posteriori da PAMDEV (LADEV) para Nitropussiato e Verapamil, em pacientes dos tipos 9 a 16 


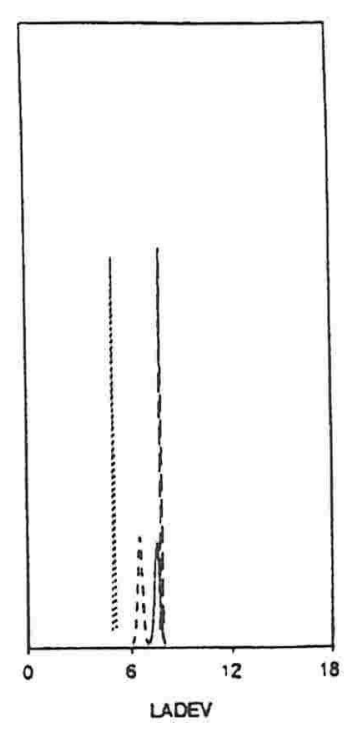

Especialista A

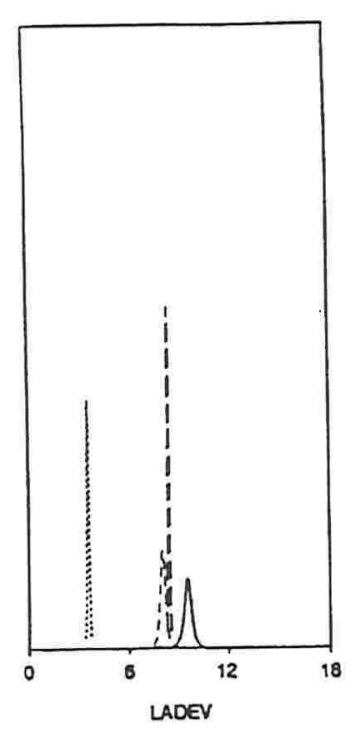

Especialista B

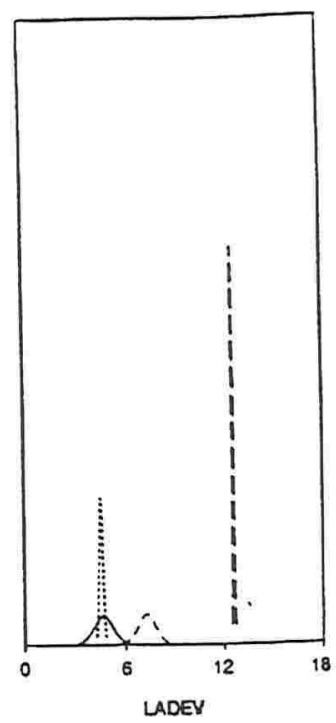

Especialista C

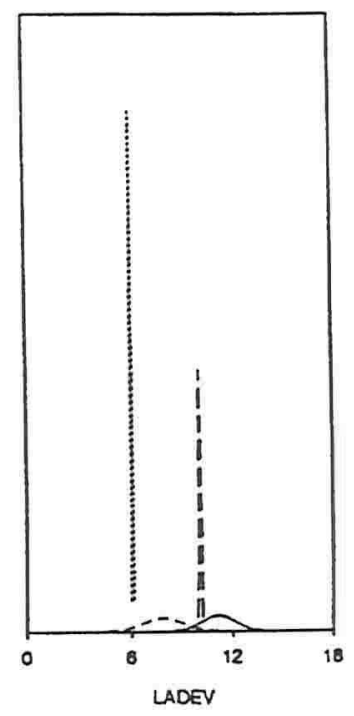

Especialista D

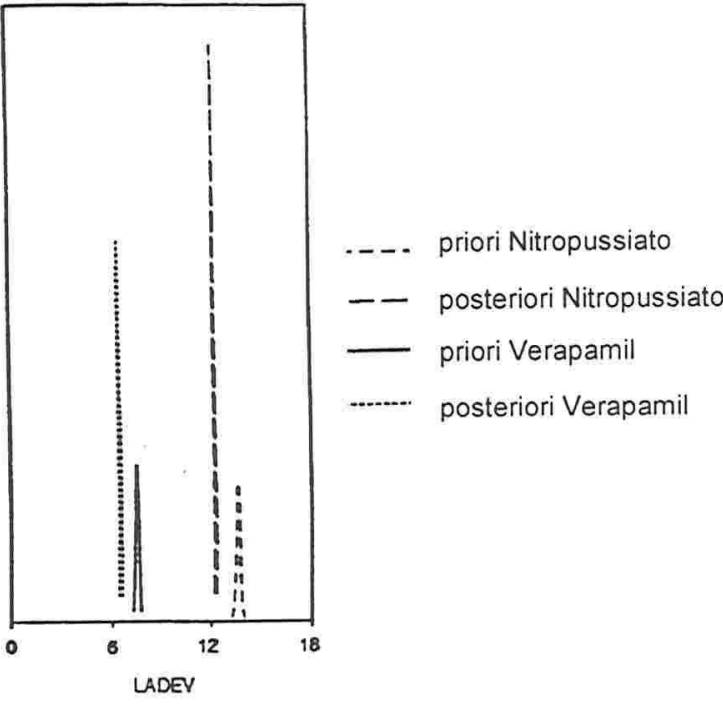

Especialista $\mathrm{E}$

Figura 6.2.a. Distribuições a priori e posteriori de cada um dos especialistas, da PAMDEV (LADEV) para o Nitropussiato e Verapamil, para pacientes do tipo 1 (que tem todos os fatores de risco) 


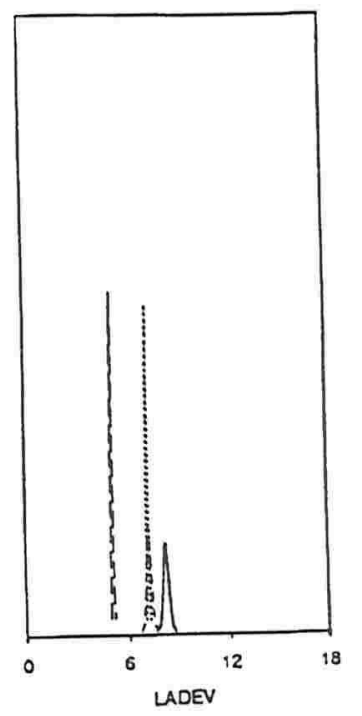

Especialista A

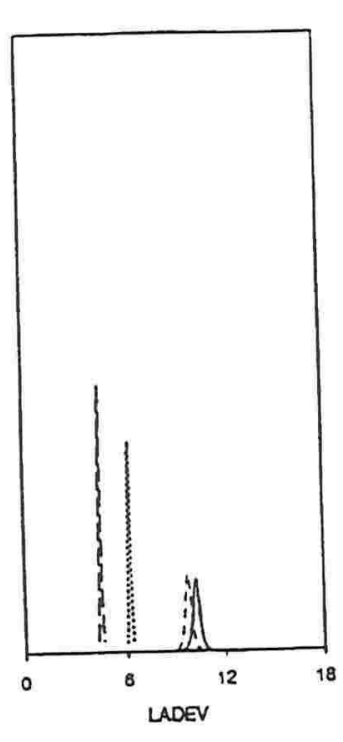

Especialista B

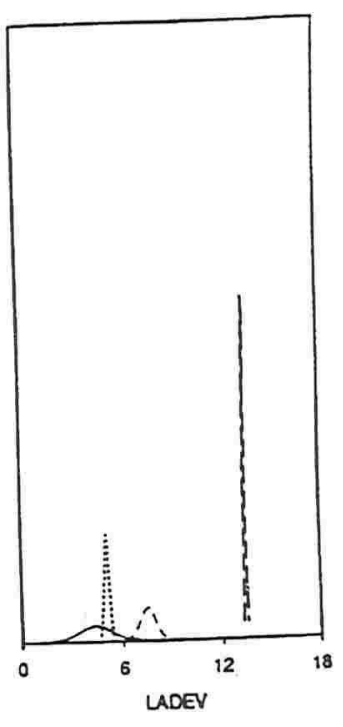

Especialista C

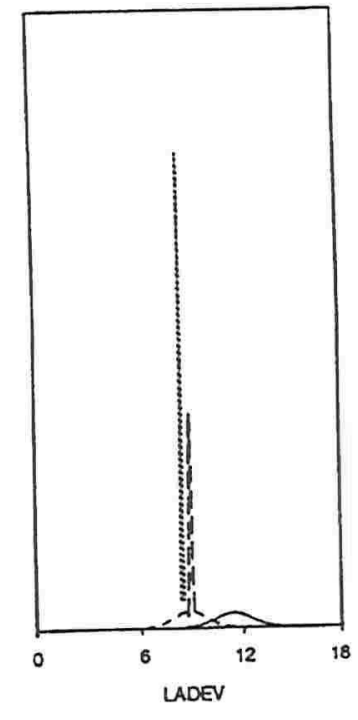

Especialista D

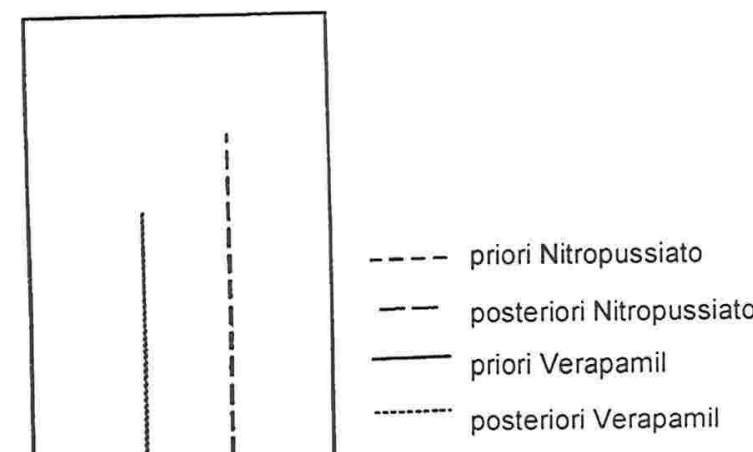

Especialista E

Figura 6.2.b. Distribuições a priori e posteriori de cada um dos especialistas, da PAMDEV (LADEV) para o Nitropussiato e Verapamil, para pacientes do tipo 9 (que tem todos os fatores de risco exceto doença vascular prévia) 


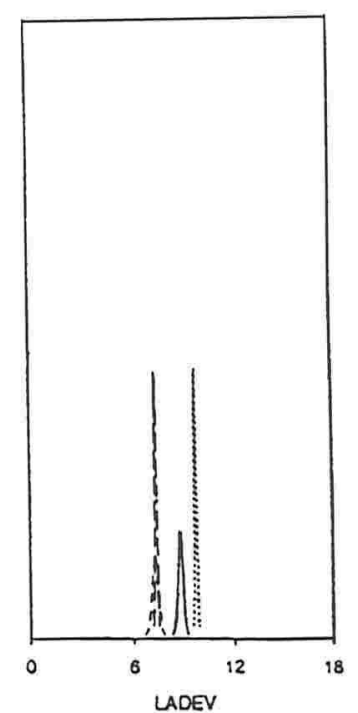

Especialista A

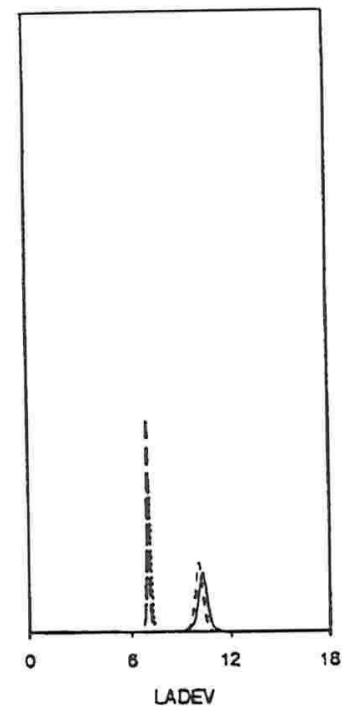

Especialista B

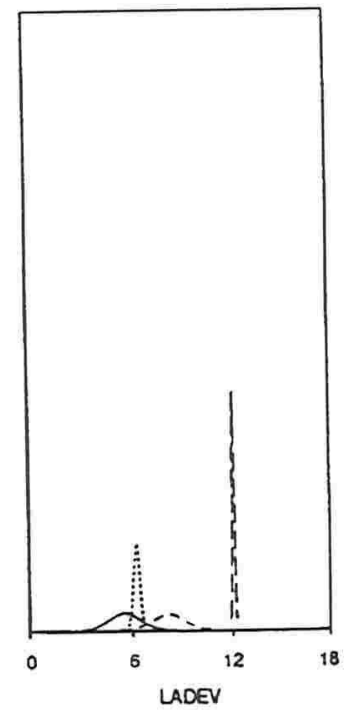

Especialista C

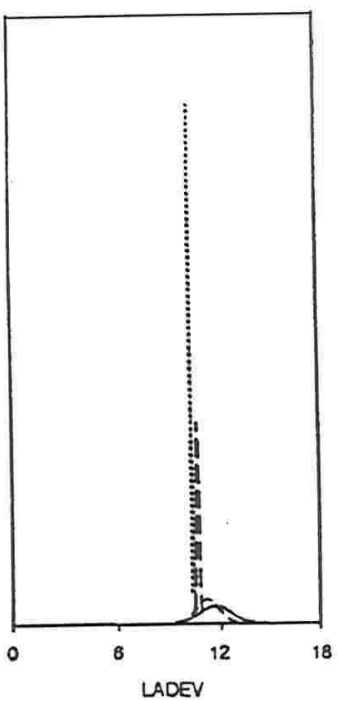

Especialista D

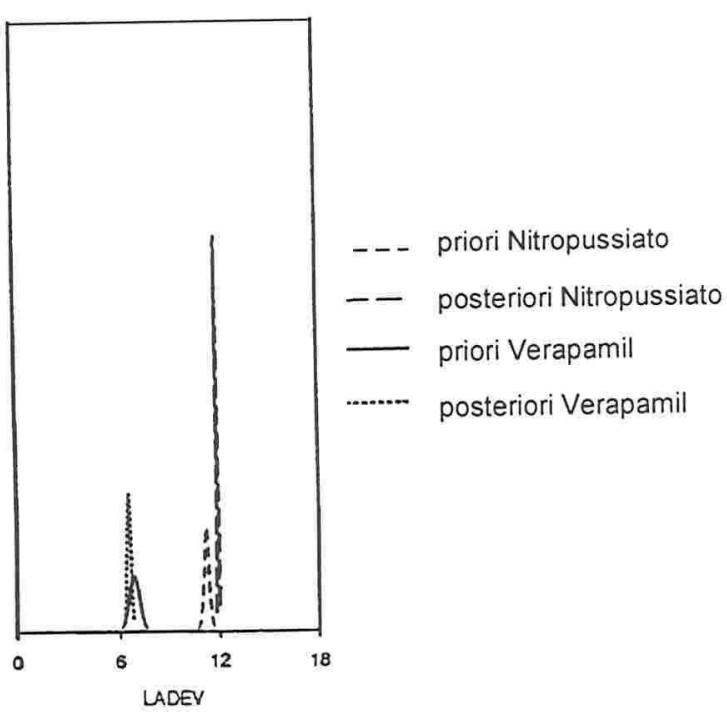

Especialista $E$

Figura 6.2.c. Distribuições a priori e posteriori de cada um dos especialistas, da PAMDEV (LADEV) para o Nitropussiato e Verapamil, para pacientes do tipo 13 (que tem anormalidade do movimento da parede do coração e hipertensão prévia) 


\section{CONSIDERAÇÕES FINAIS}

O experimento clínico aleatorizado é, por alguns autores, considerado o melhor método para se estudar a eficácia relativa de um ou mais tratamentos em seres humanos. Apesar das diversas críticas a esta metodologia, há uma utilização maciça deste método no que se trata de sua aplicação à pesquisa médica.

O aspecto mais divergente e criticado é a aleatorização enquanto método de seleção de tratamento. Evitar a introdução de vícios de seleção, bem como evitar a influência de covariáveis, são duas, dentre as três justificativas mais frequentes para a aleatorização. A aleatorização tende a balancear os grupos quanto a todos os fatores, sejam eles conhecidos ou não, distribuindo-os igualmente. A terceira justificativa está relacionada às distribuições de referência, forma através da qual a aleatoriedade é introduzida na inferência frequentista.

Segundo a inferência bayesiana, aleatorização não é requisito para a análise dos dados, uma vez que aleatoriedade pode ser introduzida a qualquer momento que haja algo desconhecido. Além disso, se vista sob um contexto de teoria da decisão, a técnica de aleatorização de tratamentos enquanto método de seleção não maximiza a utilidade esperada. Para finalizar, a crítica bayesiana mais severa à aleatorização é o fato desta violar o Princípio da Verossimilhança (a inferência não deve depender de coisas que poderiam ter sido observadas, porém não foram). A distribuição da aleatorização é, portanto irrelevante para a análise dos dados.

A aleatorização pode ser aplicada nos experimentos clínicos em diferentes momentos: no planejamento, ou na análise dos dados. A primeira situação é aceita e até mesmo recomendada pelos bayesianos: se adiada o máximo possível e utilizada apenas nesta etapa e não na análise dos dados, a aleatorização tem a vantagem de evitar os vícios de seleção e a influência de covariáveis. Kadane e Seidenfeld (1990) acreditam que em experimentos cujo interesse é demonstrar a eficácia de determinado tratamento, a divulgação científica pode ser auxiliada pelo fato de ter havido aleatorização. 
Outro aspecto frequentemente discutido em experimentos clínicos aleatorizados é sua validade ética. O dilema está na contradição entre o dever do médico em fazer o que for o melhor para o paciente em oposição às exigências desta metodologia: nem sempre o que o médico acredita ser o melhor para o paciente é o melhor para a pesquisa que está sendo conduzida. Para um médico consultado por um paciente, será ético escolher o tratamento aleatoriamente ao invés de escolher o que ele pensa ser melhor para aquele determinado caso?

Com a finalidade de abordar esta questão, Kadane (1996), propõe um planejamento bayesiano que, por um lado leva em conta os direitos do paciente e, por outro, as exigências de uma pesquisa científica. A idéia deste planejamento está relacionada ao conceito de tratamento admissivel. Para cada paciente que entra no estudo, são classificados em admissíveis ou não todos os tratamentos. A aleatorização pode ser realizada apenas dentre os tratamentos considerados admissíveis, de tal forma que os direitos do paciente são preservados, independente do grupo para o qual ele tenha sido. Outro aspecto interessante da proposta de Kadane é a constituição de uma equipe de especialistas na doença em questão, que expressa opiniões a priori do resultado de cada tratamento para pacientes com diferentes perfis, de modo que a cada paciente estudado, são obtidas opiniões atualizadas (através da fórmula de Bayes). Esta proposta é interessante na medida em que representa um compromisso entre a responsabilidade do médico em fazer o que for melhor para o paciente e a obtenção de dados que possam ser aproveitados para a realização de uma pesquisa científica.

Neste trabalho, mostramos que a aleatorização é ainda um tema complexo, polêmico e que o aprendizado da pesquisa científica com relação a este assunto não está esgotado. Concluímos que, apesar das críticas, a aleatorização tem seu valor enquanto ferramenta que pode servir para aumentar a credibilidade de um trabalho na sua divulgação científica e melhorar a comunicação entre pesquisador e leitor. 


\section{REFERÊNCIAS}

Bailar III J.C.(1983) Introduction. In.Shapiro S.H., Louis T.A. (Editors) Clinical Trial Issues and Approaches,Marcel Dekker Inc, NY

Bartlett R.H., Andrews A.F., Toomasian J.F.(1982) Extracorporeal Membrane Oxigenation for Newborn Respiratory Failure: 45 cases,Surgery,92,425-433

Bartlett R.H. e Cornell R.G. (1991) Comment. In. Royall, R.M. Ethics and Statistics in Randomized Clinical Trials Statistical Science,6 (1) 63-65

Bartlett, R.H., Roloff, D.W., Cornell, R.G., Andrews A.F., Dillon P.W. and Zwischenberger J.B.(1985) Extracorporeal circulation in neonatal respiratory failure: A prospective randomized study,Pediatrics, 76,476-487

Basu D.(1980) Randomization Analysis of Experimental Data: The Fisher Randomization Test (with discussion) Journal of the American Statistical Association, 75 (371) 575-595

Berger J.O., Wolpert R.L. (1988) The Likelihood Principle IMS Lecture Notes, Monograph Series, vol.6, 2nd edition Hayward: Institute of Mathematical Statistics

Bernardo J.M., Smith A.F.M.(1994) Bayesian Inference,John Wiley \& Sons. NY

Berry, D.(1996) Statistics - A Bayesian Perspective,Duxbury Press, USA

Birnbaum, A. (1962) On the Foundations of Statistical Inference (with discussion) Journal of the American Statistical Society, 57,269-306

Blanck T.J.J., Conahan T.J., Merin R.G., Prager R.L. Richter J.J.(1996) Being an Expert. In.Kadane J.B. (Editor) Bayesian Methods and Ethics in a Clinical Trial Design, John Wiley and Sons, NY,159-162 
Breslow N.E. (1982) Clinical Trials. In. Kotz S., Johnson N.L. (Editors) Encyclopedia of Statistical Science, John Wiley and Sons, NY, (2) 13-21

Byar D.P. (1991) Comment. In. Royall, R.M. Ethics and Statistics in Randomized Clinical Trials Statistical Science, 6 (1) 65-68

Byar D.P., Simon R.M., Friedewald W.T., Schlesselman J.J., Demets D.L., Ellenberg J.H. Gail M.H., Ware J.H. (1976) Randomized Clinical Trials: Perspective on Some Recent Ideas New England Journal of Medicien 295, 74-80

Cowan D.H. (1981) The Ethics of Trials of Ineffective Therapy IRB: A Review of Human Subjects Research, 3,10-11

Cox D.R., Fitzpatrick,R., Fletcher,A.E., Gore,S.M., Spiegelhalter,D.J., Jones,D.R.(1992) Quality-of-life Assessment : Can We Keep it Simple? Journal of the Royal Statistical Society A,155,353-393

DeGroot M.H. (1970) Optimal Statistical Decisions, McGraw-Hill, New York, NY.

DDHS (1981) Department of Health and Human Services Rules and Regulations, Federal Register, 46, 8366-8392

Emrich L.J., Sedransk N.(1996) Whether to Participate in a Clinical Trial: The Patient's View. In.Kadane J.B. (Editor) Bayesian Methods and Ethics in a Clinical Trial Design, John Wiley \& Sons. NY,267-305

Fisher R.A.(1935) Design of Experiments (1st edition), Oliver and Boyd, London

Fisher R.A.(1956) Statistical Methods and Scientific Inference, Oliver and Boyd, Edinburg

Fisher R.A.(1960) Design of Experiments (7th edition), Oliver and Boyd, London

Fleming T.R.(1992) Evaluating Therapeutic Interventions: Some Issues and Experiences, Statistical Science,7(4),428-456 
Freedman B.(1987) Equipoise and the Ethics of Clinical Research,New England Journal of Medicine, $317,141-145$

Fried C.(1974) Medical Experimentation: Personal Integrity and Social Policy,North Holland, Amsterdan

Friedman L.M. Furberg C.D., DeMets D.L. (1985) Fundamentals of Clinical Trials (2nd edition), PSG Publishing Company Inc., Littleton, Massachusetts

Galway L.A.(1996) Computational Aspects of the Verapamil/Nitropusside. In.Kadane J.B. (Editor) Bayesian Methods and Ethics in a Clinical Trial Design, John Wiley \& Sons, NY,151-158

Green S., Byar D.P. (1984) Using Observational Data from Registries to Compare Treatments: The Fallacy of Omnimetrics (with discussion) Statistics in Medicine ,3, 361-373

Heitmiller E.S. e Blanck T.J.J. (1996) The Mechannics of Conducting a Clinical Trial. In.Kadane J.B. (Editor) Bayesian Methods and Ethics in a Clinical Trial Design, John Wiley \& Sons, NY,131-143

Herman, J.(1995) The Demise of the Randomized Controlled Trial,Journal of Clinical Epidemiology, 48,985-88

Herson, J.(1979) Predictive Probability Early Termination Plans for Phase II Clinical Trials, Biometrics, 35,775-783

Hill A.B. (1963) Medical Ethics and Controlled Trials Brittish Medical Journal, 1, 1043-1049

Hinkley, D.(1980) na discussão de : Randomization Analysis of Experimental Data: The Fisher Randomization Test, Journal of the American Statistical Association, 75 (371) 582-584 
Inoue L.(1994) Desenvolvimento e Implicações do Princípio da Verossimilhança, Tese de Mestrado,Instituto de Matemática e Estatística da Universidade de São Paulo

Kadane J.B.(1986) Progress Toward a More Ethical Method for Clinical Trials, The Journal of Medicine and Philosophy,11,355-404

Kadane J.B.(1996) Bayesian Methods and Ethics in a Clinical Trial Design, ,John Wiley \& Sons, NY

Kadane J.B. e Seidenfeld T.(1990) Randomization in a Bayesian Perspective,Journal of Statistical Planning and Inference,25,329-345

Kadane J.B., Dickey J., Winkler R.L., Smith W., Peters S.(1980) Interactive elicitation of opinion for a normal linear model,Journal of the American Statistical Association, $75,845-854$

Kadane J.B., Sedransk N.(1980) Toward a More Ethical Clinical Trial. In.Bernardo et. al. (Editors) Bayesian Statistics, Valencia: University of Valencia,329-338

Kadane J.B., Sedransk N.(1996) Verapamil versus Nitropusside: Results of the Clinical Trial I. In.Kadane J.B. (Editor) Bayesian Methods and Ethics in a Clinical Trial Design, John Wiley \& Sons, NY,177-210

Kadane J.B. e Seidenfeld T.(1996) Statistical Issues in the Analysis of Data Gathered in the New Designs. In.Kadane J.B. (Editor) Bayesian Methods and Ethics in a Clinical Trial Design, John Wiley \& Sons, NY,115-125

Kempthorne O.(1986) Randomization II. In. Kotz S., Johnson N.L. (Editors) Encyclopedia of Statistical Science, John Wiley and Sons, NY, (7) 519-524

Kempthorne O.(1977) Why Randomize?Journal of Statistical Planning and Inference, 1-25 
Kirckpatrick B.V., Krumel T.M., Mueller D.G., Ornazabal M.A., Grenfield L.J., Salzberg A.M.(1983) Use of Extra-Corporeal Membrane Oxygenation for Respiratory Failure in Term Infants,Pediatrics, 72,872-876

Kleinbaum D.G., Kupper L.L., Morgenstern H.(1982) Epidemiologic Research Principle and Quantitative Methods,Lifetime Learning Publications, Belmont California, Lifetime Learning Publications, Belmont California

Levine, Lebacqz (1979) Some Ethical Considerations in Clinical Trials,Clinical Pharmacology and and Therapeutics,Clinical Pharmacology and Therapeutics, 25,728-741

Lilienfield D., Stolley P.(1994) Foundations of Epidemiology (3a. ed.) Oxford University Press, NY,Oxford University Press, NY

Lindley D.V. (1985) Making Decisions (2a. ed.) John Wiley \& Sons, NY

Loschi R.H.(1992) Coerência, Probabilidade e Calibração,Tese de Mestrado,Instituto de Matemática e Estatística da Universidade de São Paulo

Medical Research Councill(1964) Responsibility in investigations on human subjects,British Medical Journal,2,178-180

Mosteller F., Gilbert J., McPeek B.(1983) Controversies in Design and Analysis of Clinical Trials. In. Shapiro S.H., Louis T.A. (Editors) Clinical Trial - Issues and Approaches, Marcel Dekker Inc, NY

O'Hagan A. (1994) Kendall's Advanced Theory of Statistics. Vol 2B. Bayesian Inference, Edward Arnold, Cambridge, Great Britain.

Pocock S.(1983) Clinical Trials - A Practical Approach,John Wiley \& Sons, NY

Rosenberger, W. F. and Lachin, J. M.(1993) The use of response-adaptive designs in clinical trials, Controlled Clinical Trials, 14,471-484 
Royall, R. M.(1991) Ethics and Statistics in Randomized Clinical Trials (with discussion), Statistical Science, 6 (1) 52-88

Savage L.J.(1961) The Foundations of Statistics Reconsidered. In. Neyman J. (Editor) Proceedings of the Fourth Berkeley Symposium on Mathematical Statistics and Probability, University of California Press, CA,575-586

Savage L.J.(1962) Subjective Probability and Statistics in Practice. In. Bartlett M.S. (Editor) The Foundations of Statistical Inference, Methuen, London,33-34

Schaffner K.F.(1996) Ethically Optimizing Clinical Trials. In.Kadane J.B. (Editor) Bayesian Methods and Ethics in a Clinical Trial Design, John Wiley \& Sons, NY,19-63

Shapiro S.H., Louis T.A.,(1983) Clinical Trial - Issues and Approaches,Marcel Dekker Inc, NY,NY,Marcel Dekker Inc, NY

Smith T.L., Lee J.J., Kantarjian H.M., Legha S.S., Raber M.N.(1996) Design and Results of Phase I Cancer Clinicalt Trials: Three-Year Experience at M.D. Anderson Cancer Center,Journal of Clinical Oncology,14 (1) 287-295

Stone M.(1969) The role of experimental randomization in Bayesian Statistics: Finite sampling and two Bayesians,Biometrika,56,681-683

Storer B.E.(1989) Design and Analysis of Phase I Clinical Trials,Biometrics,45,925937

Tukey J.W. (1977) Some Thoughts on Clinical Trials, Especially Problems of Multiplicity Science, 198, 679-684

Ware J.H. (1989) Investigating Therapies of Potentially Great Benefit: ECMO (with discussion) Statistical Science, 4(4), 298-340

Wei L.J.(1979) Then Generalized Polya's Urn Design for Sequential Medical Trials,Annals of Statistics, 7,291-296 
Wei L.J., Durham S.(1978) The Randomized Play-the-Winner Rule in Medical Trials, Journal of the American Statistical Association,73,830-843

Wetmore N., McEwen D., O'Connor M., Bartlett R.H.(1979) Defining Indications for Artificial Organ Support in Respiratory Failure,Trans. Amer. Soc. Artificial Internal Organs, 25,459-461

World Medical Association(1948) Declaration of Geneva. reprinted in. Beauchamp, T.L., Childress, J.F. (1983). Principle of Biomedical Ethics,Oxford University Press, NY

Yao Q., Wei L.J. (1996) Play-the-Winner for Phase II/III Clinical Trials,Statistics in Medicine, 15,2413-2423

Zelen M.(1969) Play-the-Winner Rule and the Controlled Clinical Trial,Journal of the American Statistical Association,64,131-146

Zelen M.(1979) A New Design for Randomized Clinical Trials,New England Journal of Medicine,300,1242-1246 